Aus der Klinik für Neurologie

(Prof. Dr. med. M. Bähr)

der Medizinischen Fakultät der Universität Göttingen

\title{
Humane Immunglobuline als \\ Therapie im Mausmodell der Muskeldystrophie Duchenne
}

\author{
INAUGURAL-DISSERTATION \\ zur Erlangung des Doktorgrades \\ der Medizinischen Fakultät der \\ Georg-August-Universität zu Göttingen
}

\author{
vorgelegt von \\ Pia Vanessa Jouvenal \\ aus \\ Stuttgart-Bad Cannstatt
}

Göttingen 2020 
Dekan:

Prof. Dr. med. W. Brück

Referent/in:

Prof. Dr. med. J. Schmidt

Ko-Referent/in:

Prof. Dr. med. W. H. Zimmermann

Drittreferent/in:

Datum der mündlichen Prüfung: $\quad$ 07.10.2021 
Hiermit erkläre ich, die Dissertation mit dem Titel "Humane Immunglobuline im Mausmodell der Muskeldystrophie Duchenne“ eigenständig angefertigt und keine anderen als die von mir angegebenen Quellen und Hilfsmittel verwendet zu haben.

Göttingen, den 
Die Daten, auf denen die vorliegende Arbeit basiert, wurden teilweise publiziert:

Zschüntzsch J, Jouvenal PV, Zhang Y, Klinker F, Tiburcy M, Liebetanz D, Malzahn D, Brinkmeier H, Schmidt J (2020): Long-term human IgG treatment improves heart and muscle function in a mouse model of Duchenne muscular dystrophy. J Cachexia Sarcopenia Muscle 11, 1018-1031 


\section{Inhaltsverzeichnis}

Abbildungsverzeichnis ...................................................................

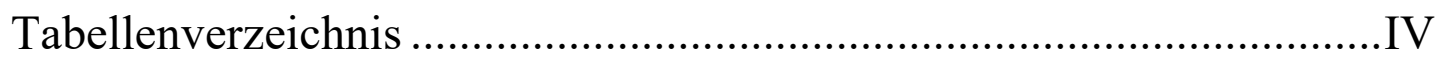

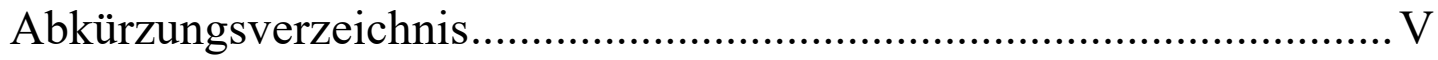

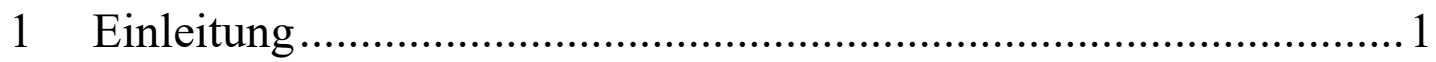

$1.1 \quad$ Die Muskeldystrophie Duchenne ...........................................................

1.2 Das Tiermodell der DMD: Mdx-Maus....................................................

1.3 Klinische und paraklinische Verlaufsparameter..........................................9

1.4 Humane Immunglobuline als Immunmodulatoren im mdx-Mausmodell ..13

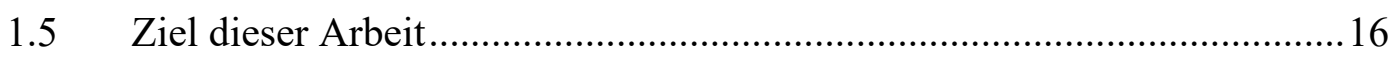

2 Material und Methoden............................................................... 17

$2.1 \quad$ Tiere

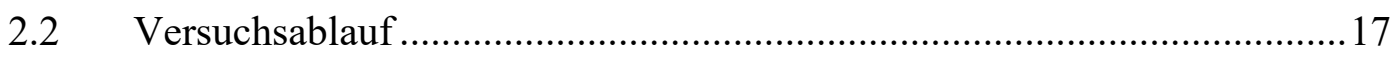

$2.3 \quad$ Therapieschema

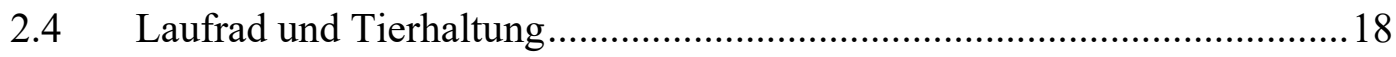

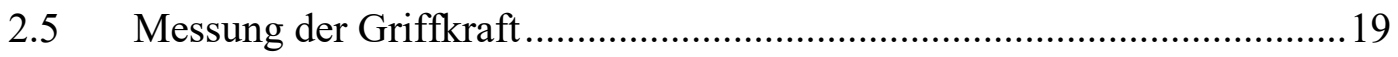

2.6 Transthorakale Echokardiografie .............................................................19

2.7 Aufarbeitung der Gewebeschnitte ……………………..........................2

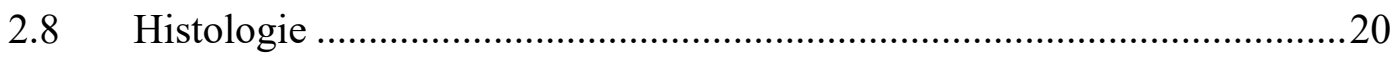

$2.9 \quad$ Auswertung der Gewebeschnitte .........................................................2

2.10 Kreatinkinase 
2.11 RNA-Extraktion und cDNA-Synthese

2.12 Quantitative real-time Polymerase-Kettenreaktion .................................22

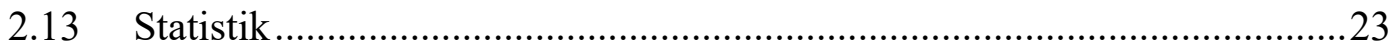

2.14 Verträglichkeit von Albumin und MS ................................................23

3 Ergebnisse ..................................................................... 25

3.1 Ergebnisse der klinischen Parameter.......................................................25

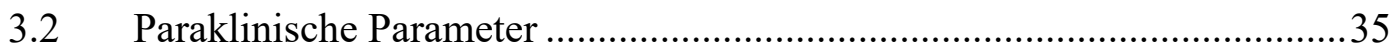

4 Diskussion................................................................... 51

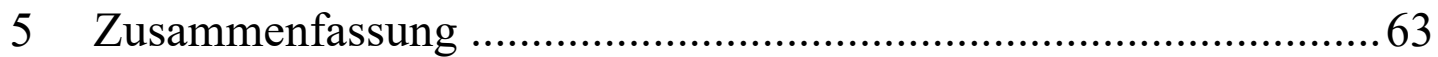

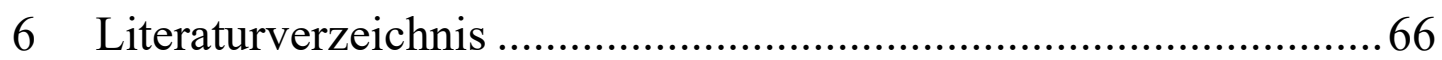




\section{Abbildungsverzeichnis}

Abbildung 1: $\quad$ Dystrophinassoziierter Glykoproteinkomplex. …............................ 7

Abbildung 2: Vermutete Wirkung von IVIG in DMD........................................ 15

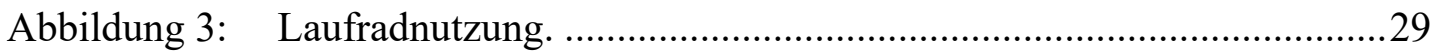

Abbildung 4: $\quad$ Langzeitverlauf des Körpergewichtes und der Griffkraft. .................31

Abbildung 5: Transthorakale Echokardiografie in Sedierung mit Isofluran. ..........34

Abbildung 6: Quantifizierung der CK-Konzentration im Serum. ..........................35

Abbildung 7: Quantifikation relevanter inflammatorischer Mediatoren durch

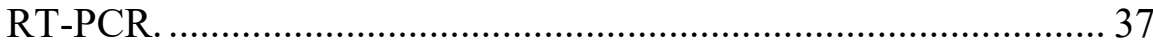

Abbildung 8: Quantifikation der TGF- $\beta$-Expression im Herzmuskel......................38

Abbildung 9: Auswertung der Muskelpathologie. ....................................................4 41

Abbildung 10: HE-Färbungen von Muskelquerschnitten........................................42

Abbildung 11: T-Zellen pro $\mathrm{mm}^{2}$ in Diaphragma, M. gastrocnemius, M. tibialis anterior und M. quadriceps femoris. ............................................44

Abbildung 12: Immunhistochemische Detektion von T-Zellen in

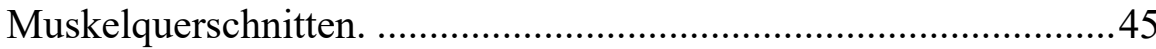

Abbildung 13: Immunhistochemische Detektion von Makrophagen im Diaphragma, M. gastrocnemius, M. tibialis anterior und $\mathrm{M}$. quadriceps femoris.

Abbildung 14: Immunhistochemische Detektion von Makrophagen in Muskelquerschnitten.

Abbildung 15: Anzahl der T-Zellen und Makrophagen im Herzen pro $\mathrm{mm}^{2}$ sowie prozentualer Anteil der Fibrose im gesamten Herzen. 


\section{Tabellenverzeichnis}

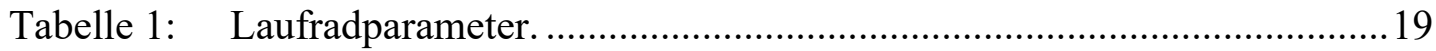

Tabelle 2: Lineare Regressionsanalysen für $\mathrm{V}_{\max }, \mathrm{N}_{\text {lauf, }}, \mathrm{T}_{\text {ges }}$ und Dist im

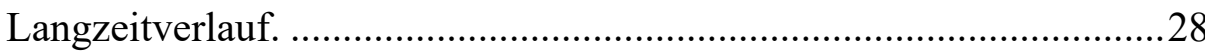

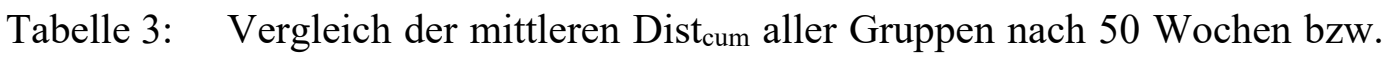
der NaCl- und IgG-Gruppe nach 70 Wochen.

Tabelle 4: Anzahl der mdx-Mäuse, die je Gruppe nach 3, 9, 12, 15 und 18 Monaten echokardiografisch untersucht wurden.

Tabelle 5: Anzahl der je Behandlungsgruppe ausgewerteten Muskeln nach HEFärbung.

Tabelle 6: Anzahl der je Behandlungsgruppe ausgewerteten Muskeln nach Färbung mit anti-humanem CD3.

Tabelle 7: Anzahl der je Behandlungsgruppe ausgewerteten Muskeln nach immunhistochemischer Färbung von Makrophagen.

Tabelle 8: Anzahl der je Behandlungsgruppe ausgewerteten Herzen. 


\section{Abkürzungsverzeichnis}

\begin{tabular}{|c|c|}
\hline BMD & Muskeldystrophie Becker \\
\hline cDNA & complementary Desoxyribonukleinsäure \\
\hline CIDP & chronisch inflammatorische Polyneuropathie \\
\hline CK & Kreatinkinase \\
\hline $\mathrm{CNI}$ & Index zentralisierter Zellkerne, central nuclear index \\
\hline d & Diastole \\
\hline DCM & dilatative Kardiomyopathie \\
\hline DGK & dystrophinassoziierter Glykoproteinkomplex \\
\hline DGN & Deutsche Gesellschaft für Neurologie \\
\hline Dist & Distanz pro Tag \\
\hline Dist $_{\text {cum }}$ & Kumulative Gesamtzdistanz \\
\hline DMD & Muskeldystrophie Duchenne \\
\hline DNA & Desoxyribonukleinsäure \\
\hline EF & Ejektionsfraktion \\
\hline EMA & European Medicines Agency \\
\hline EZM & extrazelluläre Matrix \\
\hline FAS & $\begin{array}{l}\text { zirkumferenzielle Flächen-Verkürzungsfraktion, fractional area shorten- } \\
\text { ing/change }\end{array}$ \\
\hline FS & Verkürzungsfraktion, fractional shortening \\
\hline GS & Glukokortikosteroide \\
\hline $\mathrm{h}$ & Stunden \\
\hline $\mathrm{HE}$ & Hämatoxylin-Eosin \\
\hline $\operatorname{Ig}$ & Immunglobuline \\
\hline $\operatorname{Ig} \mathrm{A}$ & Immunglobulin A \\
\hline IgG & Immunglobulin $\mathrm{G}$ \\
\hline $\operatorname{IgM}$ & Immunglobulin $\mathrm{M}$ \\
\hline i. p. & intraperitoneal \\
\hline i. v. & intravenös \\
\hline IVIG & intravenöse Immunglobuline \\
\hline KG & Körpergewicht \\
\hline LVEDD & linksventrikulärer enddiastolischer Durchmesser \\
\hline Mo. & Monate \\
\hline M. & musculus \\
\hline MCP1 & monocyte chemoattractant protein 1 \\
\hline $\operatorname{mdx}$ & x-linked muscular dystrophy \\
\hline $\mathrm{MHC}$ & myosin heavy chain \\
\hline $\mathrm{MMN}$ & multifokale motorische Neuropathie \\
\hline mRNA & Messenger-Ribonukleinsäure \\
\hline MS & Mausserum \\
\hline $\mathrm{N}$ & Newton \\
\hline $\mathrm{N}_{\text {lauf }}$ & Anzahl der Läufe \\
\hline NW & Nebenwirkungen \\
\hline
\end{tabular}


SPP1 secreted phosphoprotein 1

SOPs Angaben zum standardisierten Vorgehen, standard operating procedures

RNA Ribonukleinsäure

RT-PCR real-time Polymerase-Kettenreaktion, polymerase chain reaction

TGF- $\beta \quad$ transforming growth factor $\beta$

$\mathrm{T}_{\text {ges }} \quad$ Gesamtzeit

$\mathrm{T}_{\text {mean }} \quad$ durchschnittliche Zeit

Treat-NMD Translational Research in Europe for the Assessment and Treatment of Neuromuscular Disease

$\mathrm{V}_{\max } \quad$ Maximalgeschwindigkeit

U units 


\section{$1 \quad$ Einleitung}

Die Entdeckung des Dystrophin 1987 (Hoffman et al. 1987; Koenig et al. 1988) war ein Meilenstein in der Erforschung von neuromuskulären Erkrankungen und es folgten zahlreiche Untersuchungen, um die Pathogenese der „Dystrophinopathien“ zu verstehen. Heute, rund 30 Jahre später, sind wir um viele Erkenntnisse über dieses Krankheitsbild reicher, dennoch bleiben weiterhin viele Fragen offen.

\subsection{Die Muskeldystrophie Duchenne}

\subsubsection{Definition, Grundlagen und Epidemiologie}

Dystrophinopathien sind x-chromosomal-rezessiv vererbte Erkrankungen, die mit einer entweder gänzlich fehlenden oder fehlerhaften Produktion von Dystrophin einhergehen. Die wichtigsten Formen sind die Muskeldystrophie Typ Duchenne (DMD) und die Muskeldystrophie Typ Becker (BMD). Die DMD ist die maligne Verlaufsform mit einem fast völligen Verlust des Proteins Dystrophin, wohingegen es bei der benignen Form der BMD lediglich zu einer verminderten Bildung von Dystrophin kommt (Monaco et al. 1988). Zwischen diesen beiden Verlaufsformen existieren Übergangsformen, somit kann man von einem Kontinuum unterschiedlicher klinischer Krankheitsverläufe sprechen (Blake et al. 2002). In dieser Arbeit geht es um die maligne Verlaufsform und häufigste erbliche Myopathie, die DMD, welche mit einer Inzidenz von 1:3500 bei männlichen Neugeborenen auftritt (Emery 1991).

\subsubsection{Klinisches Erscheinungsbild und symptomatische Therapie}

Die Betroffenen werden im Alter von zwei bis sechs Jahren klinisch auffällig durch eine verzögerte motorische Entwicklung und Pseudohypertrophie der Wadenmuskulatur bei gleichzeitiger Schwäche der proximalen Muskulatur. Besonders charakteristisch für die DMD sind das Trendelenburgzeichen (Schara 2015) und das Gowers-Manöver (Blake et al. 2002; Chang und Mubarak 2012). Die fortschreitende Muskelschwäche im Beckengürtel und in den Oberschenkeln verursacht einen watschelnden Zehenspitzengang, der als Trendelenburgzeichen bezeichnet wird. Das Gowers-Manöver beschreibt das Nutzen von Gegenständen, um sich an ihnen hochzuziehen, oder das Emporklettern mit den Händen entlang der Beine, um sich aufzurichten (Gowers 1879). Neben der muskulären Funktion von 
Dystrophin spielt es jedoch auch eine funktionelle Rolle im Gehirn. Bei bis zu 30 \% der DMD-Patienten wird eine nicht fortschreitende kognitive Beeinträchtigung beschrieben (Bresolin et al. 1994). Die DMD verläuft chronisch progredient, sodass es bei den Betroffenen um das zwölfte Lebensjahr zu Gehunfähigkeit und Kontrakturen kommt (Blake et al. 2002). Zudem gibt es charakteristischerweise eine progressive Herzbeteiligung. Bereits in frühen Krankheitsstadien sind Wandveränderungen im linken Herzen zu beobachten, ohne dass es zu einer Einschränkung der Ejektionsfraktion (EF) kommt (Giglio et al. 2003). Am Ende der dritten Lebensdekade hat dann die Mehrheit der Patienten eine klinisch manifeste dilatative Kardiomyopathie (DCM) entwickelt. Die sich entwickelnde Herzinsuffizienz ist ein häufiger lebenslimitierender Faktor der Erkrankung (Moriuchi et al. 1993). Eine DCM ist durch vergrößerte Herzhöhlen, eine systolische Dysfunktion und eine folglich reduzierte Auswurfleistung, die zu einer progredienten Herzinsuffizienz führt, charakterisiert. Als Komplikationen können Herzrhythmusstörungen, Thromboembolien und Herzklappeninsuffizienzen (v. a. Mitral- und Trikuspidalklappeninsuffizienz) auftreten (Maron et al. 2006). Autopsien der Herzen und MRT-Untersuchungen von Betroffenen haben gezeigt, dass es zu einer Hypertrophie der Kardiomyozyten, sowie Fibrose und Atrophie kommt (Mavrogeni et al. 2015). Unabhängig von der Ätiologie erfolgt die Therapie der DCM bei der DMD nach den allgemeinen Leitlinien der Kardiologie für DCM. In klinischen Studien wurde gezeigt, dass durch die medikamentöse Therapie mit ACE-Hemmern, Angiotensin-II-Rezeptor-Subtyp-1- und Aldosteronantagonisten, Glukokortikosteroiden (GS) und $\beta$-Blockern der Progress der Herzinsuffizienz von DMD-Patienten verlangsamt, aber nicht aufgehalten, werden kann (McNally et al. 2015; Raman et al. 2015). In diesem Zusammenhang ist zu erwähnen, dass auch weibliche Mutationsträger häufig eine klinisch manifeste DCM entwickeln (Politano et al. 1996; Hoogerwaard et al. 1999). Des Weiteren kann es zu pulmonalen Komplikationen wie einer Pneumonie oder respiratorischen Insuffizienz kommen (Simonds 2002), die sich einerseits auf die Schwäche der Atemmuskulatur, aber auch auf die sich entwickelnde seitliche Verkrümmung der Wirbelsäule (Skoliose) zurückführen lassen. Die forcierte Vitalkapazität sinkt im Sinne einer restriktiven Lungenfunktionsstörung proportional mit der Zunahme der Skoliose (Kinali et al. 2006). Patienten mit einer DMD versterben unbehandelt häufig bis zum Ende des zweiten Lebensjahrzehnts, wobei die Mehrheit der Patienten am Versagen der Atemmuskulatur und nicht dem akuten Herzversagen verstirbt (Nigro et al. 1990). Es hat sich jedoch gezeigt, dass durch eine adäquate symptomatische Behandlung die Lebenserwartung verlängert wird (Bushby et al. 2010). Als symptomatische Therapie wird der Einsatz von GS empfohlen (Bushby et al. 2010). Durch die Behandlung 
mit GS kommt es zu einem verlangsamten Muskelschwund, einer Verzögerung der Rollstuhlpflichtigkeit und der respiratorischen Beteiligung (Biggar et al. 2006; Hoffman et al. 2012; Manzur et al. 2008).

In den vergangenen Jahren wurde intensiv an kurativen Therapiemöglichkeiten gearbeitet, und in einer 2014 veröffentlichten Phase-2b-Studie wurde eine erfolgreiche Therapie von DMD-Patienten mit einer Nonsense-Mutation mit Ataluren (PTC124) beschrieben (Bushby et al. 2014), welches seit Ende 2014 in der Europäischen Union zur Behandlung der DMD zugelassen ist. Dieses Medikament setzt als erstes zugelassenes Medikament am genetischen Defekt an, indem es ein ribosomales read through des Stoppcodon bewirkt. In den USA ist seit 2016 Eteplirsen zugelassen. Dieses Medikament bewirkt, dass das Exon 51 in der präMessenger-Ribonukleinsäure (mRNA) beim Spleißen entfernt wird (exon-skipping). Dadurch ist das Exon 51 in der mRNA nicht mehr enthalten und wird nicht translatiert. Es entsteht ein verkleinertes, jedoch in großen Teilen funktionsfähiges Dystrophin (Lim et al. 2017). Zudem wurde in den USA Ende 2019 Golodirsen zugelassen. Golodirsen ist eine antisense-Nukleotid welches exon 53 skipping induziert und zu einer Produktion von verkürztem Dystrophinprotein führt. In einer Phase I/II Studie und einer aktuell noch laufenden Phase III Studie konnte ein statistisch signifikanter Anstieg der Dystrophinproduktion in mit Golodirsen behandelten DMD-Patienten beobachtet werden (Heo 2020).

Jedoch findet sich nur bei $13 \%$ der DMD-Patienten eine Nonsense-Mutation, bei $14 \%$ eine Mutation im Exon 51 und bei 8 \% der Patienten eine Mutation im Exon 53, sodass nur ein geringer Anteil der Patienten für eine Therapie mit Ataluren, Eteplirsen oder Golodirsen in Frage kommt und der größte Teil der DMD-Patienten weiterhin nur rein symptomatisch therapiert werden kann.

\subsection{3 Ätiologie und Pathogenese der DMD}

Das Dystrophin-Gen ist auf dem kurzen Arm des Chromosoms 21 lokalisiert und mit einer Größe von zwei Megabasen das größte Gen des menschlichen Genoms (Koenig et al. 1987; Monaco et al. 1992; Hoffman und Dressman 2001). Etwa ein Drittel aller DMD-Fälle entstehen durch eine Neumutation. Die Größe des Genoms wird auch als ursächlich für die hohe 
Zahl an Neumutationen angesehen (Emery 1980). Bei rund 60-80\% handelt es sich dabei um eine Deletion, bei 10-30\% um eine Punktmutation oder Insertion und in 7-11\% der Fälle um eine Duplikation (Schara 2015). Führt die Mutation zu einer Deletion des ersten Exons oder einer Verschiebung des Leserasters (out of frame), so wird kein funktionsfähiges Dystrophin mehr gebildet, und der Betroffene erkrankt an einer DMD. Falls es jedoch zu keiner Verschiebung des Leserasters kommt (in frame), so wird der Betroffene vermindert oder gering verändertes Dystrophin bilden und an einer BMD erkranken (Monaco et al. 1988).

Im Muskel ist Dystrophin unterhalb des Sarkolemm lokalisiert und verankert das Zytoskelett mit dem Sarkolemm. Dystrophin setzt sich aus vier Domänen zusammen. Einer N-terminalen Domäne die an F-Aktin bindet (Ervasti und Campbell 1993). Zweitens einer Stabregion, welche sich aus einer 26-fachen Wiederholung einer Folge von 100 Aminosäuren zusammensetzt und eine Verbindung zu Aktin und der neuronalen Nitritoxid-Synthase bildet. Drittens einer cysteinreichen Region, welche an $\beta$-Dystroglycan bindet und als vierte Domäne ein C-terminales Ende, welches eine Verbindung zu $\alpha$-, $\beta$ - und $\gamma$-Syntrophinen herstellt (Schara 2015). Durch die cysteinreiche Region und das C-terminale Ende bildet sich der dystrophinassoziierte Glykoproteinkomplex (DGK), der als Verbindung zur extrazellulären Matrix (EZM) und zur Plasmamembran fungiert (Rybakova et al. 2000; Ervasti 2007).

Bei DMD-Patienten zeigt sich in histopathologischen Untersuchungen der Muskulatur ein Nebeneinander von normalen, nekrotischen und sich regenerierenden Muskelfasern (Heyck und Laudahn 1969; Schröder 1995). Normale, ungeschädigte Muskelfasern haben einen peripheren Zellkern, ein intaktes Sarkolemm und unfragmentiertes Sarkoplasma (Müller und Zierz 2014). In der dystrophindefizienten Muskulatur kommt es zu einem Untergang von Muskelfasern, an den sich ein Regenerationsprozess anschließt, sodass ein DegenerationsRegenerations-Zyklus entsteht (Ozawa 2006). Eine wichtige Rolle in der Regeneration spielen die in der ausgereiften Muskulatur persistierenden myoblastischen Stammzellen. Diese sogenannten Satellitenzellen sind zwischen Sarkolemm und Basallamina lokalisiert (Heyck und Laudahn 1969). Die Satellitenzellen der erwachsenen Muskulatur nehmen nicht an mitotischen Prozessen teil, d. h. sie befinden sich in der G0-Phase des Zellzyklus (Schultz et al. 1978). Unter bestimmten Bedingungen werden die Satellitenzellen aber wieder aktiviert und kehren in den Zellzyklus zurück (Snow 1977; Appell et al. 1988). Eine segmentale 
Nekrose der Muskulatur führt zur Einwanderung von Makrophagen, die Zelltrümmer phagozytieren und Zytokine freisetzen, die daraufhin Satellitenzellen aktivieren (Cantini et al. 1994; Tidball 2005). Die Satellitenzellen proliferieren und fusionieren mit erhalten gebliebenen Faserfragmenten. Dort wo Fasern komplett untergegangen sind, werden von Satellitenzellen Myotuben gebildet, die sich miteinander vereinigen, sodass neue Muskelfasern mit unterschiedlicher Muskelfaserstärke und einem zentralen Zellkern entstehen (Schmalbruch 1976). Aufgrund der begrenzten Zahl an Satellitenzellen besitzt die Muskulatur nur ein gewisses Regenerationspotenzial, sodass im Verlauf die untergegangenen Muskelfasern nicht mehr durch neue Muskelfasern, sondern komplett durch Binde- oder Fettgewebe ersetzt werden (Schröder 2013).

Die Pathomechanismen, die bei diesen Umbauprozessen ablaufen, sind im Unterschied zu deren Ätiologie noch nicht zufriedenstellend geklärt. Im folgenden Abschnitt wird auf die unterschiedlichen in der Literatur beschriebenen Pathomechanismen eingegangen.

Durch den Dystrophinmangel kommt es zu einem Abbau der DGK-Proteine und es entsteht ein Ungleichgewicht zwischen den Anteilen des Dystrophinkomplexes (Gumerson und Michele 2011). Das Ausmaß der Muskelfaserschädigung bei der DMD korreliert mit der Höhe der mechanischen Beanspruchung, was folglich den Schluss zulässt, dass Dystrophin primär ein Strukturprotein ist, welches die Zellmembran vor mechanischem Stress schützt (Petrof et al. 1993). Bei jeder Kontraktion entstehen parallel und radial wirkende Kräfte (Cecchi et al. 1990) und durch die Verankerungen der Myofilamente über den DGK im Sarkolemm übertragen sich die Spannungen auf die Muskelzellmembranen. Im dystrophindefizienten Muskel kann der DGK diese Funktion entsprechend nicht ausführen. Utrophin, ein dem Dystrophin ähnliches Protein, wird im dystrophindefizienten Muskel verstärkt exprimiert (Hirst et al. 2005). Dieses Protein ist im gesunden Muskel v. a. an der motorischen Endplatte lokalisiert. Bei der DMD ist es jedoch auch vermehrt unterhalb des Sarkolemms, der physiologischen Position des Dystrophins, zu finden (Blake et al. 1996). Es wird angenommen, dass es sich dabei um eine Art Kompensationsmechanismus handelt, um im dystrophindefizienten Muskel mechanische Kräfte besser auf das Sarkolemm zu übertragen. Außerdem ist in dystrophindefizienten Muskeln die intrazelluläre Konzentration von Kalzium-Ionen erhöht (Bodensteiner und Engel 1978; Turner et al. 1988; Mallouk et al. 2000). Die Kalziumkonzentration ist von Bedeutung für viele Funktionen des Muskels (Berchtold et al. 2000). Zahlreiche Studienergebnisse deuten darauf hin, dass in den Muskeln bei DMD 
die Regelkreisläufe des Kalziumhaushalts gestört sind und ein erhöhter intrazellulärer Kalziumspiegel zu den degenerativen Prozessen in den dystrophindefizienten Muskeln beiträgt (Turner et al. 1988; Whitehead et al. 2006). Als mögliche Ursache für den erhöhten Kalziumeinstrom charakterisierte man eine höhere Aktivität des stretch-activated channels (SACs) (Yeung et al. 2005; Matsumura et al. 2011) und des TRPV2, eines Kanals der Vanilloid-Familie, in dystrophindefizienten Muskeln (Iwata et al. 2009; Zanou et al. 2009; Harisseh et al. 2013). Es wird vermutet, dass die Kalziumionen von den Mitochondrien aufgenommen werden. In diesen kommt es dann zur verstärkten Produktion von reaktiven Sauerstoff-Produkten (engl.: reactive oxidative species, ROS), die durch Lipidperoxidation die Zellmembranen weiter schwächen (Brookes et al. 2004). Zudem kommt es zur Aktivierung kalziumabhängiger Proteasen, sogenannter Calpaine, welche in der Lage sind, eine Vielzahl von membranalen und zytoskeletalen Muskelproteinen abzubauen, und so zu einer Verstärkung des muskulären Schadens führen (Shanmuga Sundaram et al. 2006; Whitehead et al. 2006). Studien haben eine erhöhte Aktivität dieser Enzyme im $x$-linked muscular dystrophy(mdx)-Mausmodell gegenüber Wildtyp-Tieren gezeigt (Tidball und Spencer 2000). Außerdem konnten durch die Gabe eines Calpaininhibitors die Muskelnekrosen in mdx-Mäusen signifikant reduziert werden (Spencer und Mellgren 2002). Als dritter relevanter Pathomechanismus fördert die Infiltration von Immunzellen die Pathologie der DMD. Es kommt zu einer Vermehrung des Haupthistokompatibilitätskomplexes Klasse 1, es wird NfkB aktiviert, die Inflammation mit Makrophagen und T-Zellen gesteigert, Neutrophile wandern ein und die Zytokin- und Chemokinfreisetzung (IFN- $\gamma$ und TNF- $\alpha$ ) erhöht (McDouall 1989; 1990; Porter et al. 2002; Acharyya et al. 2007). In diesem inflammatorischen Prozess sind Makrophagen und CD4-positive T-Zellen die dominierenden inflammatorischen Zellen. Dabei ist jedoch zu beachten, dass es unter den Makrophagen zwei Subpopulationen mit gegensätzlicher Funktion gibt, die proinflammatorischen Makrophagen vom Typ M1 und die Regeneration induzierenden Makrophagen vom Typ M2. In der Muskulatur von mdx-Mäusen, dem international etablierten Mausmodell der DMD, sind beide Makrophagensubpopulationen gefunden worden (Villalta et al. 2009). Dabei fand man in der Phase der Muskelnekrose in der Muskulatur von mdx-Mäusen hauptsächlich Makrophagen vom M1-Typ, deren Aufgabe in der Phagozytose von Zelltrümmern liegt (Villalta et al. 2009). Während der sich anschließenden Muskelregeneration hingegen konnte eine Dominanz der Makrophagen vom M2-Typ nachgewiesen werden. Dieser Subtyp fördert die Reparatur von Muskelmembranen sowie das Wachstum und die Regeneration von Muskelfasern (Tidball und WehlingHenricks 2007). Wehling et al. (2001) haben in Studien gezeigt, dass es nach 
Makrophagendepletion zu einer deutlichen Reduktion der histopathologischen Veränderungen in der frühen Krankheitsphase kommt. Auch nach einer Depletion von CD4-positiven T-Lymphozyten konnten verringerte histopathologische Veränderungen nachgewiesen werden (Spencer und Tidball 2001).

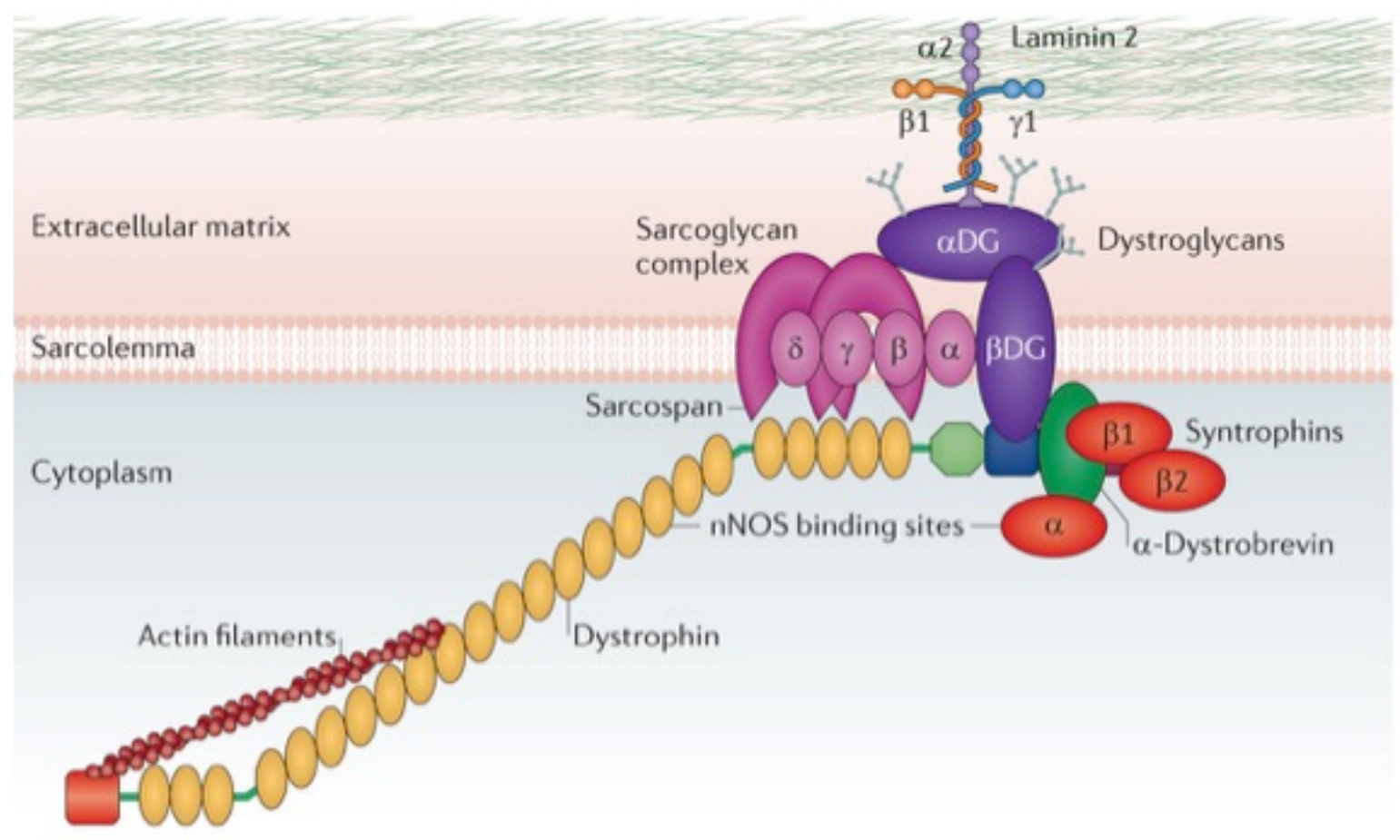

Abbildung 1: Dystrophinassoziierter Glykoproteinkomplex. Dystrophin als wichtiger Link zwischen Zytoskelett und EZM (aus: Fairclough et al. 2013. Die Verwendung erfolgt mit freundlicher Genehmigung des SpringerNature-Verlages). 
1984 wurde zufällig die der DMD analoge Mutation in einem C57BL/10ScSN-Stamm als eine Spontanmutation entdeckt (Bulfield et al. 1984). Jedoch zeigt sich im Tiermodell kein analog zur DMD von Geburt an progredienter, sondern ein biphasischer pathologischer und klinischer Krankheitsverlauf, der erst in der zweiten Krankheitsphase chronisch progredient verläuft. Direkt nach der Geburt zeigen sich in den Skelettmuskeln der mdx-Mäuse keine histologischen Veränderungen. Im Alter von drei bis vier Wochen kommt es zum akuten Beginn der Erkrankung (McGreevy et al. 2015) und bis einschließlich der achten Lebenswoche findet ein Zyklus von De- und Regeneration statt. In Untersuchungen der Muskulatur in dieser Krankheitsphase zeigen sich vermehrt Muskelfasern mit zentralisierten Zellkernen sowie eine erhöhte intrazelluläre Kalzium- und extrazelluläre Kreatinkinase (CK)-Konzentration. Es folgt eine Stabilisierung, welcher sich ein weitestgehend kontinuierlicher Verlauf bis zum einschließlich zwölften Lebensmonat anschließt. Nach dem ersten Lebensjahr kommt es zu einem erneuten Anstieg der muskulären Schädigung sowie einer deutlichen Zunahme des fibrotischen Ersatzes in den Muskeln (McGeachie et al. 1993). Das Diaphragma zeigt als einziger Muskel, auch bei der mdx-Maus, über den gesamten Krankheitsverlauf progrediente Veränderungen, sodass die Pathologie des Diaphragmas der mdxMäuse den Veränderungen der Muskulatur bei der DMD am nächsten kommt. Es gilt als Modellmuskel des Tiermodells, der den Verlauf der DMD am besten darstellt (Stedman et al. 1991; Dupont-Versteegden und McCarter 1992; Lynch et al. 1997). Mdx-Mäuse haben eine reduzierte Lebenserwartung im Vergleich zu Wildtyp-Mäusen (Pastoret und Sebille 1995; Chamberlain et al. 2007). Aufgrund der deutlichen histopathologischen Veränderungen in Herz und Diaphragma wird davon ausgegangen, dass respiratorische und kardiale Insuffizienz, analog zur DMD, die häufigsten Todesursachen sind (Chamberlain et al. 2007). Das mdx-Mausmodell ist das am häufigsten verwendete Tiermodell für die DMD, was auch auf die über 30-jährige Erfahrung mit diesem Mausmodell zurückzuführen ist. Wenn die physiologischen Unterschiede des mdx-Mausmodells sorgfältig beachtet werden, ist es ein unersetzliches Werkzeug der Erforschung von Pathogenese und Therapie der DMD. Eine genaue Erklärung für den geringer ausgeprägten Phänotyp beim Mausmodell wurde bis zum heutigen Zeitpunkt noch nicht gefunden. Eine mögliche Erklärung beruht auf der sogenannten Square-Cube-Regel, die erstmalig von Galileo 1638 beschrieben wurde (Allen 2014). Dieser Regel entsprechend kommt es beim Menschen im Vergleich zur Maus zu einem ungünstigeren Verhältnis von Körpervolumen zu Muskelfläche, was zu einer vermehrten 
mechanischen und statischen muskulären Beanspruchung führt und dementsprechend einen höheren muskulären Schaden zur Folge hat. Zudem hat die Bewegungseinschränkung aufgrund der Käfighaltung eine geringere Belastung der Muskulatur der Mäuse zur Folge. Es kommt bei den Mäusen mit ihrer vierbeinigen Körperhaltung zu einer günstigeren Verteilung des Körpergewichtes (KG) auf die Muskulatur verglichen mit dem aufrechten Gang des Menschen (Partridge 2013). Um die einwirkende Kraft auf den Muskel zu verteilen, finden sich beim Menschen verdickte Sehnen und Septen innerhalb der Muskulatur, die in der Mausmuskulatur nicht zu finden sind. Ein weiterer Unterschied zwischen Mensch und Maus besteht in der Zusammensetzung der Muskulatur hinsichtlich ihrer Muskelfasertypen (Harrison et al. 2011). Die Fasertypen werden unterteilt nach der Expression der vorherrschenden Myosin-Heavy-Chain(MHC)-Isoform. Dabei unterscheidet man die sich schnell kontrahierenden Typ-II-Fasern, zu denen MHC-IIa, -b und -x gehören, von den sich langsam kontrahierenden Fasern, den MHC-I-Fasern. Adenosintriphosphat wird in den Typ-IIa- und I-Fasern hauptsächlich oxidativ und in den Typ-IIb- und IIx-Fasern glykolytisch produziert (Smerdu et al. 1994). MHC-IIb ist der vorherrschende Fasertyp in der Skelettmuskulatur von Ratten und Mäusen (Harrison et al. 2011). In der Muskulatur eines untrainierten Menschen wiederum dominieren die MHC-I Fasern (Pette 1999). Jedoch ist die Skelettmuskulatur in der Lage, sich an Stress und Trainingsanforderungen anzupassen, sodass das Verteilungsmuster zwischen den Individuen insgesamt variiert (Pette und Staron 1997).

\subsection{Klinische und paraklinische Verlaufsparameter}

\subsubsection{Klinische Verlaufsparameter}

Zur Beurteilung des klinischen Verlaufs haben wir ein Laufradsystem verwendet, sowie wöchentliche Gewichts- und Griffkraftmessungen und in regelmäßigen Abständen Echokardiografien durchgeführt. Das Laufradsystem hat sich als eine Methode zur klinischen Verlaufsbeobachtung etabliert. Mit diesem System können die krankheitsbedingten Beeinträchtigungen der muskulären Funktion und die Auswirkungen einer spezifischen Behandlung auf die physikalische Aktivität untersucht werden. Es hat sich gezeigt, dass mdx-Mäuse eine deutlich herabgesetzte Laufleistung im Vergleich zu Kontrollmäusen haben (DupontVersteegden et al. 1994; Weller et al. 2012). An der Universitätsmedizin Göttingen wurde das Laufradsystem bereits in verschiedensten Studien genutzt, sodass eine weitreichende Erfahrung mit diesem System besteht (Liebetanz und Merkler 2006; Liebetanz et al. 2007). 
Unsere Arbeitsgruppe hat das System bereits zweimal in Studien mit dem mdx-Mausmodell verwendet (Weller et al. 2012; Zschüntzsch et al. 2016). Durch das vollcomputerisierte System können unabhängig vom Untersucher über 24 Stunden (h) präzise Laufdistanz, Laufzeit, Laufgeschwindigkeit, Anzahl der täglichen Läufe sowie die Laufdauer evaluiert werden. In den bisherigen Studien anderer Arbeitsgruppen beim mdx-Mausmodell wurden Laufradsysteme genutzt, die nur einzelne Parameter, wie z. B. die Distanz, aufzeichneten (Call et al. 2008; Selsby et al. 2013). Zudem hat dieses Experiment erstmals die langfristige Laufradnutzung über einen Zeitraum von 18 Monaten (Mo.) untersucht. In murinen Studien zu Myopathien ist die Griffkraftmessung der Vorderläufe der am häufigsten verwendete In-vivoTest. Mit dieser Untersuchung können die Beeinträchtigung der Gliedmaßen, der Effekt des kontinuierlichen Trainings und die Wirkung von Therapien evaluiert werden (Granchelli et al. 2000; De Luca et al. 2003).

Auch bei den mdx-Mäusen kommt es analog zu den DMD-Patienten zur Entwicklung einer DCM. Jedoch werden klinisch relevante kardiale Veränderungen erst bei älteren Tieren beschrieben. Die Studienlage ist hinsichtlich des Beginns der kardialen Manifestation uneinheitlich. Bereits im präklinischen Stadium lassen sich in der Magnetresonanztomografie Veränderungen der links- und rechtsventrikulären Wand und deren Motilität nachweisen (Li et al. 2009; Stuckey et al. 2012). Durch diese Veränderungen kommt es aber noch nicht zu einer relevanten Auswirkung auf die kardiale Kontraktilität und damit Auswurfleistung (Stuckey et al. 2012; Wagner et al. 2012). Echokardiografisch zeigen sich nach rund neun bis zehn Monaten moderat veränderte Werte für linksventrikuläre Parameter (Quinlan et al. 2004; Spurney et al. 2008), aber klinisch relevante Veränderungen zeigen sich nicht vor dem 15. Lebensmonat (Bostick et al. 2008;2009; Bish et al. 2011). Mit dem Alter kommt es zu einer beschleunigten Verschlechterung der kardialen Funktion (Quinlan et al. 2004). Die Veränderungen im linken Herzen, die zur DCM führen, lassen sich auf eine moderate Fibrose und Nekrose der Myozyten, fokale Degeneration sowie Inflammation zurückführen (Quinlan et al. 2004; Spurney et al. 2008). Das Netzwerk Treat-NMD (Translational Research in Europe for the Assessment and Treatment of Neuromuscular Disease), welches ein internationaler Zusammenschluss zur Erforschung neuromuskulärer Erkrankungen ist, empfiehlt in seinen Angaben zum standardisierten Vorgehen (engl.: standard operating procedures, SOPs) die Echokardiografie, um in präklinischen Studien Medikamentenwirkungen auf die kardiale Funktion von mdx-Mäusen zu untersuchen. Dementsprechend wurden in dieser Studie, ebenfalls in regelmäßigen Abständen, transthorakale Echokardiografien 
durchgeführt, um den Einfluss einer Therapie auf die Herzfunktion zu beurteilen. Mit dieser routinemäßig angewendeten Untersuchungsmethode können nichtinvasiv Morphologie, Motilität und Funktion des Herzens beurteilt werden. Dabei wurde die Funktion des linken Herzens untersucht und linksventrikuläre Parameter ermittelt. Zu den erhobenen Parametern zählen die EF und die zirkumferenzielle Flächen-Verkürzungsfraktion (engl.: fractional area shortening/change, FAS). Diese Parameter werden routinemäßig im klinischen Alltag bei Patienten (Ashwath et al. 2014; Jo et al. 2016), aber auch bei Mausmodellen (Au et al. 2011; Bish et al. 2011; Fayssoil et al. 2013), erhoben.

\subsubsection{Paraklinische Verlaufsparameter}

Die CK im Serum, Expression von Mediatoren auf mRNA-Ebene, der Index zentralisierter Zellkerne (CNI), die Kaliberschwankungen der Muskelfasern sowie die Anzahl der Makrophagen und T-Zellen im Skelett- und Herzmuskel wurden in dieser Studie als paraklinische Parameter erhoben. Das Enzym CK ist ein typischer serologischer Aktivitätsmarker für dystrophe Erkrankungen. Durch den Untergang der Muskulatur und die erhöhte Membrandurchlässigkeit bei der DMD und der mdx-Maus kommt es zu einer massiven Freisetzung der CK, sodass die Serumkonzentration dieses Enzyms deutlich erhöht ist. Damit ist die CK ein guter Parameter, um den muskulären Schaden zwischen Gruppen zu vergleichen (Coulton et al. 1988; Zatz et al. 1991).

Im Immunsystem wird die Kommunikation zwischen dem Gewebe - im Fall der DMD der Muskulatur - und den dort wirkenden inflammatorischen Zellen durch membranständige Proteine und lösliche Signalstoffe vermittelt. Diese Signalstoffe werden auch als Mediatoren bezeichnet. Eine Hochregulation der Expression von Mediatoren hat demnach auch eine Erhöhung der Anzahl inflammatorischer Zellen zur Folge. Dementsprechend werden molekulare Therapieeffekte auch durch eine veränderte Expression von Entzündungsmediatoren auf mRNA-Ebene widergespiegelt. In dieser Studie haben wir die Expression von transforming growth factor $\beta$ (TGF- $\beta$ ), secreted phosphoprotein 1 (SPP1) und monocyte chemoattractant protein 1 (MCP1) im Diaphragma, M. gastrocnemius, M. tibialis anterior und M. quadriceps femoris bestimmt. Diese Mediatoren wurden bereits in zahlreichen Studien mit dem mdx-Mausmodell analysiert. TGF- $\beta$ ist ein pleiotropes Zytokin mit inflammatorischen und antiinflammatorischen Effekten. Durch die Inflammation kommt es im dystrophen 
Skelettmuskel zu einer lokalen Freisetzung von TGF- $\beta$, was zu einer Aktivierung der EZM und folglich einer Proliferation des Bindegewebes führt. TGF- $\beta$ wirkt sich jedoch auch negativ auf die Muskelregeneration aus, indem es Satellitenzellen inhibiert und die Fusion der Muskelfasern verhindert (De Paepe und De Bleecker 2013). Es hat sich gezeigt, dass eine Inhibition der TGF- $\beta$-Aktivität sowohl die Kraft der Vorderläufe, als auch die des Diaphragmas, der interkostalen Muskulatur und damit die respiratorische Funktion verbessert (Nelson et al. 2011). SPP1, auch Osteopontin genannt, wurde als phosphoryliertes Glykoprotein im Jahre 1986 in Osteoblasten entdeckt (Oldberg et al. 1986), jedoch später auch aus anderen Geweben wie Knochenmarkzellen, Makrophagen, der glatten Muskulatur und der Haut isoliert. Osteopontin ist ein multifunktionales Molekül, das auch zu Degeneration der EZM, Inflammation im Muskel sowie De- und Regeneration im Muskel führt. Dystrophindefiziente Muskeln, sowohl beim Menschen als auch in der mdx-Maus, zeigen erhöhte SPP1Konzentrationen. In Studien, die versucht haben, eine Art dystrophiespezifischen molekularen Fingerabdruck zu erstellen, wurden Desoxyribonukleinsäure(DNA)-Microarray-Analysen an verschiedenen mdx-Muskeln durchgeführt. Hier fand sich SPP1 unter den am stärksten überexprimierten Genen in der Beinmuskulatur und im Zwerchfell (Porter et al. 2003). Entzündliche Muskelerkrankungen zeigen jedoch kein auffälliges SPP1-Level, was dafür spricht, dass eine SPP1-Erhöhung eher mit einem Muskelumbau verbunden ist (Marhaug et al. 2008). In Studien wurde beschrieben, dass sich in der mdx-Maus ein erniedrigtes Level von SPP1 positiv auf den Phänotyp und die Kraft bei jungen mdx-Mäusen auswirkt (Vetrone et al. 2009; Capote et al. 2016). Im Widerspruch dazu steht aber, dass DMD-Patienten mit dem selteneren Genotyp, dem sogenannten less common $G$ allele of the osteopontin promoter polymorphism, bei dem es zu einer verminderten Bildung von SPP1-mRNA kommt, eine frühere Rollstuhlpflichtigkeit und eine ausgeprägtere Muskelschwäche gegenüber Patienten mit dem häufigeren Genotyp haben, bei dem mehr SPP1-mRNA gebildet wird (Nadarajah et al. 2011; Pegoraro et al. 2011). MCP1, auch CC-Chemokin-Ligand-2 (CCL2) genannt, ist ein Ligand des cc chemokine receptor type 2. Dieses Chemokin bedingt einerseits die Chemotaxis von Immunzellen zum Ort der Entzündung (Lu et al. 1998). Jedoch scheint MCP1 andererseits auch essentiell für eine adäquate inflammatorische Antwort bei der Reparatur von akuten Muskelschädigungen zu sein. Es wird sowohl von Satellitenzellen als auch von inflammatorischen Zellen sezerniert. MCP1 aktiviert die Einwanderung von Makrophagen. Es hat sich gezeigt, dass CCL2-defiziente Mäuse weniger Muskelinflammation, Phagozytose sowie eine beeinträchtigte und verlangsamte Regeneration der Muskulatur aufweisen (Warren et al. 2004 ; 2005; Lu et al. 2011). 
Die Zahl der Muskelfasern mit einem zentralisierten Kern und die Variabilität der Faserkaliber ist ein Parameter für das Ausmaß von De- und Regeneration in der Muskulatur (Briguet et al. 2004). Wenn eine Therapie zu einer signifikanten Reduktion der Nekrose führt, so spiegelt sich dies in einer reduzierten Anzahl von Muskelfasern mit zentralisiertem Zellkern wider. Auch bei der mdx-Maus kommt es zu einer Infiltration mit Immunzellen. Diese beginnt analog zu den histopathologischen Veränderungen in der zweiten bis vierten Woche und ist hauptsächlich von Makrophagen und T-Zellen geprägt (Spencer et al. 2001; Wehling et al. 2001). Nach einem initialen Gipfel kommt es nach 8 (Makrophagen) bzw. 14 (T-Zellen) Wochen zu einer Reduktion dieser und anderer inflammatorischer Zellen im Muskel. Wie bereits erwähnt, kommt es in den Herzen der mdx-Mäuse ebenfalls zur Inflammation (Bridges 1986). Zudem findet ein fibrotischer Umbau des Herzmuskels statt, der vermutlich durch die Inflammation im Herzmuskel bedingt wird.

\section{$1.4 \quad$ Humane Immunglobuline als Immunmodulatoren im mdx-Mausmodell}

Die aktuell empfohlene symptomatische Therapie mit GS bei der DMD ist hinsichtlich ihres Nutzen-Risiko-Profils nicht unumstritten. Aus diesem Grund haben wir uns in dieser Studie für die intraperitoneale (i. p.) Therapie mit hochdosierten humanen Immunglobulinen (Ig) als immunmodulierendes Medikament entschieden. Intravenöse (i. v.) und subkutan (s. c.) applizierte Ig werden heute bei vielen neurologischen Erkrankungen eingesetzt (Feasby et al. 2007). Zudem haben Ig eine gute Verträglichkeit bei Kindern gezeigt, was in Bezug auf die sich im Kindesalter manifestierende DMD von Bedeutung ist (Singhi et al. 1999; OatesWhitehead et al. 2003).

Ig, auch Antikörper genannt, werden als Teil des adaptiven Immunsystems von B-Zellen produziert und können über variable Domänen Antigene binden. Es existieren fünf Isotypen: IgA, IgD, IgM, IgE und IgG, wobei IgG weiter in die Subklassen IgG1 bis IgG4 unterteilt werden. IgG haben mit 80 \% den größten Anteil unter den Ig im menschlichen Körper (Roitt 1988), dienen der Opsonierung und Neutralisierung von Bakterien, Viren und Toxinen und aktivieren das Komplementsystem (Murphy 2012). Das adaptive Immunsystem beinhaltet ca. $10^{11}$ unterschiedliche Antikörper. Diese Antikörpervielfalt ist auf Neukombination von Erbmaterial, auch als somatische Rekombination bezeichnet, in somatischen Zellen während der Reifung der B-Zellen im Knochenmark zurückzuführen. Bei Antigenkontakt entstehen 
Antikörper, die gegen die verschiedenen Epitope des Antigens gerichtet sind. Demnach sind unterschiedliche B-Zellklone an der Immunantwort beteiligt, und das Blutserum enthält entsprechend polyklonale Antikörper (Murphy 2012).

Ig werden aus Blutplasma oder durch Plasmapherese gewonnen. Anschließend werden die Ig-Präparate in einem mehrstufigen Verfahren hergestellt. Die heute meist intravenös verabreichten Präparate, demnach auch als IVIG (für: intravenöse Immunglobuline) bezeichnet, werden von ca. 1000 Patienten gepoolt und auf unterschiedliche Weisen aufgereinigt. Die Präparate bestehen meist nur aus IgG, manche beinhalten aber zu einem geringen Anteil auch IgA und IgM. Dabei unterscheiden sich die Präparate je nach Hersteller in den verwendeten Stabilisatoren. Verabreicht werden Sie nach den Richtlinien der European Medicines Agency (EMA 2018). Ig werden in den letzten Jahren auch vermehrt s. c. appliziert, da ein immunmodulierender Effekt auch bei dieser Darreichungsform nachgewiesen werden konnte (Harbo et al. 2009;2010; Misbah et al. 2009). 1981 wurden IVIG erstmals erfolgreich zur Therapie der autoimmunen idiopathischen thrombozytopenischen Purpura eingesetzt (Imbach et al. 1981). Heute sind IVIG die in der Leitlinie der Deutschen Gesellschaft für Neurologie (DGN) empfohlene Therapie beim Guillain-Barré-Syndrom (auch akute inflammatorische demyelinisierende Polyneuropathie genannt, AIDP), der multifokalen motorischen Neuropathie (MMN) und der chronischen inflammatorischen demyelinisierenden Polyneuropathie (CIDP) (DGN 2018). Es wird beispielsweise empfohlen, initial zur Therapie der CIDP eine Gesamtdosis von $2 \mathrm{~g} / \mathrm{kg} \mathrm{KG}$ über zwei bis vier Tage verteilt zu verabreichen, eine Dosis die sich in Studien als geeignet erwiesen hat (Hughes et al. 2008; Eftimov et al. 2013). Danach wird eine Erhaltungsdosis zwischen 0,4 und 1,2 g/kg KG verabreicht (Yoon et al. 2011). Da die Wirkung von IVIG nur kurz anhält, muss die Behandlung in regelmäßigen Abständen wiederholt werden. Eine Erhaltungsdosis wird alle zwei bis sechs Wochen appliziert, wobei das jeweilige Intervall individuell bestimmt und im Verlauf überprüft werden muss (Yoon et al. 2011).

Ig werden eine Vielzahl von immunmodulierenden Effekten zugeschrieben. Die entzündungshemmende Wirkung der IVIG wird nach der aktuellen Studienlage durch die sialylation des N-linked glycan des IgG-Fc-Fragments bedingt (Kaneko et al. 2006; Quast et al. 2015). IgG wirken hemmend auf das Komplementsystem (Frank et al. 1992; Brannagan et al. 1996; Dalakas 2004) und die Formation des Membranangriffskomplexes (Dalakas 2004), wirken am FC-Rezeptor von Makrophagen (Samuelsson et al. 2001; Dalakas 2004) und 
B-Zellen (Kondo et al. 1994) und reduzieren das Zytokinlevel von z. B. TNF- $\alpha$ und IL-1 (Sharief et al. 1999; Dalakas 2004). Im Weiteren wird die Migration von Zellen durch die Modulation von Adhäsionszellen (Xu et al. 1998; Vassilev et al. 1999) reguliert und T- und B-Zellen bei einer IVIG-Gabe beeinflusst. Auf T-Zellen wirken die IVIG-Präparate z. B. durch die enthaltenen Anti-CD4-Antikörper, die an die CD4-positiven T-Zellen binden (Hurez et al. 1994), zudem führen sie zu einer Expansion der regulatorischen T-Zellen (Kaufman et al. 2015) und einer Reduktion der autoreaktiven T-Zellen (Klehmet et al. 2015). Die Differenzierung von B-Zellen (Stohl und Elliot 1996) wird beeinflusst, die antiidiotypische Bindung von Autoantikörpern (Rossi et al. 1988) induziert, die Antikörperproduktion reduziert (Kondo et al. 1994) und Apoptose von B-Zellen eingeleitet. Es wird vermutet, dass die Wirkweise der IVIG auch je nach Erkrankung unterschiedlich ist. So wird z. B. in mehreren Studien beschrieben, dass bei der MMN die IVIG gezielt die anti-GM1-IgM-vermittelte Komplementaktivierung blockieren (Piepers et al. 2010; Yuki et al. 2011).

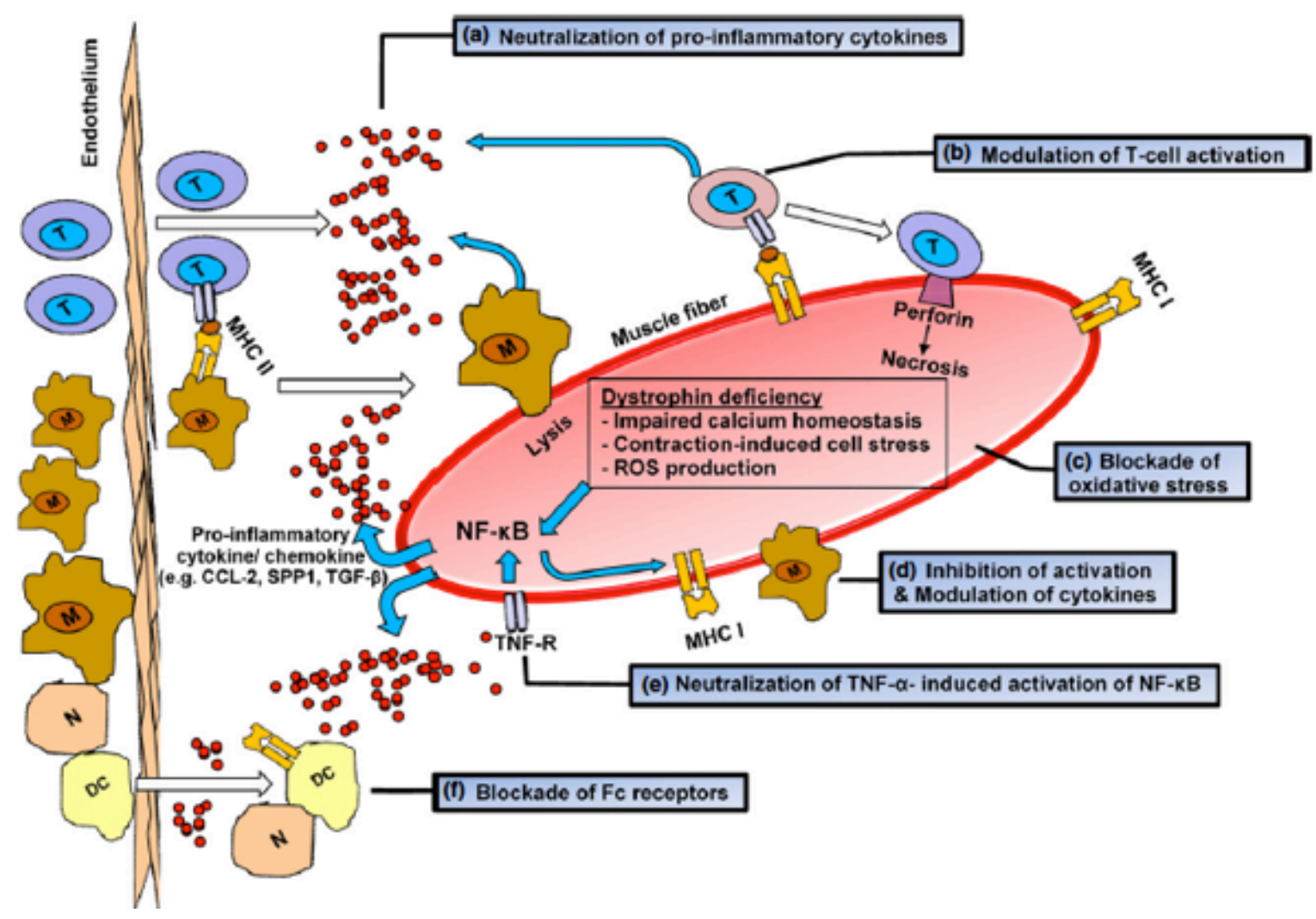

Abbildung 2: Vermutete Wirkung von IVIG in DMD. IVIG wirken hemmend auf pro-inflammatorische Zytokine und Chemokine wie TNF- $\alpha$, SPP1 oder TGF- $\beta$, modulieren T-Zellen, Zytokine und FC-Rezeptoren (aus: Zschüntzsch et al. 2016. Die Verwendung erfolgt mit freundlicher Genehmigung des John Wiley and Sons-Verlages). 
Allgemein gelten Ig als ein nebenwirkungsarmes und sicheres Therapeutikum. Dennoch gibt es einige leichte, aber auch schwerwiegende Nebenwirkungen (NW), die auftreten können. $\mathrm{Zu}$ den leichten NW zählen Allgemeinreaktionen wie Kopfschmerzen, Fieber, Müdigkeit oder Übelkeit. Zu den potentiell schwerwiegenden NW gehören beispielsweise eine anaphylaktische Reaktion, thromboembolische Ereignisse, Hämolyse oder akutes Nierenversagen (Stangel et al. 2003; Wittstock et al. 2003). Klinische Studien beschreiben Kopfschmerzen als die häufigste auftretende symptomatische NW. Die Prävalenz von Kopfschmerzen schwankt jedoch je nach Studie zwischen $7 \%$ (Wittstock et al. 2003) und $30 \%$ (Stangel et al. 2003). Nur selten kommt es zu schwerwiegenden NW bei einer Therapie mit IVIG. Zudem sind die gravierenden NW häufig mit einem entsprechenden Risikoprofil assoziiert. So wird in der Literatur berichtet, dass es bei Patienten mit Risikofaktoren wie Immobilität, Thrombophilie, einer tiefen Beinvenenthrombose oder Thromboembolie in der Vorgeschichte in 1-3\% der Fälle zum Auftreten eines thromboembolischen Ereignis unter der Therapie mit IVIG kam (Brannagan et al. 1996; Stangel et al. 2003; Wittstock et al. 2003; Dalakas 2004). Eine anaphylaktische Reaktion wurde vorzugsweise bei Patienten mit einem selektiven IgA-Mangel beobachtet (Eijkhout et al. 2003) und als Risikofaktoren für ein akutes Nierenversagen werden eine vorbestehende Niereninsuffizienz, Diabetes mellitus oder Volumenmangel angesehen (Tan et al. 1993; Ahsan et al. 1994).

\subsection{Ziel dieser Arbeit}

Es wurde bereits erfolgreich eine Behandlung mit humanem IgG im mdx-Mausmodell über einen Zeitraum von drei Monaten durchgeführt. Die mit IgG behandelten mdx-Mäuse zeigten eine stabilere Aktivität im Laufrad, und ihre Ausdauer in der Ex-vivo-Muskelkontraktionskraftmessung war erhöht. Weiter ist es zu einer reduzierten Inflammation und weniger myopathischen Veränderungen in der Muskulatur gekommen (Zschüntzsch et al. 2016). Die vorliegende Arbeit hat das Ziel, eine langfristige Therapie mit IgG über 18 Monate zu untersuchen. Es wurde der Einfluss der Therapie auf diverse klinische und paraklinische Verlaufsparameter, die eine Wirksamkeit der Therapie widerspiegeln, untersucht. Zu den untersuchten klinischen Parametern zählen Laufradaktivität, Ex-vivo-Muskelkontraktionskraft und Griffkraftmessung. Als paraklinische Verlaufsparameter wurden die CK-Konzentration im Serum, mRNA-Expression von relevanten Mediatoren, Zahl der CD4-positiven T-Zellen und Makrophagen sowie histopathologische Veränderungen untersucht. 


\section{$2 \quad$ Material und Methoden}

Die in dieser Studie gewählten Methoden entsprechen den von Treat-NMD empfohlenen SOPs für präklinische Studien im mdx-Mausmodell (Grounds et al. 2008; Grounds 2014; Grange 2015; Spurney 2015; Nagaraju und Gordish 2017; De Luca 2019 a; b).

\section{$2.1 \quad$ Tiere}

Die Experimente wurden von der dafür zuständigen Veterinärbehörde genehmigt, und bei der Durchführung wurden die Bestimmungen der Bezirksregierung Braunschweig (Niedersachsen, Deutschland) eingehalten. Die verwendeten Tiere stammen aus der hauseigenen Zucht der Tierexperimentellen Einrichtung der Georg-August-Universität Göttingen. Die zur Zucht verwendeten mdx-Mäuse (C57BL/10ScSn-mdx/J) wurden uns freundlicherweise von Ralf Herrmann (Universität Essen, Deutschland) gestellt. Bei diesen Tieren waren die männlichen Mäuse für das mdx-Gen heterozygot und die weiblichen Mäuse homozygot. Die Tiere haben handelsübliches Nagerfutter sowie Trinkwasser ad libitum erhalten.

\subsection{Versuchsablauf}

Die mdx-Mäuse wurden in drei gleich große Gruppen mit jeweils 19 Tieren eingeteilt, wobei Männchen und Weibchen gleichmäßig auf die Versuchsgruppen verteilt wurden. Im Alter von drei bzw. sechs Wochen kamen die Tiere jeweils einzeln in einen Käfig mit einem für die Maus jederzeit zugänglichen Laufrad. Ein Computerprogramm zeichnete durchgängig über den gesamten Untersuchungszeitraum die Laufradaktivität auf. Einmal pro Woche wurde das aktuelle Gewicht der Tiere bestimmt und eine Griffkraftmessung durchgeführt. Nach drei Monaten wurden bei einigen Tieren jeder Behandlungsgruppe erstmalig Echokardiografien durchgeführt. Zur Verlaufskontrolle der kardialen Funktion erfolgten dann im Abstand von jeweils drei bis vier Monaten weitere Echokardiografien. Die Tiere einer Gruppe erhielten alle vier Wochen eine i. p.-Injektion mit 2 g/kg KG IgG, Natriumchlorid $(\mathrm{NaCl})$ oder Mausserum (MS). Im initialen Studienaufbau gab es Kontrollgruppen mit Albumin- oder NaCl-Behandlung. Jedoch starben die meisten der Tiere in der Gruppe mit Albumintherapie nach der vierten Injektion. Danach wurde eine zusätzliche Kontrollgruppe mit einer MS-Behandlung begonnen. Die mit MS behandelten mdx-Mäuse befanden sich 
nach rund zwölf Monaten in einem sehr schlechten Allgemeinzustand, sodass ein vorzeitiges Versuchsende notwendig wurde. Nach 12 bzw. 18 Monaten wurden die Tiere - zur Durchführung des Ex-vivo-Muskelkontraktionstestes - zur Kooperationsgruppe von Prof. Brinkmeier an die Universität Greifswald gesendet. Dort wurden die Tiere durch eine letale Kohlenstoffdioxid-Dosis getötet und daraufhin präpariert. Die präparierten Proben der Muskeln wurden im Anschluss zurück nach Göttingen gesendet. Tiere, die bereits während des laufenden Experiments verstorben waren, wurden auf dieselbe Weise in Göttingen präpariert. Zusätzlich wurde post mortem über eine intrakardiale Kanüle Blut entnommen und zur Gewinnung von Serum zentrifugiert.

\section{Therapieschema}

Die medikamentöse Therapie wurde nach erfolgreicher Entwöhnungsphase am 22. Tag, einen Tag nach Beginn der Laufradnutzung, begonnen. Den Tieren wurde i. p. 2 g/kg KG humanes IgG (Sandoglobin Liquid, CSL Behring, Marburg, Deutschland) injiziert. Als Kontrollsubstanzen wurden i. p. 0,9\% NaCl und MS ebenfalls mit einer Dosis $2 \mathrm{~g} / \mathrm{kg} \mathrm{KG}$ appliziert. Anschließend wurde im vierwöchigen Rhythmus eine i. p.-Injektion mit der jeweiligen Substanz durchgeführt.

\section{$2.4 \quad$ Laufrad und Tierhaltung}

Die Tiere wurden jeweils in einem Einzelkäfig mit einem frei zugänglichen Laufrad (Durchmesser $38 \mathrm{~cm}$ ) gehalten. Die Software Matlab (The MathWorks, Natick, MA, USA) zeichnete durchgängig die Laufradaktivität der einzelnen Tiere auf (Tab. 1) (Kutschenko et al. 2011; Weller et al. 2012; Zschüntzsch et al. 2016). Im Raum betrug die Temperatur konstant $24{ }^{\circ} \mathrm{C}$, die Luftfeuchtigkeit war bei ca. 45 \%. Das Licht war auf einen zwölfstündigen HellDunkel-Rhythmus - mit einer Lichtphase im Zeitraum von 7.00-19.00 Uhr - eingestellt. Die Besuchszeiten wurden auf 90 Minuten zu Beginn und Ende dieser Lichtphase beschränkt, um den Schlaf-Wach-Rhythmus der Tiere möglichst gering zu beeinflussen. 
Tabelle 1: Laufradparameter.

\begin{tabular}{|l|l|l|l|}
\hline Parameter & Kurzform & Definition & Einheit \\
\hline Maximalgeschwindigkeit & $\mathrm{V}_{\max }$ & $\begin{array}{l}\text { Maximale Laufgeschwindigkeit } \\
\text { pro Tag }\end{array}$ & $\mathrm{M}$ \\
\hline Anzahl der Läufe (\#) & $\mathrm{N}_{\text {lauf }}$ & Anzahl der Läufe pro Tag & $\#$ \\
\hline Gesamtzeit & $\mathrm{T}_{\text {ges }}$ & Kumulative Laufzeit pro Tag & Min \\
\hline $\begin{array}{l}\text { Quotient Gesamtzeit/Anzahl } \\
\text { der Läufe }\end{array}$ & $\mathrm{T}_{\text {ges }} / \mathrm{N}_{\text {lauf }}$ & $\begin{array}{l}\text { Durchschnittliche Dauer eines Lau- } \\
\text { fes pro Tag }\end{array}$ & $\mathrm{min} / \#$ \\
\hline Distanz & Dist & Kumulative Laufdistanz pro Tag & $\mathrm{M}$ \\
\hline Kumulative Gesamtdistanz & Dist $\mathrm{cum}_{\text {cum }}$ & $\begin{array}{l}\text { Kumulative Gesamtdistanz im } \\
\text { Untersuchungszeitraum }\end{array}$ & $\mathrm{M}$ \\
\hline
\end{tabular}

\subsection{Messung der Griffkraft}

Mittels eines Griffkraftmessers (engl.: grip strength meter) (TSE-Systems, Bad Homburg, Deutschland) wurde die individuelle Griffkraft jeder Maus einmal wöchentlich bestimmt. Bei dieser Messung hält sich die Maus mit den Vorderläufen an einer Strebe, und der Untersucher hält währenddessen die Maus am Schwanz. Die kontinuierliche Darstellung auf einer digitalen Anzeige erlaubt das Ablesen, wobei pro Messung von jedem Tier drei Werte gemessen und deren Mittelwert berechnet wurde.

\subsection{Transthorakale Echokardiografie}

Für die Echokardiografie wurden die Mäuse mit Isofluran narkotisiert und unter laufender Kontrolle der Herzfrequenz mit dem Vevo-1000-System (FUJIFILM VisualSonics, Toronto, Kanada) eine Untersuchung des Herzens durchgeführt. Dabei kommt es bekannterweise auch durch die Narkose zu einer Beeinflussung der Herzfunktion, v. a. ein kardiodepressiver Effekt von Narkotika ist vorbeschrieben (Hart et al. 2001; Peña und Wolska 2005). Studien haben gezeigt, dass die Werte, die wir in dieser Studie erheben wollen, unter Verwendung von Isofluran am besten reproduzierbar sind (Roth et al. 2002). Die Untersuchungen und Auswertungen wurden jeweils von derselben Person durchgeführt, um untersucherabhängige Unterschiede zu vermeiden. Dabei wurden jeweils insgesamt 18 Parameter erhoben. In der parasternalen kurzen Achse des B- und M-Mode wurden Vorder- und Hinterwanddicke sowie der Durchmesser des linken Ventrikels in Systole (s) und Diastole (d) 
bestimmt. Es wurden zusätzlich im B-Mode die Endokard- und Epikardfläche und in langer Achse die Länge der Strecke von Aortenklappe bis Endokard gemessen. Aus den erhobenen Werten konnten FAS und EF bestimmt werden. Die FAS wird mit folgender Formel: FAS $=(($ Area d - Area s $) /$ Area d $) \times 100)$ und die EF mit: EF $=((\operatorname{Vol~d}-$ Vol s $) /$ Vol d $\times 100))$, berechnet.

\subsection{Aufarbeitung der Gewebeschnitte}

Den Tieren wurden jeweils der rechte oder linke M. tibialis anterior, M. gastrocnemius, $\mathrm{M}$. quadriceps femoris, das Diaphragma und das Herz entnommen. Die Muskeln wurden durch scharfe Schnitte in zwei Muskelsektionen geteilt. Ein Fragment wurde in ein Eppendorfgefäß $(1,3 \mathrm{ml})$ überführt, bei $-80{ }^{\circ} \mathrm{C}$ eingefroren und bis zur späteren RNA-Extraktion gelagert. Das zweite Fragment wurde auf ein Korkplättchen gelegt, mit Tissue-Tek (Sakura, Niederlande) überschichtet und in n-Methylbutan (C. Roth, Karlsruhe, Deutschland), mittels - 159,9 ${ }^{\circ} \mathrm{C}$ gekühlt flüssigem Stickstoff, eingefroren. Bis zur Herstellung der histologischen Schnitte wurden die Proben bei $-80{ }^{\circ} \mathrm{C}$ gelagert.

\section{$2.8 \quad$ Histologie}

Von den Muskelproben wurden mit einem Kryomikrotom (Leica CM3050 S, Leica Mikrosysteme, Wetzlar, Deutschland) Querschnitte mit einer Dicke von $10 \mu \mathrm{m}$ angefertigt, auf Adhäsions-Objektträger (LabSolute, Th. Geyer Gruppe, Renningen, Deutschland) aufgebracht und anschließend bei $-80^{\circ} \mathrm{C}$ gelagert. Später wurden die Schnitte unterschiedlich gefärbt. Zum einen wurde nach standardisierten Methoden eine Hämatoxylin-Eosin(HE)-Färbung (Mayers Hämalaunlösung, Merck, Darmstadt, Deutschland; Eosin G, Merck, Darmstadt, Deutschland) angefertigt. Zum anderen wurden für immunhistochemische Färbung der Makrophagen und T-Zellen die Schnitte über Nacht mit den primären Antikörpern MAC3 (clone $m C A$ 497, AbD Serotec, Düsseldorf, Deutschland) und anti-humanem CD3 (clone KT 3, AbD Serotec, Düsseldorf, Deutschland) inkubiert. Am folgenden Tag wurden die Schnitte mit dem zweiten Antikörper anti-rat Immunoglobulin G Biotin (BA-4001, Vector Laboratories, Burlingame, CA, USA) für eine Stunde bei Raumtemperatur und im Anschluss eine weitere Stunde mit Extravidin-Peroxidase (Sigma-Aldrich, Steinheim, Deutschland) in-

kubiert. Um die Aktivität der Peroxidase zu zeigen, wurde mit 3,3'-Diaminobenzidin 
(Merck, Darmstadt, Deutschland) inkubiert, welches in Gegenwart von Peroxidase ein unlösliches braunes Endprodukt bildet. Dann wurden alle Schnitte für 120 Sekunden mit Hämatoxylin gegengefärbt, in einer aufsteigenden Alkoholreihe (70 \%, $96 \%, 99 \%)$ dehydriert, in Xylol fixiert und mit Entellan (Merck, Darmstadt, Deutschland) eingedeckelt. Zur Darstellung der Fibrose des Herzens wurden Schnitte nach der Methode Elastika-van-Gieson-Färbung gefärbt. Dazu wurden die Schnitte zuerst in einer absteigenden Alkoholreihe (99\%, $96 \%, 80 \%$ ) dehydriert und mit Resorcin-Fuchs-Lösung (C. Roth, Karlsruhe, Deutschland) für 15 Minuten inkubiert. Nach Spülung mit Leitungs- und destilliertem Wasser wurden die Schnitte mit Van-Gieson-Pikrofuchsin-Lösung (C. Roth, Karlsruhe, Deutschland) für drei Minuten gefärbt. Zuletzt mit $70 \%$ und $96 \%$ Ethanol kurz gewaschen. Dann zweimal mit $100 \%$ Ethanol gewaschen und zuletzt mit Xylol fixiert.

\subsection{Auswertung der Gewebeschnitte}

Die Schnitte wurden nach der Färbung und Trocknung mit einem aufrechten Mikroskop (BX51, Olympus, Hamburg, Deutschland) betrachtet und einer digitalen Mikroskopkamera (Color View, Soft Imaging Systems, Olympus, Hamburg, Deutschland) in zehnfacher Vergrößerung fotografiert. Mit der Software Analysis B-1045 (Olympus, Hamburg, Deutschland) wurden manuell die zentralisierten Zellkerne und peripheren Kerne von ca. 200-500 Fasern pro untersuchtem Querschnitt gezählt, sowie der Faserdurchmesser der Zellen bestimmt. In gleicher Weise wurden in einer 40-fachen Vergrößerung zehn Aufnahmen der immunhistochemischen Färbungen der Makrophagen und T-Zellen manuell gezählt. Die gesamte Mikroskopie erfolgte verblindet.

\subsection{Kreatinkinase}

Die Bestimmung der CK-Konzentration im Serum der mdx-Mäuse wurde nach Beendigung der Behandlung in der Abteilung für Klinische Chemie der Universitätsmedizin Göttingen durchgeführt. 
$\mathrm{Zu}$ Beginn wurden die Muskelanteile in speziellen Säulen mit enthaltenen Keramikkügelchen überführt und mit $900 \mu \mathrm{l}$ Trizol überschichtet. Durch ein zyklisches Verfahren - mit dreimaliger Homogenisation für 45 Sekunden und jeweils 15 Sekunden Pause zwischen den Zyklen - wurde eine Suspension hergestellt. Für die Extraktion der Ribonukleinsäure (RNA) wurde das Qiagen-Rneasy-Kit (Qiagen Hamburg GmbH, Hamburg, Deutschland) gemäß Herstellerangaben verwendet. Die extrahierte RNA wurde bei $-80^{\circ} \mathrm{C}$ gelagert. Um die Konzentration der RNA zu bestimmen, wurde ein Nanodrop-Spektralphonometer (NanoDrop 2000, NanoDrop Products, Wilmigton, USA) genutzt. Die gewonnene RNA wurde daraufhin $\mathrm{zu}$ complementary DNA (cDNA) mit dem SuperScripTMI-Kit (Life Technologies GmbH, Darmstadt, Deutschland) synthetisiert. Als Startpunkt der Reaktion für die RNAabhängige DNA-Polymerase diente Oligo-dT-Nukleotid (10-15 Desoxythymitidin), außerdem wurde über dNTP-Mix und Reverse Transkriptase der cDNA-Strang vervollständigt. Es folgte eine Reaktion in der doppelständige cDNA gebildet wird. Die synthetisierte cDNA wurde bis zur weiteren Verwendung bei $-20^{\circ} \mathrm{C}$ gelagert.

\subsection{Quantitative real-time Polymerase-Kettenreaktion}

Mit einer real-time Polymerase-Kettenreaktion (RT-PCR) wird die Expression expliziter Gene analysiert. Die nötigen Oligonukleotid-Primer und ein Universal-qPCR-Master-Mix wurden von der Firma Applied Biosystem bezogen und nach den Angaben des Herstellers verwendet. Für die PCR enthielt jeder Ansatz insgesamt $20 \mu \mathrm{l}$ mit jeweils $1 \mu \mathrm{l}$ cDNA. Die Amplifikation wurde mit dem RT-PCR-System ABI (Applied Biosystem, Darmstadt, Deutschland) durchgeführt. In dem System kam ein Zeit-Temperatur-Programm zur Anwendung mit zunächst holding stage über 2 Minuten bei $50^{\circ} \mathrm{C}$, dann 10 Minuten bei $95^{\circ} \mathrm{C}$ und anschließendem cycling stage mit 15 Sekunden bei $95^{\circ} \mathrm{C}$ und 60 Sekunden bei $60{ }^{\circ} \mathrm{C}$. Glyzerinaldehyd-3-phosphat-Dehydrogenase (GAPDH) wird üblicherweise von allen Muskelzellen der Mäuse exprimiert und wird demnach als sogenanntes Housekeeping-Gen verwendet. Dieses Gen wurde zur Kontrolle ebenfalls amplifiziert, um Ergebnisverfälschungen z. B. durch Qualitäts- oder Mengenunterschiede der verwendeten cDNA zu detektieren. Die Ergebnisse für die Gene wurden auf die entsprechenden Ergebnisse der GAPDH-Messung bezogen und die Expression der jeweilige mRNA mit der $\Delta \mathrm{CT}$-Methode berechnet. 


\subsection{Statistik}

Die erhobenen Daten wurden mittels one-way Anova (nach der engl. Bezeichnung one-way analysis of variance) zum Vergleich mehrerer Gruppen, bzw. t-Tests für den Vergleich von zwei Gruppen, in GaphPad Prism 7.0 (GraphPad Software, Inc.) statistisch ausgewertet. Zur Analyse von Ausreißern wurde der Grubbs-Test (QuickCal, GraphPad Software, Inc.) verwendet. Das Signifikanzniveau wurde durchgehend bei $\mathrm{p}<0,5$ festgelegt. Weiterhin wurde in Zusammenarbeit mit Dr. Dörthe Malzahn (Genetische Epidemiologie, Universitätsmedizin Göttingen) eine lineare Regressionsanalyse mit random subject intercept der Ergebnisse aus der Laufrad-, Gewichts- und Griffkraftmessung durchgeführt. Der random subject intercept kompensiert die Tatsache, dass die Tiere bei Experimenteintritt leicht im Alter variieren und deshalb je nach Behandlungsgruppe bereits eine höhere oder niedrigere Leistungsfähigkeit hatten. Zudem werden durch den intercept Unterschiede zwischen Männchen und Weibchen adjustiert. Von der Auswertung der Laufraddaten wurden aus der IgG-Gruppe zwei Tiere, aus der NaCl-Gruppe ein Tier und aus der MS-Gruppe fünf Tiere wegen ungültiger Messreihen ausgeschlossen. Bei der Regressionsanalyse der Daten aus Körpergewicht- und Griffkraftmessung wurde aus der IgG- und NaCl-Gruppe jeweils ein Tier als ungültig gewertet.

\subsection{Verträglichkeit von Albumin und MS}

In der Studie von Zschüntzsch et al. (2016) wurde eine Albumintherapie in der Kontrollgruppe über einen Zeitraum von drei Monaten durchgeführt, und die dreimalige Injektion wurde von den Tieren gut vertragen. Im Rahmen der vorliegenden Arbeit verstarben die meisten Tiere nach der vierten Injektion. Ein Tier verstarb nach dem achten Behandlungsmonat und zwei weitere Tiere lebten 18 Monate. Um die Ursache des Todes nach vier Monaten zu klären wurde die Obduktion eines betroffenen Tieres durchgeführt. Dabei zeigte sich als zentraler Befund ein sich vorrangig im Septum des Herzmuskels befindliches Infiltrat pleomorpher Zellen mit hoher Mitoserate und Nekrose, verdächtig auf einen malignen mesenchymalen Tumor, z. B. Rhabdomyosarkom. Der weitere Befund war unauffällig. Als Ersatz für die Albumintherapie wurde eine MS-Therapiegruppe eingeführt. Jedoch zeigte diese Gruppe nach einem anfangs unauffälligen Verlauf im letzten Monat des ersten Lebensjahres einen sich rapide verschlechternden Allgemeinzustand, sodass ein frühzeitiges Studienende dieser Gruppe notwendig war. Eine genaue Ursache für diesen Leistungsabfall 
konnte nicht eruiert werden. Die Obduktion eines MS-Tieres ergab eine chronische interstitielle und glomeruläre Nephritis mit begleitender Glomerulosklerose und Rindenatrophie. Ansonsten zeigte sich ein unauffälliger organischer Befund, abgesehen von den erwarteten Veränderungen in der Muskulatur. 


\section{Ergebnisse}

\subsection{Ergebnisse der klinischen Parameter}

\subsubsection{Einfluss der 18-monatigen Behandlung mit humanem IgG auf die frei- willige Laufradaktivität von mdx-Mäusen}

$\mathrm{Ab}$ der dritten Lebenswoche wurden die mdx-Mäuse in Einzelkäfigen mit frei zugänglichem Laufrad gehalten und durch ein vollcomputerisiertes System konnte die Laufradaktivität der Tiere registriert und die Parameter tägliche Maximalgeschwindigkeit $\left(\mathrm{V}_{\max }\right)$, Anzahl der täglichen Läufe ( $\mathrm{N}_{\text {lauf }}$, Laufzeit pro Tag ( $\left.\mathrm{T}_{\text {ges }}\right)$, Distanz pro Tag (Dist) und mittlere kumulative Gesamtdistanz (Dist $t_{\text {cum }}$ ) ermittelt werden (siehe Tab. 1). In der initialen Phase zeigte sich während der dritten bis fünften Lebenswoche in allen Behandlungsgruppen eine kontinuierliche Steigerung in der Nutzung des Laufrades, die der Gewichtszunahme und wachsenden Muskelkraft zugeschrieben werden kann. Mit der siebten Lebenswoche begann eine Plateauphase, die bis einschließlich der elften Woche andauerte und bereits in anderen Studien beobachtet wurde (Weller et al. 2012; Zschüntzsch et al. 2016). Anschließend folgte ein linearer Abfall der Laufradaktivität in allen untersuchten Gruppen. Um den Abfall zwischen den Gruppen zu vergleichen, wurde eine lineare Regressionsanalyse ab dem Tag 65 im Laufrad, in der zwölften Lebenswoche, durchgeführt. Für den Vergleich der mittleren kumulativen Gesamtdistanz wurde ein One-way-Anova-Test zum Vergleich dreier Gruppen und zum Vergleich von zwei Gruppen der t-Test durchgeführt.

Die $\mathrm{V}_{\max }$ pro Tag gilt als Parameter für die absolute Leistungsfähigkeit. Die Regressionsanalyse zeigte, dass mit IgG behandelte Tiere im Langzeitverlauf eine statistisch signifikant höhere absolute Leistungsfähigkeit pro Tag im Vergleich zu beiden Kontrollgruppen haben. In der IgG-Gruppe betrug die $\mathrm{V}_{\max }$ in der zwölften Woche im Mittel 1,03 +/- 0,07 m/s und fiel im Verlauf um täglich 0,0009 m/s ab. Die $\mathrm{V}_{\max }$ der NaCl-Gruppe war in der zwölften Woche zwar mit 1,04+/- 0,09 m/s pro Tag etwas höher im Vergleich zur IgG-Gruppe, fiel dann aber um $0,0011 \mathrm{~m} / \mathrm{s}$ pro Tag ab, sodass die mit IgG behandelten mdx-Mäuse in dem Zeitraum ab der zwölften Woche einen im Vergleich zur NaCl-Gruppe statistisch signifikanten verlangsamten Abfall der täglichen $\mathrm{V}_{\max }\left(\mathrm{p}=2,1 \cdot 10^{-74}\right)$ aufwiesen. In der zwölften Woche war die tägliche $\mathrm{V}_{\max }$ in der MS-Gruppe mit 1,04+/- 0,11 m/s ebenfalls höher als in der IgG-Gruppe, sank dann aber im Langzeitverlauf täglich sogar um 0,0021 m/s, sodass die mdx-Mäuse der IgG-Gruppe ebenfalls gegenüber der MS-Gruppe einen statistisch 
signifikant langsameren Abfall im Langzeitverlauf zeigten $\left(\mathrm{p}=4,4 \cdot 10^{-303}\right)$ (Tab. 2, Abb. 3 a). Auch für $\mathrm{N}_{\text {lauf }}$ zeigten sich Unterschiede zwischen den Behandlungsgruppen. Die Regressionsanalyse zeigte für die IgG-Gruppe eine signifikant höhere $\mathrm{N}_{\text {lauf }}$ pro Tag verglichen mit den Kontrollgruppen. In der zwölften Woche unternahmen die mit IgG behandelten mdx-Mäuse durchschnittlich 281 +/- 173 Läufe pro Tag, dann fiel $\mathrm{N}_{\text {lauf }}$ in dieser Gruppe im Langzeitverlauf um 0,23 pro Tag ab. Die $\mathrm{N}_{\text {lauf }}$ der NaCl-Gruppe betrug in der zwölften Woche 224 +/- 88 Läufe pro Tag, war damit bereits niedriger als $\mathrm{N}_{\text {lauf }}$ der IgG-Gruppe zu diesem Zeitpunkt, und fiel dann täglich um 0,4 Läufe ab, sodass $\mathrm{N}_{\text {lauf }}$ in diesem Zeitraum in der IgG-Gruppe gegenüber der NaCl-Gruppe statistisch signifikant verlangsamt abfiel $\left(\mathrm{p}=9,4 \cdot 10^{14}\right)$. Mdx-Mäuse der MS-Gruppe liefen in der zwölften Woche mit durchschnittlich 211 +/- 90 Läufen pro Tag bereits weniger im Vergleich zu den mdx-Mäusen der IgGGruppe, zudem sank im Langzeitverlauf $\mathrm{N}_{\text {lauf }}$ in der MS-Gruppe mit 0,51 pro Tag stärker ab. Verglichen zur MS-Gruppe ist der Abfall von $\mathrm{N}_{\text {lauf }}$ in der IgG-Gruppe $\left(\mathrm{p}=6,9 \cdot 10^{-9}\right)$ statistisch signifikant verlangsamt (Tab. 2, Abb. 3 b). Eine Behandlung mit IgG hat auch zu einer signifikant höheren zeitlichen Nutzung des Laufrades pro Tag geführt. Mit IgG behandelte mdx-Mäuse liefen in der zwölften Woche durchschnittlich 11116 +/- 3456 Sekunden pro Tag. Anschließend sank die Nutzung um 11,1 Sekunden täglich. In der zwölften Woche betrug $\mathrm{T}_{\text {ges }}$ in der NaCl-Gruppe 10263 +/- 3883 Sekunden, war demnach bereits niedriger als die $\mathrm{T}_{\text {ges }}$ der IgG-Gruppe und fiel dann um 16,9 Sekunden pro Tag. Im Vergleich zur NaCl-Gruppe fiel im Langzeitverlauf $T_{\text {ges }}$ in der IgG-Gruppe statistisch signifikant langsamer $\mathrm{ab}\left(\mathrm{p}=6,4 \cdot 10^{-23}\right)$. In der zwölften Woche betrug $\mathrm{T}_{\text {ges }}$ in der MS-Gruppe 8540 +/- 3521 Sekunden täglich, war demnach bereits deutlich geringer im Vergleich zur IgG-Gruppe und sank in dem sich anschließenden Zeitraum um 26,2 Sekunden pro Tag. Gegenüber der MS-Gruppe sank $\mathrm{T}_{\text {ges }}$ bei den mit IgG behandelten mdx-Mäusen statistisch signifikant weniger nach der zwölften Woche $a b\left(p=1,2 \cdot 10^{-40}\right)$ (Tab. 2, Abb. 3 c). Die mit IgG behandelten mdx-Mäuse legten im Vergleich zu den Kontrollgruppen jeden Tag eine statistisch signifikant längere Dist zurück. Zu Beginn der Regressionsanalyse in der zwölften Woche betrug Dist in der IgG-Gruppe 5794 +/- 1977 m pro Tag und nahm im Langzeitverlauf dann um 6,1 m pro Tag ab. In der NaCl-Gruppe lag die Dist bereits in der zwölften Woche bei durchschnittlich 5294 +/- 2204 m pro Tag, sank dann täglich um 8,5 m pro Tag, sodass die Dist der IgG-Gruppe in dem untersuchten Zeitraum im Vergleich zur NaClGruppe statistisch signifikant langsamer absank $\left(p=3,1 \cdot 10^{-19}\right)$. Bei einer Behandlung mit MS betrug Dist in der zwölften Woche im Mittel 4342 +/- 2183 m pro Tag und sank dann täglich um 15,6 m ab. Im Vergleich zur MS-Gruppe fiel in der IgG-Gruppe die Distanz in 
der Zeit nach der zwölften Woche statistisch signifikant langsamer ab $\left(p=4,2 \cdot 10^{-79}\right)$ (Tab. 2, Abb. 3 d). Aufgrund des vorzeitigen Endes der MS-Tiere nach der 50. Lebenswoche verglichen wir die mittlere kumulative Gesamtdistanz zwischen allen Gruppen nach 50 Wochen und zusätzlich die zwischen der IgG- und NaCl-Gruppe nach 70 Wochen. Mit IgG behandelte mdx-Mäuse liefen weitere mittlere kumulative Distanzen im Vergleich zu beiden Kontrollgruppen. Nach 50 Wochen war die mittlere kumulative Gesamtdistanz der IgG-Gruppe (Dist cumIgG 50 Wochen $=844+/-272 \mathrm{~km}$ ) $100 \mathrm{~km}$ länger im Vergleich zur NaCl-Gruppe (Dist ${ }_{\text {cumNaCl }} 50$ Wochen $=744$ +/- 278 km, p = 0,3383). Gegenüber der MS-Gruppe (Dist cumMS 50 Wochen $=519$ +/- $170 \mathrm{~km}$ ) liefen mdx-Mäuse der IgGGruppe kumulativ $324 \mathrm{~km}$ weiter, was statistisch signifikant war $(\mathrm{p}=0,027)$. Die mittlere kumulative Gesamtdistanz einer mdx-Maus, die mit IgG behandelt worden war, lag nach 70 Wochen bei durchschnittlich 977 +/- 353 km. Eine mdx-Maus der NaCl-Gruppe war in derselben Zeit $217 \mathrm{~km}$ weniger gelaufen (Dist cumNaCl 70 Wochen $=760+/-297 \mathrm{~km}$ ). Sodass die mdx-Mäuse der IgG-Gruppe eine längere mittlere kumulative Dist cum $_{\text {gelaufen sind, was }}$ jedoch nicht statistisch signifikant war $(\mathrm{p}=0,1331)$ (Tab. 3, Abb. 3 e).

Zusammenfassend lässt sich sagen, dass mdx-Mäuse mit IgG-Therapie eine signifikant höhere tägliche Maximalgeschwindigkeit, Anzahl täglicher Läufe, tägliche Nutzungsdauer, Laufdistanz/Tag und eine insgesamt höhere kumulative Laufdistanz gegenüber den Kontrollen aufwiesen. 
Tabelle 2: Lineare Regressionsanalysen für $\mathbf{V}_{\max }, \mathbf{N}_{\text {lauf, }} \mathbf{T}_{\text {ges }}$ und Dist im Langzeitverlauf.

\begin{tabular}{|c|c|c|c|c|c|c|}
\hline Zeitraum & Parameter & Behandlung & $\mathbf{n}$ & $\begin{array}{l}\text { Abfall pro } \\
\text { Tag }\end{array}$ & \multicolumn{2}{|c|}{$\begin{array}{l}\text { P-Wert Regressionsanalyse } \\
\text { (IgG vs. Kontrolle) }\end{array}$} \\
\hline \multirow{12}{*}{$\begin{array}{l}\geq \\
12 . \\
\text { Woche }\end{array}$} & \multirow{3}{*}{$\mathrm{V}_{\max }$} & $\operatorname{IgG}$ & 17 & $0,0009 \mathrm{~m} / \mathrm{s}$ & & \\
\hline & & $\mathrm{NaCl}$ & 18 & $0,0011 \mathrm{~m} / \mathrm{s}$ & IgG vs. $\mathrm{NaCl}$ & $\mathrm{p}=2,1 \cdot 10^{-74}$ \\
\hline & & MS & 14 & $0,0021 \mathrm{~m} / \mathrm{s}$ & IgG vs. MS & $\mathrm{p}=4,4 \cdot 10^{-303}$ \\
\hline & \multirow{3}{*}{$\mathrm{N}_{\text {lauf }}$} & $\operatorname{IgG}$ & 17 & 0,23 & & \\
\hline & & $\mathrm{NaCl}$ & 18 & 0,4 & IgG vs. $\mathrm{NaCl}$ & $\mathrm{p}=9,4 \cdot 10^{-14}$ \\
\hline & & MS & 14 & 0,51 & IgG vs. MS & $\mathrm{p}=6,9 \cdot 10^{-9}$ \\
\hline & \multirow{3}{*}{$\mathrm{T}_{\text {ges }}$} & $\operatorname{IgG}$ & 17 & $11,1 \mathrm{~s}$ & & \\
\hline & & $\mathrm{NaCl}$ & 18 & $16,9 \mathrm{~s}$ & IgG vs. $\mathrm{NaCl}$ & $\mathrm{p}=6,4 \cdot 10^{-23}$ \\
\hline & & MS & 14 & $26,2 \mathrm{~s}$ & IgG vs. MS & $\mathrm{p}=1,2 \cdot 10^{-40}$ \\
\hline & \multirow{3}{*}{ Dist } & $\operatorname{IgG}$ & 17 & $6,1 \mathrm{~m}$ & & \\
\hline & & $\mathrm{NaCl}$ & 18 & $8,5 \mathrm{~m}$ & IgG vs. $\mathrm{NaCl}$ & $\mathrm{p}=3,1 \cdot 10^{-19}$ \\
\hline & & MS & 14 & $15,6 \mathrm{~m}$ & IgG vs. MS & $\mathrm{p}=4,2 \cdot 10^{-79}$ \\
\hline
\end{tabular}

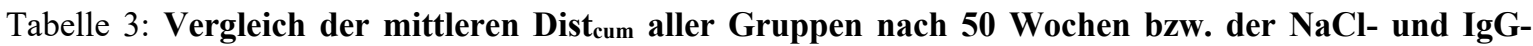
Gruppe nach 70 Wochen.

\begin{tabular}{|l|l|l|l|l|l|}
\hline \multirow{2}{*}{ Zeitraum } & \multirow{2}{*}{ Parameter } & Behandlung & N & \multicolumn{2}{|l|}{ P-Wert (IgG vs. Kontrolle) } \\
\hline $\begin{array}{l}\text { nach der } \\
50 . \\
\text { Woche }\end{array}$ & \multirow{2}{*}{ Dist $_{\text {cum }}$} & IgG & 17 & \multicolumn{2}{|l|}{} \\
\cline { 3 - 6 } & $\mathrm{NaCl}$ & 18 & IgG vs. NaCl & $\mathrm{p}=0,3383$ \\
\cline { 3 - 6 } $\begin{array}{l}\text { nach der } \\
70 . \\
\text { Woche }\end{array}$ & \multirow{2}{*}{ Dist $_{\text {cum }}$} & $\mathrm{MS}$ & 14 & IgG vs. MS & $\mathrm{p}=0,027$ \\
\cline { 3 - 6 } & $\mathrm{IgG}$ & 17 & & $\mathrm{p}=0,1331$ \\
\hline
\end{tabular}


(a)

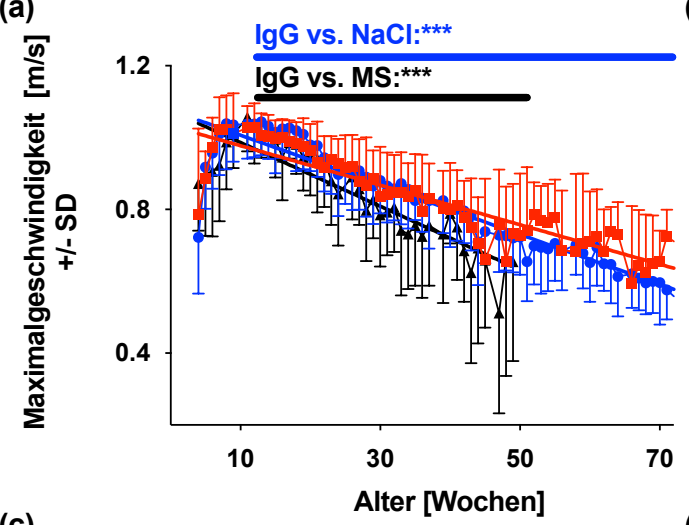

(c)

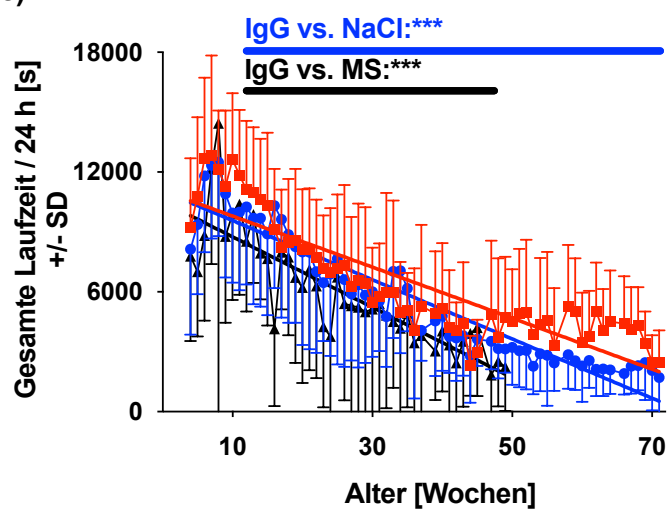

(b)

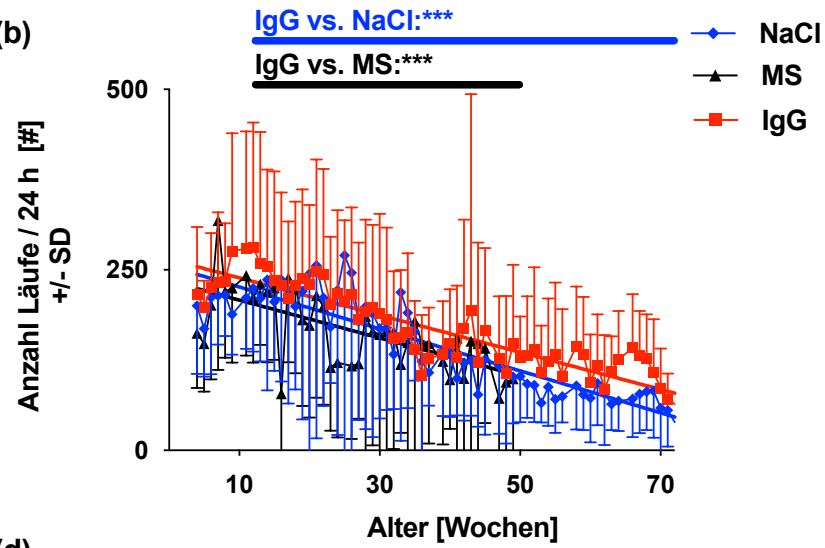

(e)
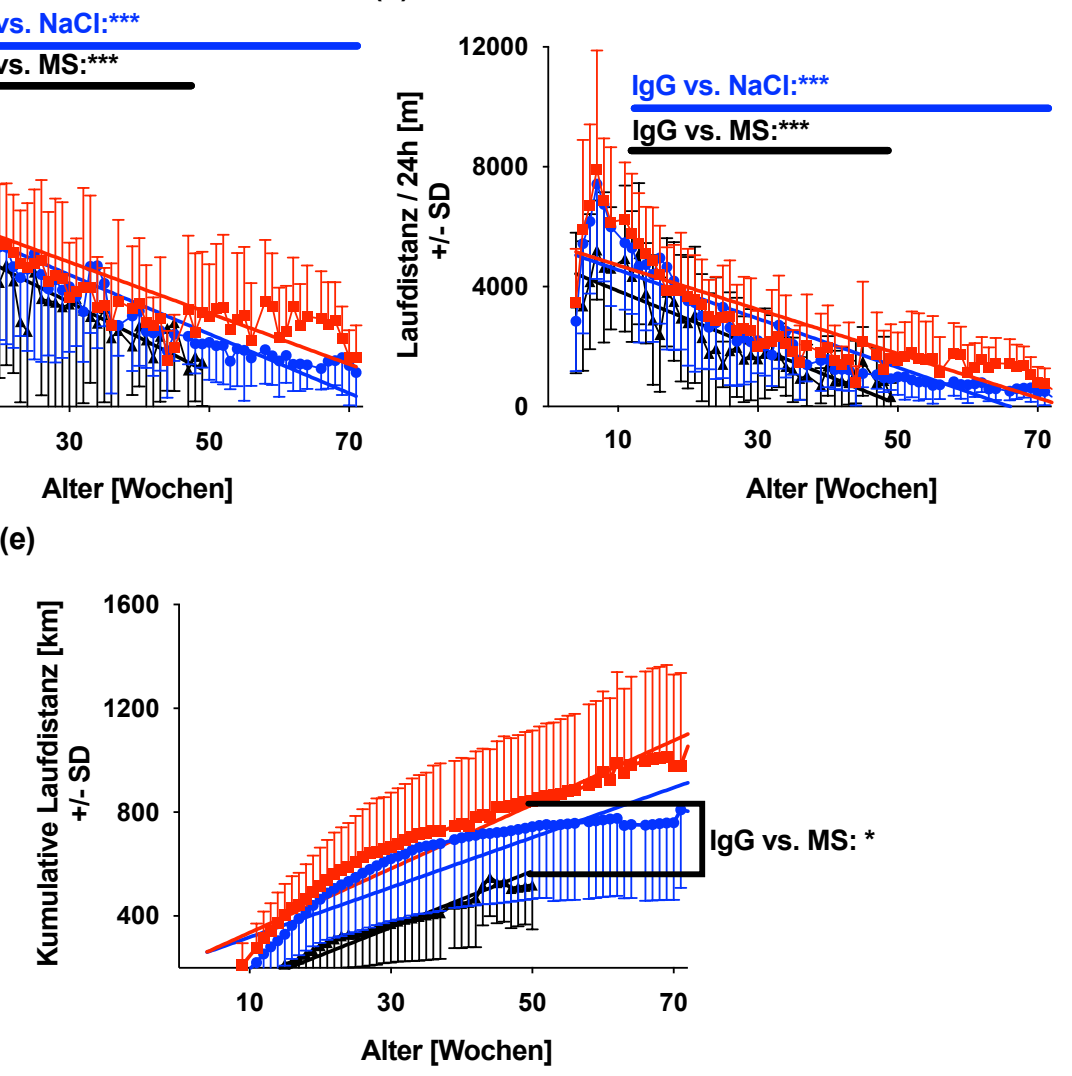

Abbildung 3: Laufradnutzung. Mdx-Mäuse, die mit $\operatorname{IgG}(\mathrm{n}=17)$ behandelt wurden, zeigten im Vergleich zu den mit $\mathrm{NaCl}(\mathrm{n}=18)$ u. MS $(\mathrm{n}=14)$ behandelten Tieren einen geringeren Abfall in der Nutzung des Laufrades. P-Werte beziehen sich auf die Gruppenvergleiche der Regressionsanalyse ab der zwölften Woche von IgG vs. $\mathrm{NaCl}$ und IgG vs. MS. (a) Mittlere Maximalgeschwindigkeit, die pro Tag erreicht wurde. (b) Über die gesamte Zeit war die Anzahl der täglichen Läufe bei IgG höher. (c) Insgesamt längere tägliche Nutzungsdauer des Laufrades in der Gruppe mit IgG-Behandlung. (d) Pro Ta4g liefen die IgG-Tiere längere Distanzen. (e) Nach zwölf Monaten war die kumulative Distanz in der IgG-Gruppe höher als in der NaCl- und MS-Gruppe, was gegenüber der MS-Gruppe statistisch signifikant war. IgG war zudem höher gegenüber der NaCl-Gruppe nach der 70. Woche. Die Werte für $\mathrm{V}_{\max }, \mathrm{N}_{\text {lauf, }} \mathrm{T}_{\text {ges, }}$, Dist $\mathrm{u}$. Distcum sind als Mittelwerte mit Standardabweichung (SD) dargestellt. (a)-(e) Lineare Regressionsanalyse mit random subject intercept. (e) One-way Anova u. tTest. * < p 0,05, **<p 0,01, ***<p 0,001. 


\subsubsection{Beeinflussung des Gewichtes und der Griffkraft von mdx-Mäusen durch eine langfristige Behandlung mit humanem IgG}

Das Gewicht und die Griffkraft aller Mäuse wurden einmal wöchentlich, beginnend ab der dritten Lebenswoche, bestimmt. Bis zur 23. Messwoche kam es in allen Gruppen zu einem Anstieg des Körpergewichtes. Anschließend sanken Körpergewicht und Griffkraft in allen untersuchten Gruppen. Um den Abfall zwischen den Gruppen zu vergleichen, wurde eine lineare Regressionsanalyse ab der 23. Woche durchgeführt. Es zeigten sich über den gesamten Untersuchungszeitraum Gewichtsunterschiede zwischen den Geschlechtern. In der 23. Woche waren die Weibchen aller Gruppen 5,7 g leichter als die Männchen $\left(\mathrm{p}=6,7 \cdot 10^{-6}\right)$ und verloren wöchentlich 0,049 g mehr Gewicht gegenüber den männlichen mdx-Mäusen $\left(\mathrm{p}=2,7 \cdot 10^{-46}\right)$. Im Langzeitverlauf war das Gewicht der Männchen unter IgG- und NaClBehandlung stabil. Es zeigten sich zwischen diesen beiden Gruppen weder in der 23. Messwoche $(p=0,29)$ noch im Langzeitverlauf $(p=0,4222)$ Unterschiede. In der MS-Gruppe kam es hingegen bei beiden Geschlechtern zu einem beschleunigten Gewichtsverlust. So verloren die mdx-Mäuse mit einer MS-Behandlung im Langzeitverlauf 0,0362 g mehr Gewicht im Vergleich zur NaCl-Gruppe $\left(\mathrm{p}=1,2 \cdot 10^{-12}\right)$. Bei den Männchen kam es zuerst zu einem Gewichtsabfall, sodass diese bereits in der 23. Messwoche um 2,9 g leichter als die männlichen mdx-Mäusen mit einer NaCl-Behandlung waren $(p=0,0319)$. Die Weibchen hatten $\mathrm{zu}$ diesem Zeitpunkt noch ein gegenüber der NaCl-Gruppe stabiles Gewicht $(\mathrm{p}=0,0625)$ (siehe Abb. $4 \mathrm{a}, \mathrm{b})$.

Auch die Griffkraftmessung ergab statistisch signifikante Geschlechtsunterschiede in allen Gruppen, und die Weibchen waren im Mittel um 6,62 mN schwächer als die Männchen $(\mathrm{p}=0,0004)$. Für die lineare Regressionsanalyse der Griffkraftmessung ab der 23. Lebenswoche wandten wir, analog zu den Laufraddaten, einen random subject intercept an, um die o. g. Unterschiede zwischen Männchen und Weibchen zu adjustieren. Mdx-Mäuse der IgGGruppe hatten im Langzeitverlauf ab der 23. Woche eine statistisch signifikant höhere Griffkraft. In der 23. Woche betrug die Griffkraft in der IgG-Gruppe $119+/-13 \mathrm{mN}$, fiel dann um $0,563 \mathrm{mN}$ pro Woche ab. Bei einer Behandlung mit $\mathrm{NaCl}$ war die Griffkraft in der 23. Woche mit $127+/-14 \mathrm{mN}$ sogar höher als in der IgG-Gruppe, fiel im Langzeitverlauf aber um 0,619 $\mathrm{mN}$ pro Woche ab, sodass die IgG-Gruppe gegenüber der NaCl-Gruppe einen tendenziell verlangsamten Abfall der Griffkraft hatte, was jedoch nicht statistisch signifikant war $(p=0,2496)$. Bei einer MS-Behandlung war die Griffkraft in der 23. Woche mit 
$126+/-16 \mathrm{mN}$ sogar höher als in der IgG-Gruppe, fiel dann im Verlauf aber um 1,17 mN pro Woche ab. Verglichen mit der MS-Gruppe sank die Griffkraft bei den mit IgG behandelten mdx-Mäusen statistisch signifikant weniger in der Zeit nach der 23. Woche ab $\left(p=5,2 \cdot 10^{-16}\right)($ Abb. $4 c)$.

Zusammenfassend lässt sich sagen, dass eine IgG-Therapie zu keinen signifikanten Unterschieden auf die Gewichtsentwicklung zwischen den Geschlechtern, jedoch zu einer besseren Griffkraft gegenüber Kontrollgruppen führt.

(a)

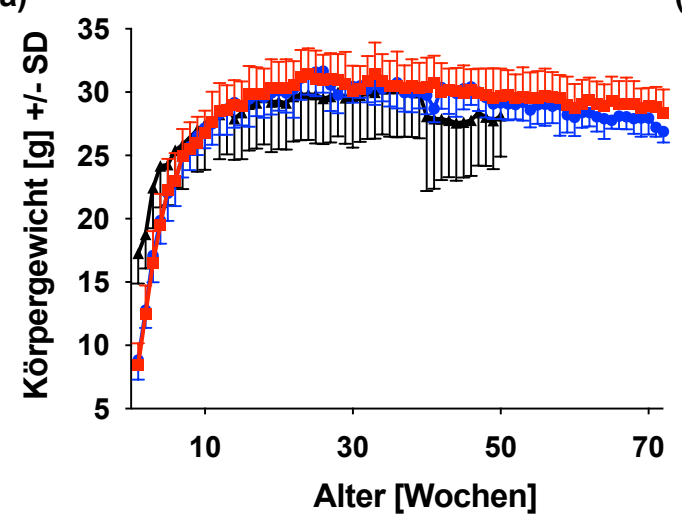

(b)

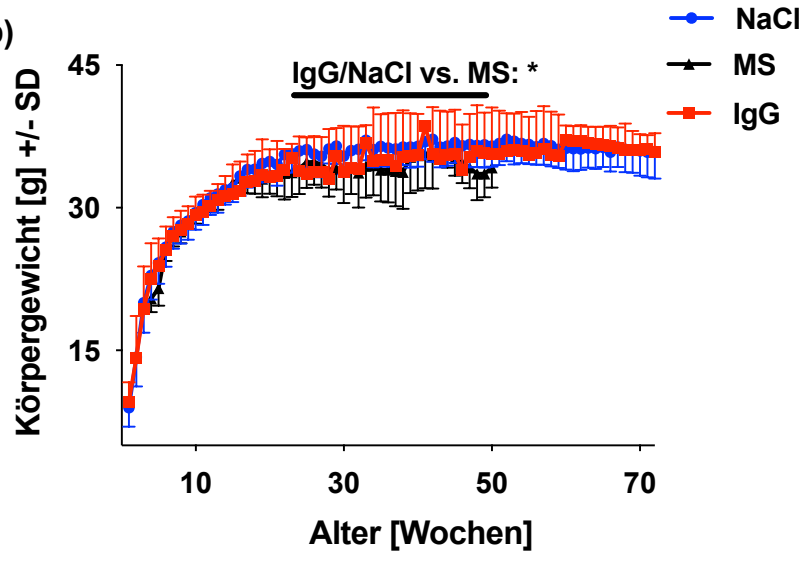

(c)

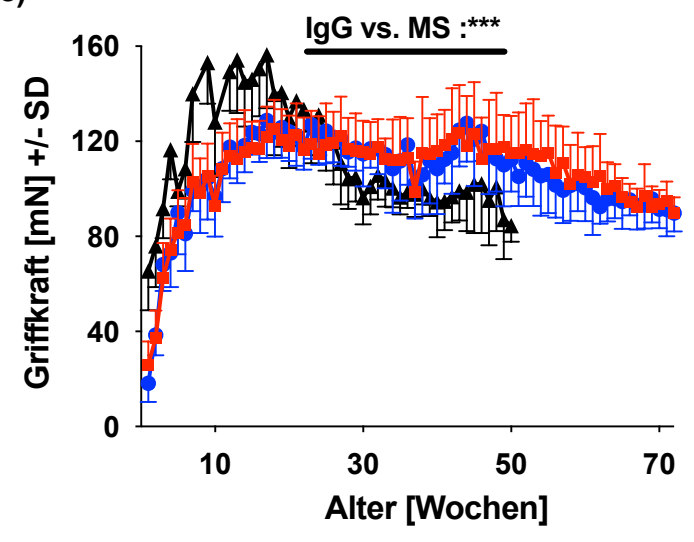

Abbildung 4: Langzeitverlauf des Körpergewichtes und der Griffkraft. (a) Körpergewicht weiblicher mdxMäuse und (b) männlicher mdx-Mäuse im Verlauf des gesamten Untersuchungszeitraumes nach einer Behandlung mit IgG $(\mathrm{n}=18), \mathrm{NaCl}(\mathrm{n}=18)$ und MS $(\mathrm{n}=19)$. (c) Durchschnittliche Griffkraft der Vorderläufe pro Woche im Langzeitverlauf. Mdx-Mäuse, die mit IgG behandelt worden waren, zeigten im Vergleich zu den mit $\mathrm{NaCl}$ und MS behandelten Tieren einen geringeren Abfall der Griffkraft im Langzeitverlauf. P-Werte beziehen sich auf die Gruppenvergleiche der Regressionsanalyse ab der 23. Woche von IgG vs. $\mathrm{NaCl}$ und $\mathrm{NaCl}$ vs. MS. Die Griffkraft der mit IgG behandelten mdx-Mäuse sank gegenüber den MS-behandelten mdx-Mäusen statistisch signifikant weniger in der Zeit nach der 23. Woche $\left(p=5,2 \cdot 10^{-16}\right)$. Die Werte sind als Mittelwerte mit Standardabweichung dargestellt. Lineare Regressionsanalyse mit random subject intercept. $* \mathrm{p}<0,05$, $* * \mathrm{p}<0,01, * * * \mathrm{p}<0,001$. 


\subsubsection{Wirkung der IgG-Behandlung auf die kardiale Funktion der mdx-Mäuse}

Die initialen Echokardiografien wurden nach drei Monaten zur Erhebung von Ausgangswerten und erneut nach 9 und 12 in der MS-Gruppe, bzw. 9, 12, 15 und 18 Monaten in der $\mathrm{NaCl}$ - und IgG-Gruppe, durchgeführt. In Tabelle 4 ist die Anzahl der je Behandlungsgruppe zu jedem Untersuchungszeitpunkt durchgeführten Echokardiografien aufgeführt. Aus den echokardiografisch erhobenen Parametern wurden die mittlere FAS und EF berechnet. Die FAS ist ein Parameter zur Beurteilung der systolischen Pumpfunktion des Herzens. Mit IgG behandelte mdx-Mäuse hatten über den gesamten Untersuchungszeitraum eine erhöhte systolische Pumpfunktion im Vergleich zu beiden Kontrollgruppen. Bereits in der ersten Messung im dritten Monat war die FAS in der mit IgG (FAS IgG 3 Mo. = 39,3 +/- 4,3 \%) therapierten Gruppe höher als in der Gruppe die mit $\mathrm{NaCl}\left(\mathrm{FAS}_{\mathrm{NaCl}} 3 \mathrm{Mo} .=33,4\right.$ +/- 7,2 \%) oder MS (FAS 3 Mo. 3 30,7 +/- 4,9 \%) behandelt worden waren. Hierbei war die FAS der IgGGruppe statistisch signifikant gegenüber der MS-Gruppe erhöht $(\mathrm{p}=0,0032)$. Nach neun Monaten war die FAS in der IgG-Gruppe (FAS IgG $_{9}$ Mo. = 37,87 +/- 4,9 \%) leicht abgefallen, aber weiterhin höher als die Werte in der $\mathrm{NaCl}$ - und MS-Gruppe $\left(\mathrm{FAS}_{\mathrm{NaCl}}\right.$ 9 Mo. $=35,7+/-7,1 \%$, FAS $_{\text {MS }} 9$ Mo. = 35,54 +/- 4,4 \%). Auch nach zwölf Monaten war die FAS in der IgG-Gruppe höher als in beiden Kontrollgruppen. Gegenüber den Werten nach neun Monaten war die FAS in der IgG- und NaCl-Gruppe $\left(\mathrm{FAS}_{\mathrm{IgG}} 12 \mathrm{Mo}\right.$. = 41,5 +/- 4,6 \%, FAS $_{\mathrm{NaCl}} 12$ Mo. $=38,3+/-5,1 \%$ ) angestiegen. Sie blieb in der MS-Gruppe (FAS 12 Mo. $=35,75+/-5,5 \%)$ konstant. Dann sank die FAS in der IgG-Gruppe, blieb aber in der NaClGruppe konstant, sodass nach 15 Monaten die Werte in der IgG- und NaCl-Gruppe $\left(\right.$ FAS $_{\text {IgG }}$ 15 Mo. $=37,5+/-4,6 \%$, FAS $_{\mathrm{NaCl}} 15$ Mo. $\left.=37,68+/-5,4 \%\right)$ nahezu gleich waren. In der letzten Echokardiografie wiederum zeigte sich ein Anstieg der FAS in der IgG-Gruppe und ein Abfall bei den mit $\mathrm{NaCl}$ behandelten mdx-Mäusen. FAS war nach 18 Monaten in der IgG-Gruppe im Vergleich zur NaCl-Gruppe $\left(\mathrm{FAS}_{\mathrm{IgG}} 18 \mathrm{Mo} .=39,42+/-4,5 \%\right.$, $\mathrm{FAS}_{\mathrm{NaCl}}$ 18 Mo. $=33,15+/-3,8 \%)$ statistisch signifikant höher $(p=0,0067)$ (Abb. 5 a). Als EF bezeichnet man den Prozentsatz des Blutvolumens im linken Ventrikel, der während einer Herzaktion ausgeworfen wird. Nach drei Monaten war die EF in der IgG-Gruppe $\left(\mathrm{EF}_{\mathrm{IgG}}\right.$ 3 Mo. $=45,34+/-4,2 \%)$ nur geringfügig gegenüber der NaCl-Gruppe $\left(\mathrm{EF}_{\mathrm{NaCl}}\right.$ 3 Mo. $=47,33+/-9,1 \%)$ reduziert. Jedoch war die EF der MS-Gruppe (EFMS 3 Mo. $=39,51+/-5,7 \%$ ) deutlich niedriger im Vergleich zur IgG- und NaCl-Gruppe, was gegenüber der NaCl-Gruppe statistische Signifikanz erreichte $(p=0,0386)$. Nach neun Monaten war die EF in der IgG-Gruppe $\left(\mathrm{EF}_{\mathrm{IgG}} 9 \mathrm{Mo.}=40,96+/-6,4 \%\right)$ und NaCl-Gruppe 
$\left(\mathrm{EF}_{\mathrm{NaCl}} 9\right.$ Mo. $\left.=40,69+/-6,13 \%\right)$ etwa gleich abgefallen, aber weiterhin höher als in der MS-Gruppe (EF 9 Mo. 9 44,25 +/- 4,9 \%). Nach zwölf Monaten stieg die EF bei den Tieren mit IgG-Behandlung $\left(\mathrm{EF}_{\mathrm{IgG}} 12 \mathrm{Mo.}=48,3+/-3,9 \%\right)$, ebenso in der NaCl-Gruppe $\left(\mathrm{EF}_{\mathrm{NaCl}} 12 \mathrm{Mo} .=46,1+/-5,9 \%\right)$ und blieb bei einer MS-Behandlung konstant $\left(\mathrm{EF}_{\mathrm{MS}} 12\right.$ Mo. $\left.=44,32+/-6,5 \%\right)$ gegenüber den ersten Werten. Die EF war nach 15 Monaten jedoch in der IgG-Gruppe $\left(\mathrm{EF}_{\mathrm{IgG}} 15 \mathrm{Mo} .=46,66+/-4,2 \%\right)$ demgegenüber abgefallen und blieb in der NaCl-Gruppe $\left(\mathrm{EF}_{\mathrm{NaCl}} 15 \mathrm{Mo} .=45,26\right.$ 7,6 \% $)$ stabil. In der Echokardiografie nach 18 Monaten war die $\mathrm{EF}$ bei mdx-Mäusen mit IgG-Behandlung ( $\mathrm{EF}_{\mathrm{IgG}}$ 18 Mo. $=47,98+/-4,3 \%$ ) verglichen mit dem Wert nach 15 Monaten angestiegen, sodass die $\mathrm{EF}$ verglichen mit der $\mathrm{EF}$ der NaCl-Gruppe $\left(\mathrm{EF}_{\mathrm{NaCl}} 18 \mathrm{Mo.}=41,57\right.$ +/- 3,9 \%) zu diesem Zeitpunkt statistisch signifikant höher war $(\mathrm{p}=0,0059)(\mathrm{Abb} .5 \mathrm{~b})$.

Es lässt sich zusammenfassend sagen, dass IgG einer progredienten kardialen Beteiligung entgegenwirkt, wofür eine statistisch signifikant höhere FAS und EF in der Gruppe mit IgGBehandlung sprechen.

Tabelle 4: Anzahl der mdx-Mäuse, die je Gruppe nach 3, 9, 12, 15 und 18 Monaten echokardiografisch untersucht wurden.

\begin{tabular}{|c|c|c|c|c|c|}
\hline $\mathbf{N}$ & 3 Monate & 9 Monate & 12 Monate & 15 Monate & 18 Monate \\
\hline $\mathrm{NaCl}$ & 10 & 6 & 11 & 9 & 9 \\
\hline $\mathrm{MS}$ & 11 & 12 & 8 & - & - \\
\hline $\mathrm{IgG}$ & 10 & 6 & 9 & 8 & 8 \\
\hline
\end{tabular}


(a)

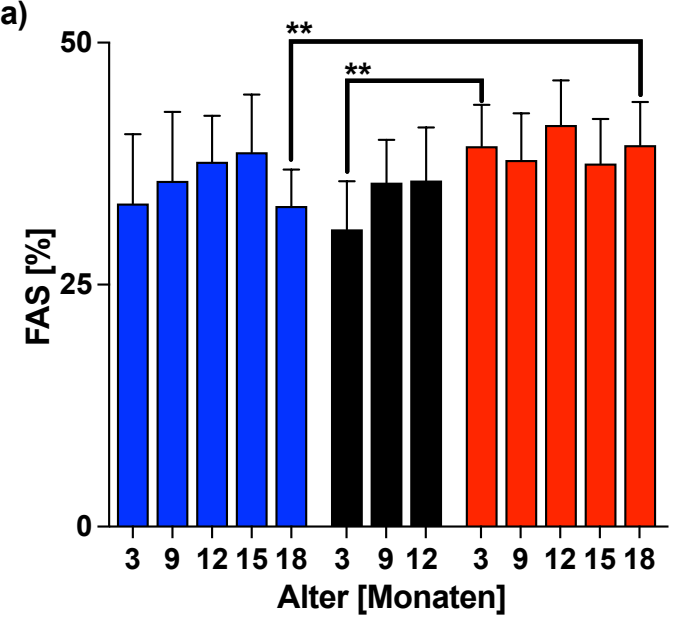

(c)

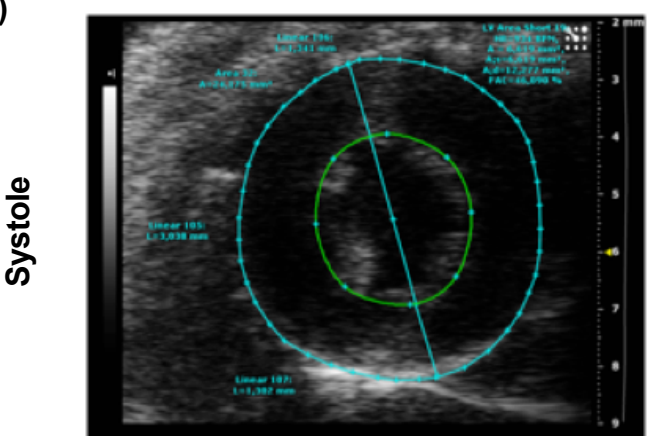

(b)

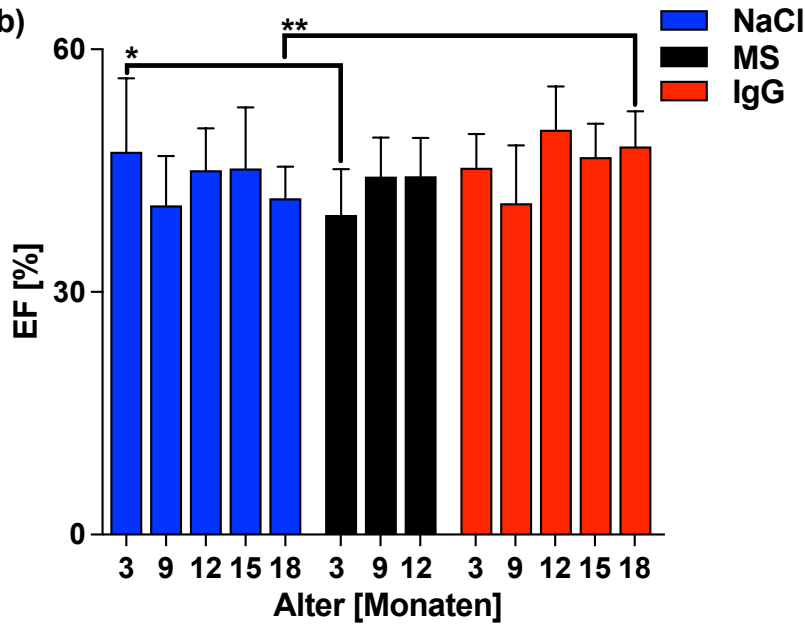

(d)

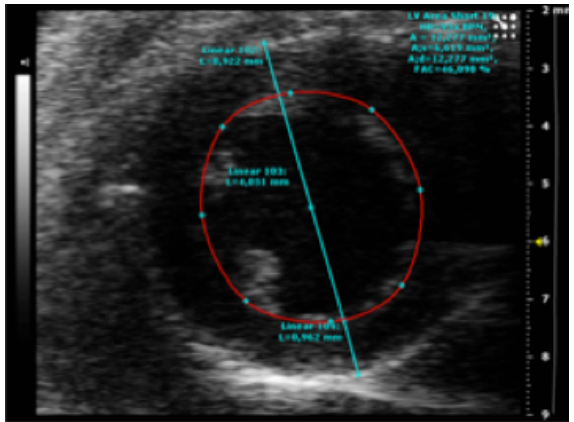

Abbildung 5: Transthorakale Echokardiografie in Sedierung mit Isofluran. (a) FAS und (b) EF der mit $\mathrm{NaCl}$, MS und IgG behandelten mdx-Mäuse nach drei $\left(\mathrm{n}_{\mathrm{IgG}}=11, \mathrm{n}_{\mathrm{NaCl}}=, 10 \mathrm{n}_{\mathrm{MS}}=11\right)$, neun $\left(\mathrm{n}_{\mathrm{IgG}}=6, \mathrm{n}_{\mathrm{NaCl}}=6\right.$, $\left.\mathrm{n}_{\mathrm{MS}}=12\right)$, und zwölf $\left(\mathrm{n}_{\mathrm{IgG}}=9, \mathrm{n}_{\mathrm{NaCl}}=11, \mathrm{n}_{\mathrm{MS}}=8\right)$ Monaten von allen Gruppen bzw. zusätzlich nach 15 $\left(\mathrm{n}_{\mathrm{IgG}}=8, \mathrm{n}_{\mathrm{NaCl}}=9\right)$ und $18\left(\mathrm{n}_{\mathrm{IgG}}=8, \mathrm{n}_{\mathrm{NaCl}}=9\right)$ Monaten von der IgG- und NaCl-Gruppe. Nach drei Monaten war die FAS in der IgG-Gruppe im Vergleich zur MS-Gruppe statistisch signifikant höher $(p=0,0032)$ sowie nach 18 Monaten gegenüber der NaCl-Gruppe $(\mathrm{p}=0,0067)$. Auch die EF war in der IgG-Gruppe nach 18 Monaten statistisch signifikant gegenüber der NaCl-Gruppe $(p=0,0059)$ erhöht. Die Ergebnisse sind als Mittelwerte mit Standardabweichung dargestellt. Statistische Berechnung mit One-way Anova oder t-Test. $* \mathrm{p}<0,05,{ }^{* *} \mathrm{p}<0,01, * * * \mathrm{p}<0,001$. Echokardiografie mit B-Mode der kurzen Achse in (c) Systole und (d) Diastole. 


\subsubsection{Serum-Kreatinkinase}

Da es durch die muskuläre Schädigung zu einer massiven Freisetzung der im Zytosol vorkommenden CK kommt, ist diese im Serum von DMD-Patienten deutlich erhöht (Coulton et al. 1988; Zatz et al. 1991). Ebenso ist die CK bei der mdx-Maus verglichen mit der Wildtyp-Maus erhöht (Spurney et al. 2009). Wir haben post mortem über eine intrakardiale Kanüle Blut entnommen und die CK-Konzentration im Serum bestimmt. Es zeigte sich eine geringere mittlere Serumkonzentration des Enzyms in den mit $\operatorname{IgG}\left(\mathrm{CK}_{\mathrm{IgG}}\right.$ $=837 \mathrm{U} / 1+/-441)$ und MS $\left(\mathrm{CK}_{\mathrm{MS}}=796 \mathrm{U} / 1\right.$ +/- 307) behandelten mdx-Mäusen gegenüber den mdx-Mäusen mit einer NaCl-Behandlung $\left(\mathrm{CK}_{\mathrm{NaCl}}=1012 \mathrm{U} / 1+/ 611\right)$. Da die Tiere der MS-Gruppe zum Zeitpunkt der CK-Bestimmung 12 Monate und die Tiere der IgG- und $\mathrm{NaCl-Gruppe} 18$ Monate alt waren haben wir mit einem t-Test nur die CK-Werte der IgGmit NaCl-Gruppe verglichen. Die Reduktion der CK-Konzentration in der IgG-Gruppe gegenüber der NaCl-Gruppe war nicht statistisch signifikant ( $p=0,498$, Abb. 6).

Die Therapie mit IgG führt, zusammenfassend gesagt, zu einem Trend einer niedrigeren CKSerumkonzentration.

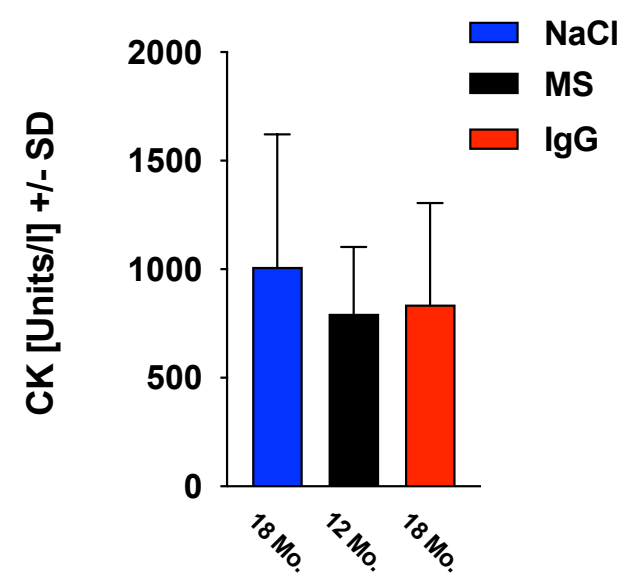

Abbildung 6: Quantifizierung der CK-Konzentration im Serum. Den Tieren wurde post mortem transkardial Blut entnommen. Es zeigte sich in der IgG-Gruppe $(n=9)$ eine niedrigere CK-Konzentration im Vergleich zur NaCl-Gruppe $(\mathrm{n}=10)$ welche jedoch nicht statistisch signifikant war. Die Ergebnisse sind als Mittelwert mit Standardabweichung dargestellt. Ausreißer wurden durch einen Grubbs-Test berechnet. Statistische Berechnung mit dem t-Test. 


\subsubsection{Einfluss von IgG-Gabe auf die mRNA Expression der Entzündungsmedia- toren TGF- $\beta$, SPP1 und MCP1 in der Skelettmuskulatur}

Aus den entnommenen Muskeln wurde mRNA extrahiert, in cDNA umgeschrieben und die mRNA-Expression mittels RT-PCR von den relevanten Mediatoren TGF- $\beta$, SPP1 und MCP1 bestimmt, um Therapieeffekte auch auf molekularer Ebene zu detektieren. Es fielen starke interindividuelle Schwankungen auf und eine deutlich höhere Expression der Mediatoren im Diaphragma im Vergleich zu den Extremitätenmuskeln, was bereits in früheren Studien beschrieben wurde (Weller et al. 2012; Zschüntzsch et al. 2016). Nur im Tibialis anterior konnte eine statistisch signifikant reduzierte mRNA-Expression von SSP1 in der NaCl- $(p=0,0424)$ und IgG-Gruppe $(p=0,0492)$ im Vergleich zur MS-Gruppe nachgewiesen werden (Abb. 7 a-c).

Zusammenfassend konnte in der Skelettmuskulatur kein modulierender Effekt der IgG-Therapie auf die mRNA-Expression von relevanten Entzündungsmediatoren im Alter von 12 bzw. 18 Monaten nachgewiesen werden. 
(a)

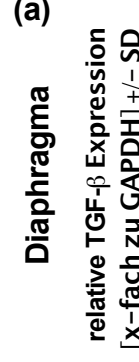

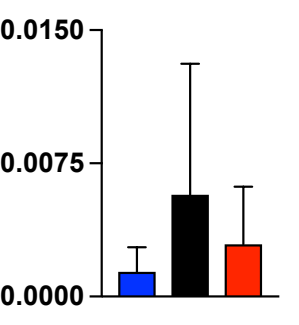

(b)

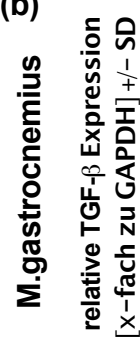

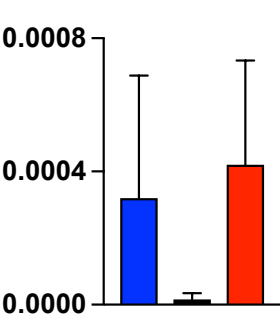
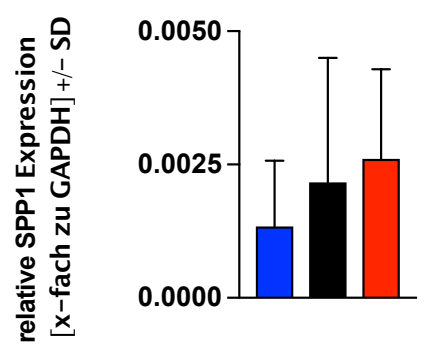

0.0000
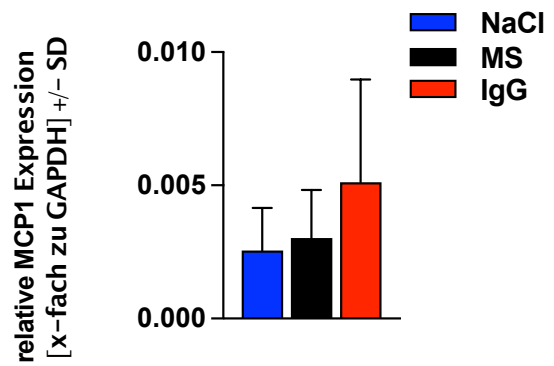

(c)

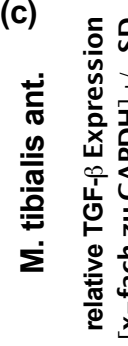

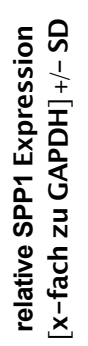
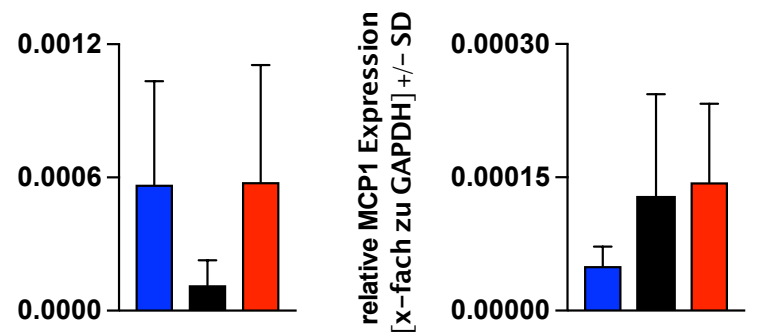

(d)

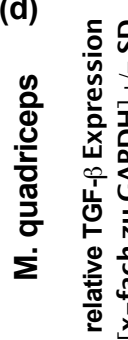

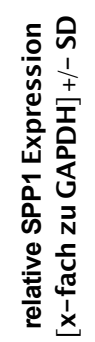
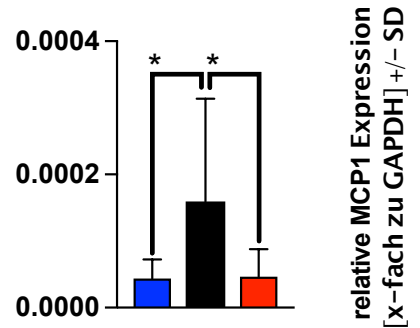

Abbildung 7: Quantifikation relevanter inflammatorischer Mediatoren durch RT-PCR. (a) Relative mRNA-Expression im Diaphragma (TGF- $\beta$ : $\mathrm{n}_{\mathrm{NaCl}}=8, \mathrm{n}_{\mathrm{MS}}=8, \mathrm{n}_{\mathrm{IgG}}=10, \mathrm{SSP} 1: \mathrm{n}_{\mathrm{NaCl}}=7, \mathrm{n}_{\mathrm{MS}}=7, \mathrm{n}_{\mathrm{IgG}}=8$ und MCP1: $\mathrm{n}_{\mathrm{NaCl}}=8, \mathrm{n}_{\mathrm{MS}}=8, \mathrm{n}_{\mathrm{IgG}}=10$ ). (b) M. gastrocnemius (TGF- $\beta: \mathrm{n}_{\mathrm{NaCl}}=8, \mathrm{n}_{\mathrm{MS}}=8, \mathrm{n}_{\mathrm{IgG}}=10, \mathrm{SSP} 1: \mathrm{n}_{\mathrm{NaCl}}=$ $\left.7, \mathrm{n}_{\mathrm{MS}}=7, \mathrm{n}_{\mathrm{IgG}}=9, \mathrm{MCP} 1: \mathrm{n}_{\mathrm{NaCl}}=7, \mathrm{n}_{\mathrm{MS}}=7, \mathrm{n}_{\mathrm{IgG}}=7\right)$. (c) M. tibialis anterior $\left(\right.$ TGF- $\beta: \mathrm{n}_{\mathrm{NaCl}}=7, \mathrm{n}_{\mathrm{MS}}=8, \mathrm{n}_{\mathrm{IgG}}$ $=9, \mathrm{SSP} 1: \mathrm{n}_{\mathrm{NaCl}}=9, \mathrm{n}_{\mathrm{MS}}=8, \mathrm{n}_{\mathrm{IgG}}=9, \mathrm{MCP} 1: \mathrm{n}_{\mathrm{NaCl}}=9, \mathrm{n}_{\mathrm{MS}}=7, \mathrm{n}_{\mathrm{IgG}}=9$ ) und (d) M. quadriceps femoris (TGF$\left.\beta: \mathrm{n}_{\mathrm{NaCl}}=7, \mathrm{n}_{\mathrm{MS}}=7, \mathrm{n}_{\mathrm{IgG}}=9, \mathrm{SSP} 1: \mathrm{n}_{\mathrm{NaCl}}=7, \mathrm{n}_{\mathrm{MS}}=9, \mathrm{n}_{\mathrm{IgG}}=10, \mathrm{MCP} 1: \mathrm{n}_{\mathrm{NaCl}}=7, \mathrm{n}_{\mathrm{MS}}=8, \mathrm{n}_{\mathrm{IgG}}=8\right)($ Abb. 7. a-

d). Nur im M. tibialis anterior war eine statistisch signifikant reduzierte mRNA-Expression von SSP1 in der NaCl- $(p=0,0424)$ und IgG-Gruppe $(p=0,0492)$ nachweisbar (Abb. 7 c). Die Ergebnisse sind als Mittelwert mit Standardabweichung dargestellt. Zur Ausreißeranalyse wurde ein Grubbs-Test durchgeführt. Statistische Berechnung mit one-way Anova. ${ }^{*} \mathrm{p}<0,05,{ }^{* *} \mathrm{p}<0,01,{ }^{* * *} \mathrm{p}<0,001$. 


\subsubsection{Expression der mRNA von TGF- $\beta$ in der Herzmuskulatur nach IgG-Behandlung über 18 Monate}

In der Herzmuskulatur kommt es, wie bereits erläutert, als Folge der muskulären Schädigung ebenfalls zu einer inflammatorischen Antwort und einem fibrotischen Umbau (Dahiya et al. 2011). Aufgrund der zuvor aufgeführten Ergebnisse in der Skelettmuskulatur haben wir in der Herzmuskulatur die Expression des mit Fibrose assoziierten Markers TGF- $\beta$ nur stichpunktartig untersucht. Hier zeigte sich eine deutliche Variabilität in der Expression und keine statistische Signifikanz (Abb. 8).

Zusammenfassend lässt sich sagen, dass es durch $\operatorname{IgG}$ zu einer reduzierten Expression von TGF- $\beta$ in der Herzmuskulatur kam.

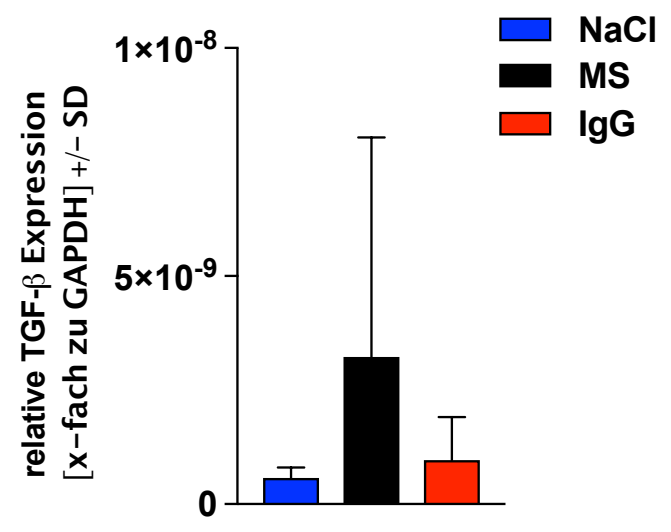

Abbildung 8: Quantifikation der TGF- $\beta$-Expression im Herzmuskel. Relative mRNA-Expression von TGF- $\beta$ im Herzmuskel zeigt eine Reduktion in der IgG- und NaCl-Gruppe $\left(\mathrm{n}_{\mathrm{NaCl}}=6, \mathrm{n}_{\mathrm{IgG}}=6\right)$ gegenüber der MS-Gruppe $\left(\mathrm{n}_{\mathrm{MS}}=6\right)$. Darstellung der Ergebnisse als Mittelwert mit Standardabweichung. Zur Berechnung von Ausreißern wurde ein Grubbs-Test durchgeführt. Statistische Berechnung mit one-way Anova. * $\mathrm{p}<0,05$, $* * \mathrm{p}<0,01, * * * \mathrm{p}<0,001$. 


\subsubsection{Effekt von IgG auf myopathische Veränderungen in der Skelettmusku- latur}

Zur Darstellung der Muskelpathologie wurden HE-Färbungen von Diaphragma und verschiedenen Skelettmuskeln angefertigt und die Schnitte auf Zeichen von De- und Regeneration untersucht. Als solche Zeichen werden Veränderungen bestimmter Parameter angesehen, wie die Anzahl der Muskelfasern mit peripheren und zentralisierten Zellkernen sowie die durchschnittlichen Faserdurchmesser und die Schwankungen der Kaliber. Dementsprechend haben wir in dieser Studie diese Parameter bestimmt und fanden in allen Muskelgruppen, die bei einer DMD bzw. in mdx-Mäusen typischen, zu erwartenden myopathischen Veränderungen. Die Tabelle 5 führt die Anzahl der ausgewerteten Muskelquerschnitte, die je Behandlungsgruppe gewertet worden sind, auf. Zuvor wurden Ausreißer mit dem GrubbsTest berechnet. In dieser Studie variierte der Faserdurchmesser zwischen 16,5 und 46,8 $\mu \mathrm{m}$. Auch in früheren Studien, in denen die Muskelpathologie von Mäusen, die älter als ein Jahr waren, untersucht wurden, hatten sich solche Kaliberschwankungen gezeigt (Pastoret und Sebille 1995). Als Index für myopathische Veränderungen in der Muskulatur wurde der CNI (prozentualer Anteil der Muskelfasern mit einem zentralisierten Zellkern) bestimmt. Es zeigte sich in allen Muskelgruppen ein gegenüber Kontrollen geringerer CNI bei einer IgGBehandlung. Statistisch signifikant war die Reduktion des CNI der IgG-Gruppe im Diaphragma $(\mathrm{p}=0,002)$ gegenüber der NaCl-Gruppe, im M. tibialis anterior gegenüber der MSGruppe $(\mathrm{p}=0,02)$ und im M. quadriceps femoris gegenüber der NaCl-Gruppe $(\mathrm{p}=<0,001)$ und der MS-Gruppe ( $\mathrm{p}=<0,001)$. Nur die Tiere der NaCl- und IgG-Gruppe wurden 18 Monate lang behandelt und demnach befand sich nur das untersuchte Muskelgewebe dieser beiden Gruppen in der Krankheitsphase mit ausgeprägteren histopathologischen Veränderungen. Eine Reduktion des CNI spricht demnach für einen therapeutischen Effekt der IgGTherapie auf die de- und regenerativen Prozesse in dystrophindefizienten Muskeln.

Zusammenfassend zeigte sich eine Reduktion des myopathischen Parameters CNI durch die IgG-Behandlung. 
Tabelle 5: Anzahl der je Behandlungsgruppe ausgewerteten Muskeln nach HE-Färbung.

\begin{tabular}{|c|c|c|c|c|}
\hline $\mathbf{N}$ & Diaphragma & M. gastrocnemius & M. tibialis anterior & M. quadriceps femoris \\
\hline $\mathrm{NaCl}$ & 7 & 7 & 8 & 7 \\
\hline $\mathrm{MS}$ & 7 & 8 & 7 & 7 \\
\hline $\mathrm{IgG}$ & 8 & 8 & 9 & 7 \\
\hline
\end{tabular}

Ausreißer wurden mit dem Grubbs-Test berechnet. Es wurden in zehnfacher Vergrößerung pro Muskel durchschnittlich 200-500 Muskelfasern ausgewertet, periphere und zentralisierte Zellkerne manuell gezählt und der durchschnittliche Muskelfaserdurchschnitt bestimmt. 


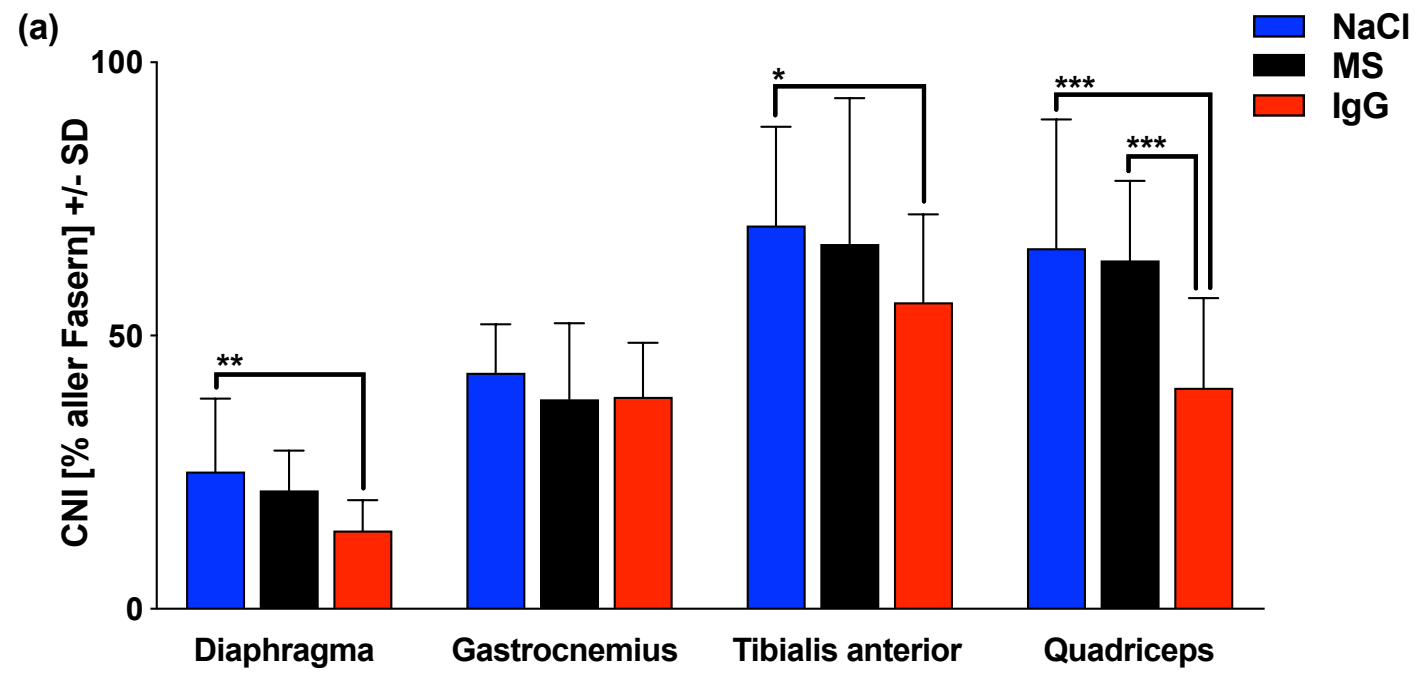

(b)

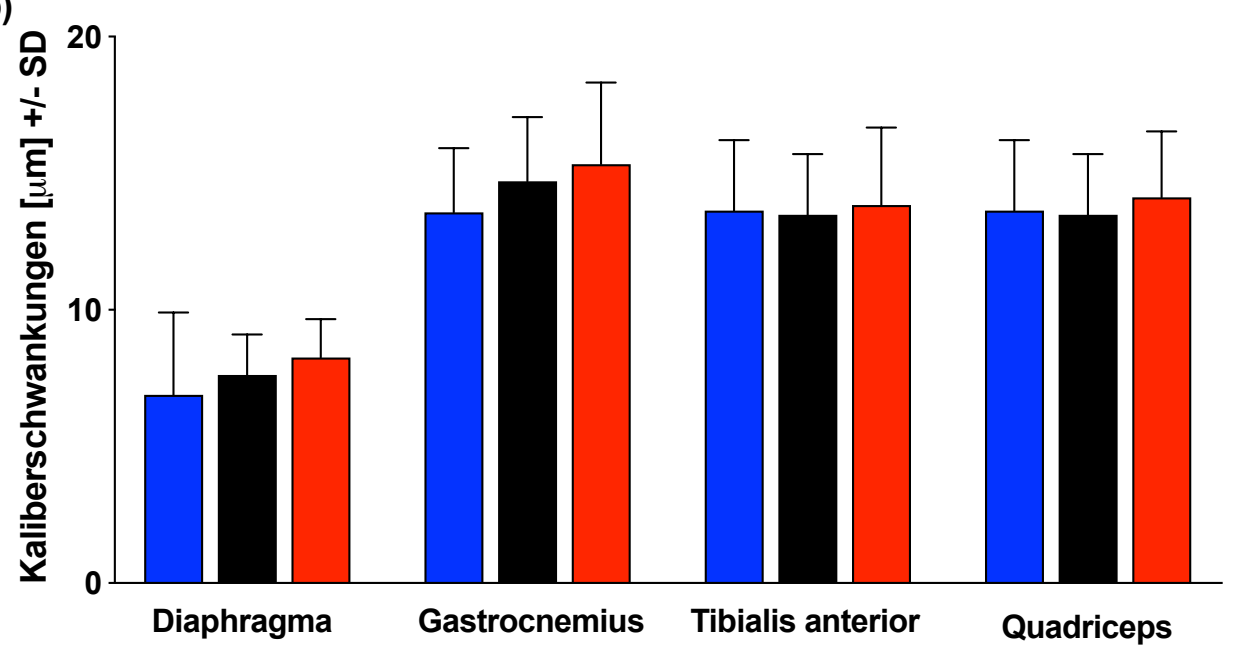

(c)

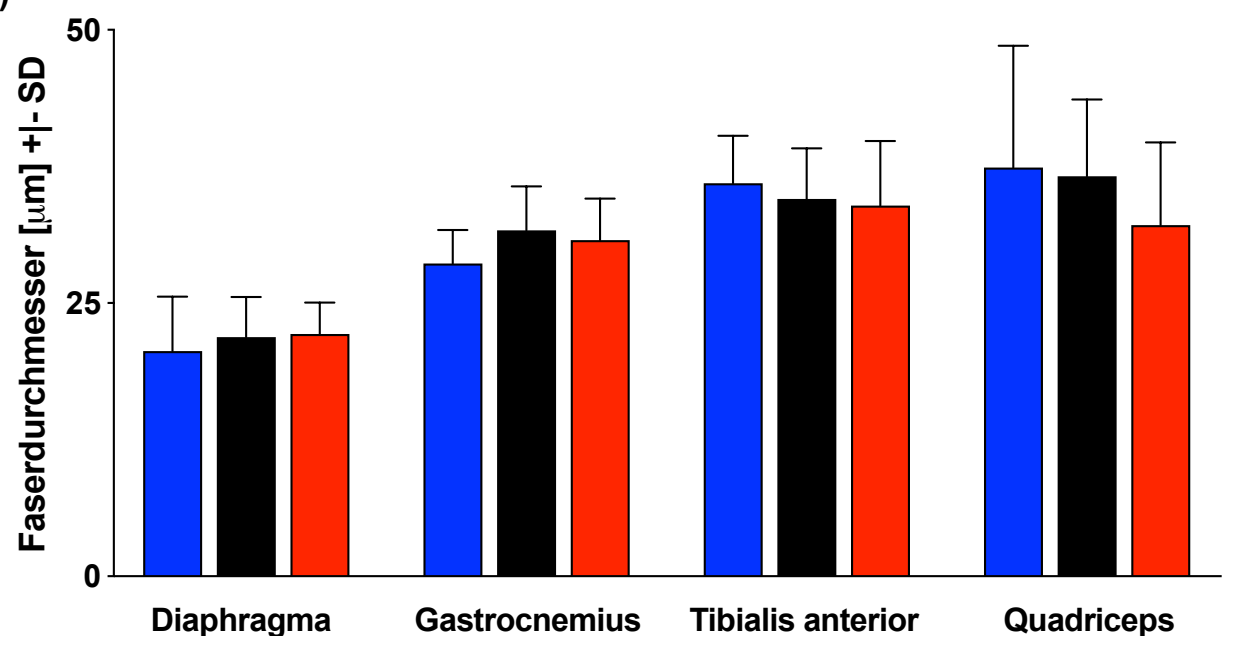

Abbildung 9: Auswertung der Muskelpathologie. (a) CNI, (b) durchschnittliche Muskelfasergröße und (c) Kaliberschwankungen. Dabei zeigte sich in der Anzahl der zentralisierten Zellkerne eine statistisch signifikante Reduktion nach einer IgG-Therapie im Diaphragma $\left(\mathrm{n}_{\mathrm{NaCl}}=7, \mathrm{n}_{\mathrm{MS}}=7, \mathrm{n}_{\mathrm{IgG}}=8, \mathrm{p}=0,002\right)$ und M. quadriceps femoris $\left(\mathrm{n}_{\mathrm{NaCl}}=7, \mathrm{n}_{\mathrm{MS}}=7, \mathrm{n}_{\mathrm{IgG}}=7, \mathrm{p}=<0,001\right)$ gegenüber der NaCl-Gruppe. Im M. quadriceps femoris $(\mathrm{p}=<0,001)$ und $\mathrm{M}$. tibialis anterior $\left(\mathrm{n}_{\mathrm{NaCl}}=8, \mathrm{n}_{\mathrm{MS}}=7, \mathrm{n}_{\mathrm{IgG}}=9, \mathrm{p}=0,02\right)$ war der CNI statistisch signifikant, verglichen zu den Muskeln der Tiere mit einer MS-Behandlung, erniedrigt. Die Ergebnisse sind als Mittelwert mit Standardabweichung dargestellt. Statistische Berechnung mit one-way Anova. ${ }^{*} \mathrm{p}<0,05,{ }^{* *} \mathrm{p}<0,01$, $* * * \mathrm{p}<0,001$. 

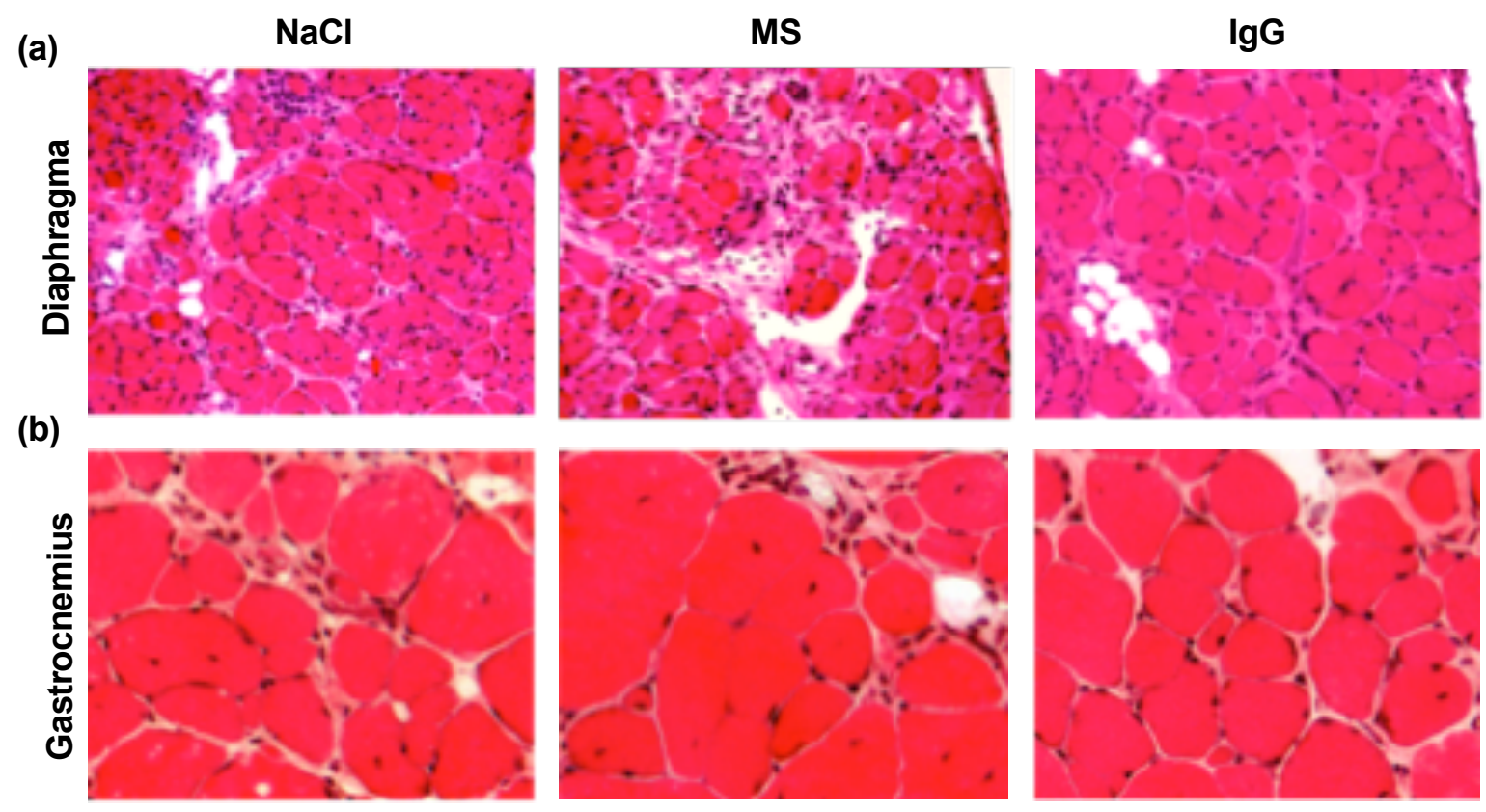

(c)
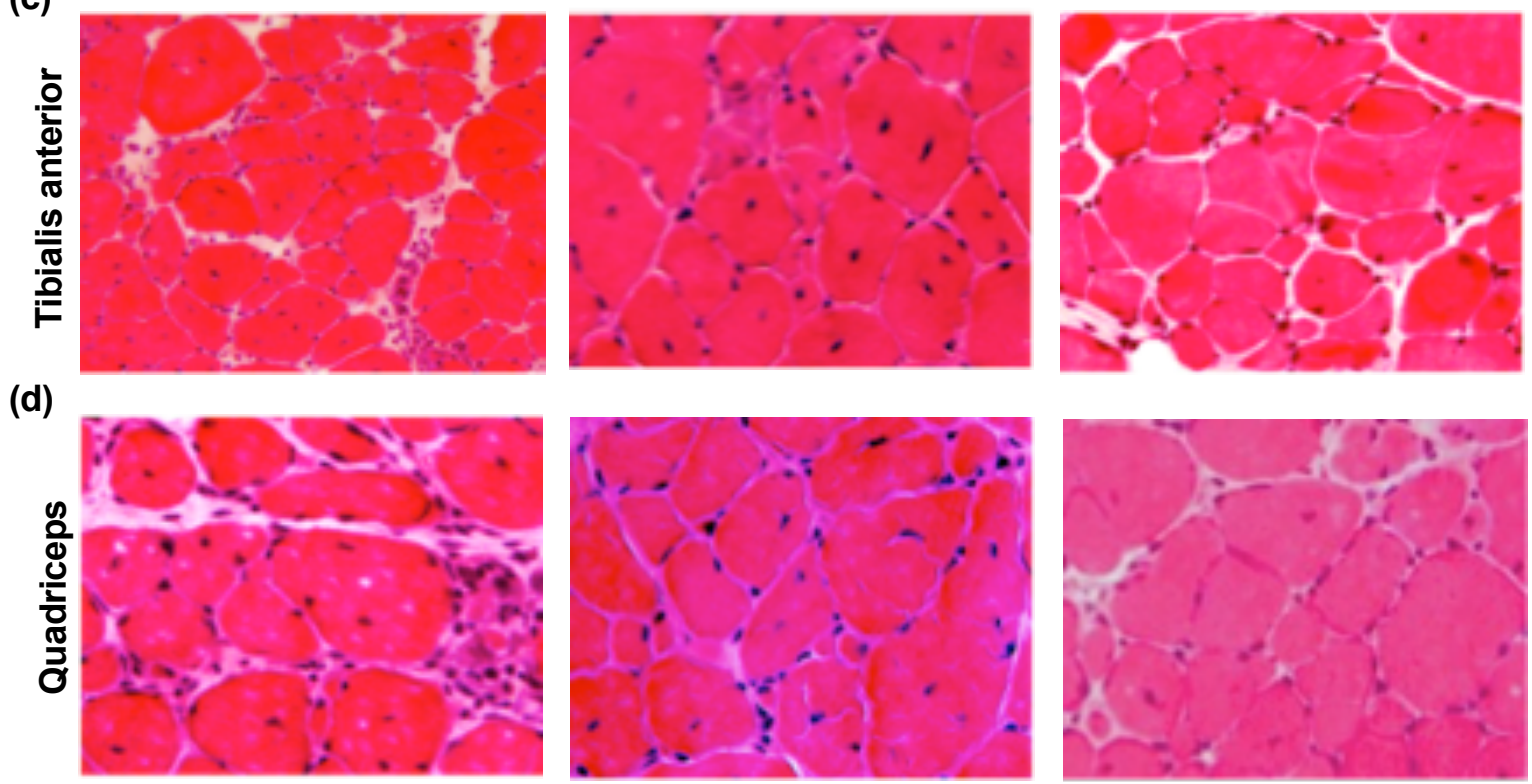

Abbildung 10: HE-Färbungen von Muskelquerschnitten. (a) Diaphragma, (b) M. gastrocnemius, (c) M. tibialis anterior und (d) M. quadriceps femoris nach einer 18-monatigen Behandlung mit $\mathrm{NaCl}$ und IgG bzw. 12-monatigen Behandlung mit MS und täglicher Laufradnutzung. Ausschnitte von Aufnahmen in zehnfacher Vergrößerung mit der Mikroskopkamera. 


\subsubsection{Wirkung von IgG auf Infiltration mit T-Zellen und Makrophagen in der Skelettmuskulatur}

Makrophagen und T-Zellen sind die dominierenden inflammatorischen Zellen, die nach muskulärer Schädigung im dystrophindefizienten Muskel auftreten. In allen untersuchten Muskelgruppen zeigte sich im Vergleich zu Kontrollen nach einer IgG-Therapie eine reduzierte Anzahl an Makrophagen und T-Zellen (Abb. 11-14). In den Tabellen sechs und sieben ist die Anzahl der ausgewerteten Muskeln, nach vorheriger Bereinigung von Ausreißern, die je Behandlungsgruppe gewertet wurden, dargestellt. Eine statistisch signifikante Reduktion der T-Zellen war im Diaphragma in den mdx-Mäusen mit einer NaCl-Behandlung ( $\mathrm{p}=<0,001)$ und IgG-Behandlung $(\mathrm{p}=<0,001)$, verglichen mit der MS-Gruppe sowie der IgG-Gruppe, gegenüber der NaCl-Gruppe nachweisbar $(p=0,01)$. Im M. gastrocnemius zeigte sich eine signifikant reduzierte Anzahl der T-Zellen in den mit IgG behandelten Tieren gegenüber der NaCl-Gruppe $(p=0,01)$ und MS-Kontrollgruppe $(p=0,001)$. Die Anzahl der T-Zellen war im M. tibialis anterior der mdx-Mäuse, die eine IgG-Behandlung erhalten hatten, gegenüber der MS-Gruppe statistisch signifikant erniedrigt $(p=0,04)$. Im M. quadriceps femoris war das Signal für T-Zellen nach einer Behandlung mit IgG im Vergleich zur NaCl-Gruppe $(p=0,04)$ statistisch signifikant reduziert (Abb. 11).

Tabelle 6: Anzahl der je Behandlungsgruppe ausgewerteten Muskeln nach Färbung mit anti-humanem CD3.

\begin{tabular}{|c|c|c|c|c|}
\hline $\mathbf{N}$ & Diaphragma & M. gastrocnemius & M. tibialis anterior & M. quadriceps femoris \\
\hline $\mathrm{NaCl}$ & 7 & 7 & 9 & 8 \\
\hline $\mathrm{MS}$ & 8 & 8 & 8 & 8 \\
\hline $\mathrm{IgG}$ & 8 & 9 & 8 & 9 \\
\hline
\end{tabular}

In einer 40-fachen Vergrößerung wurden pro Muskel zehn Aufnahmen gemacht und die T-Zellen manuell gezählt. Berechnung der Ausreißer mit dem Grubbs-Test. 


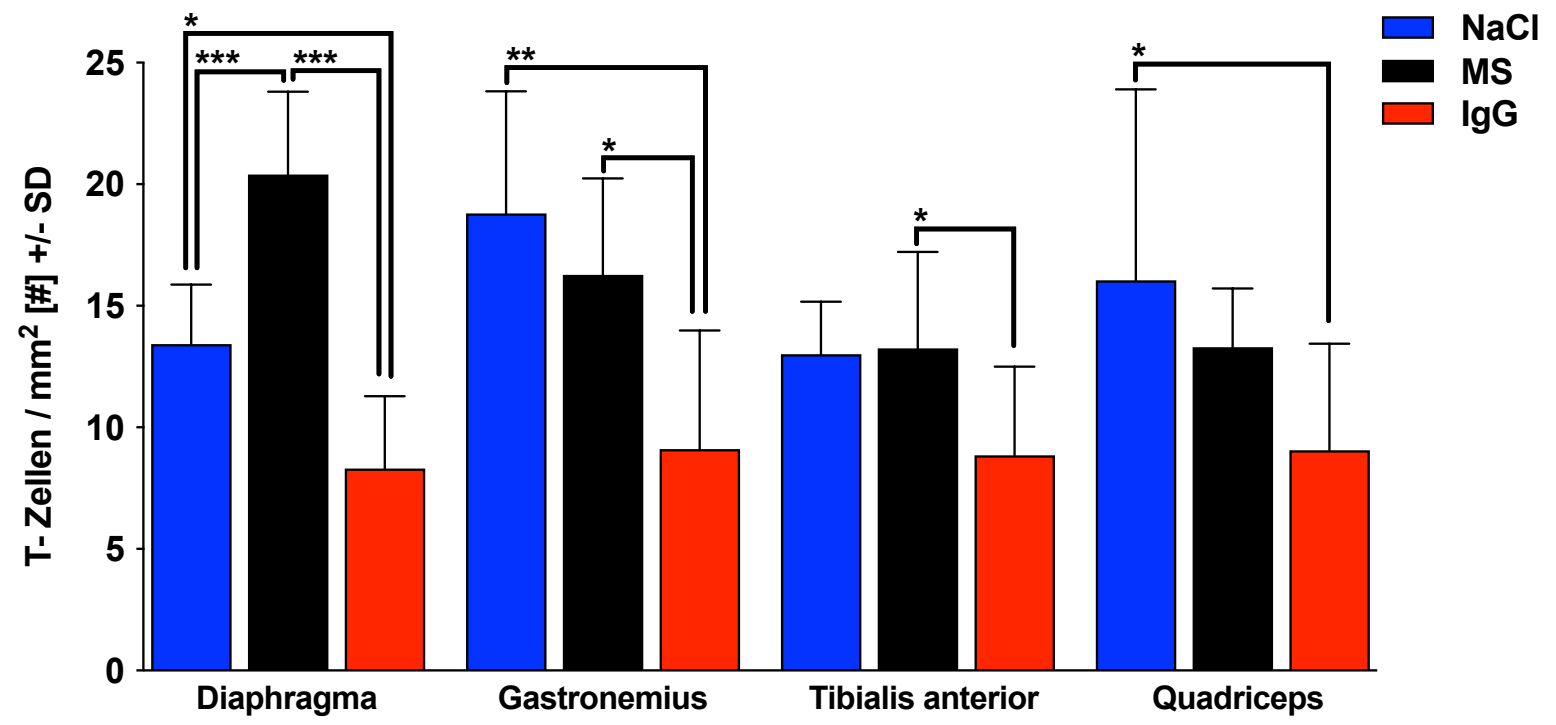

Abbildung 11: T-Zellen pro $\mathbf{m m}^{2}$ in Diaphragma, M. gastrocnemius, M. tibialis anterior und M. quadriceps femoris. Diese wurden in vier nicht überlappenden Feldern in 40-facher Vergrößerung quantifiziert. Im Diaphragma $\left(\mathrm{n}_{\mathrm{NaCl}}=7, \mathrm{n}_{\mathrm{MS}}=8, \mathrm{n}_{\mathrm{IgG}}=8\right)$ zeigte sich eine statistisch signifikante Reduktion der T-Zellen in der NaCl-Gruppe $(p=<0,001)$ und IgG-Gruppe $(p=<0,001)$ im Vergleich zur MS-Gruppe sowie in der IgGGruppe gegenüber der NaCl-Gruppe $(\mathrm{p}=0,01)$. Im M. gastrocnemius $\left(\mathrm{n}_{\mathrm{NaCl}}=7, \mathrm{n}_{\mathrm{MS}}=8, \mathrm{n}_{\mathrm{IgG}}=9\right)$ zeigte sich eine signifikante Reduktion in den mit IgG behandelten Tieren gegenüber der NaCl-Kontrollgruppe $(p=0,001)$ und MS-Kontrollgruppe $(\mathrm{p}=0,01)$. Eine statistisch signifikante Reduktion der T-Zellen konnte im M. tibialis anterior $\left(\mathrm{n}_{\mathrm{NaCl}}=9, \mathrm{n}_{\mathrm{MS}}=8, \mathrm{n}_{\mathrm{IgG}}=8\right)$ durch eine Therapie mit IgG gegenüber der MS-Kontrollgruppe $(\mathrm{p}=0,04)$ erreicht werden. Das Signal der T-Zellen war im M. quadriceps femoris $\left(\mathrm{n}_{\mathrm{NaCl}}=8, \mathrm{n}_{\mathrm{MS}}=8, \mathrm{n}_{\mathrm{IgG}}=9\right)$ in der IgG-Gruppe im Vergleich zur NaCl-Gruppe statistisch signifikant $(p=0,04)$ reduziert. Die Ergebnisse sind als Mittelwert mit Standardabweichung dargestellt. Zur Berechnung von Ausreißern wurde ein Grubbs-Test durchgeführt. Statistische Berechnung mit one-way Anova. ${ }^{*} \mathrm{p}<0,05,{ }^{*} \mathrm{p}<0,01, * * * \mathrm{p}<0,001$. 
(a)

(b)
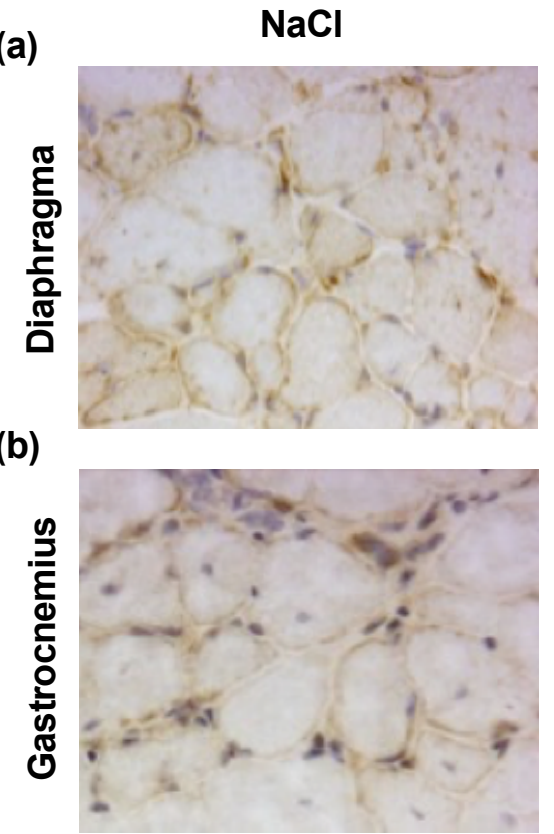

(c)

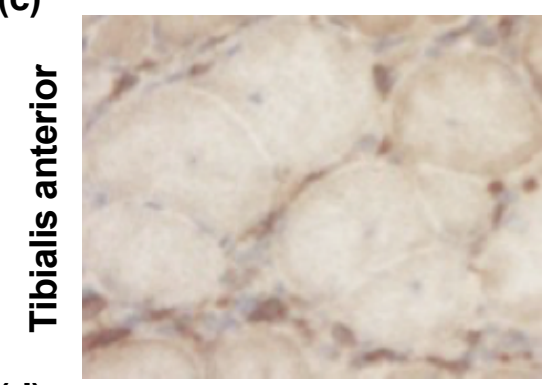

(d)

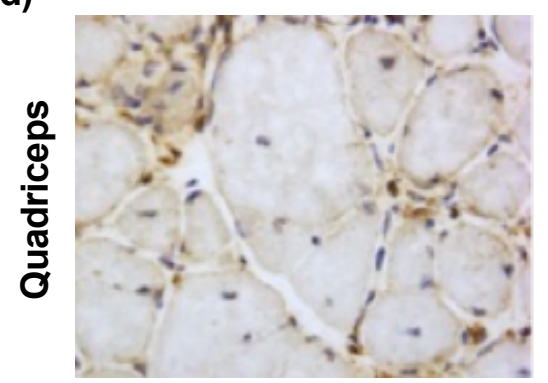

MS
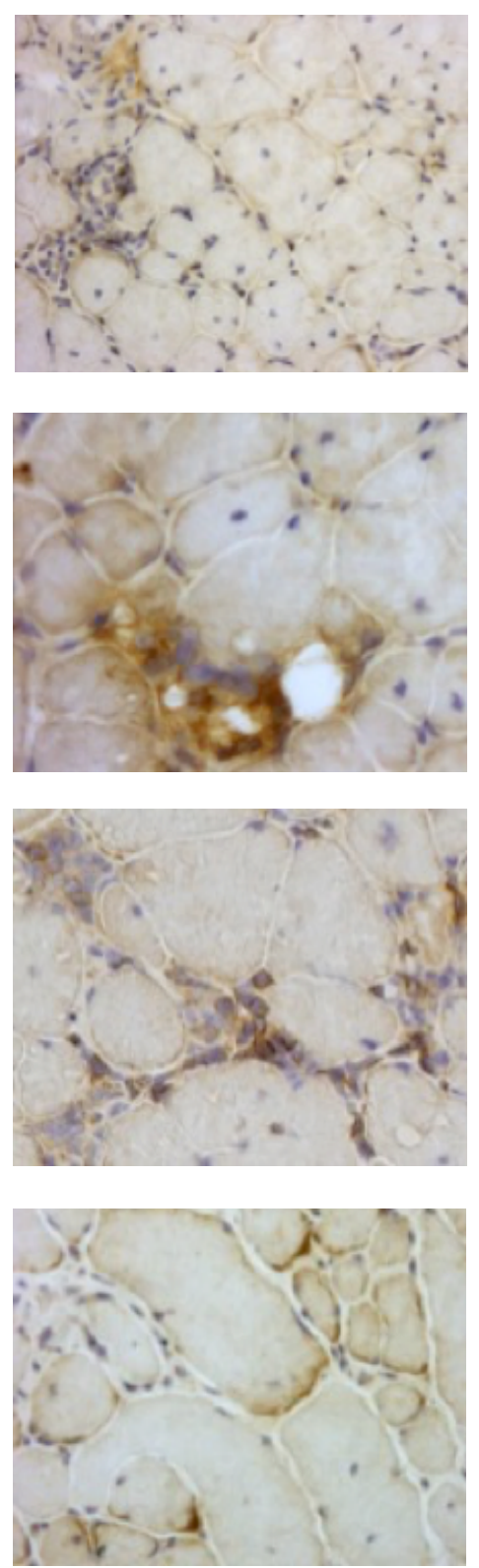

$\lg \mathbf{G}$
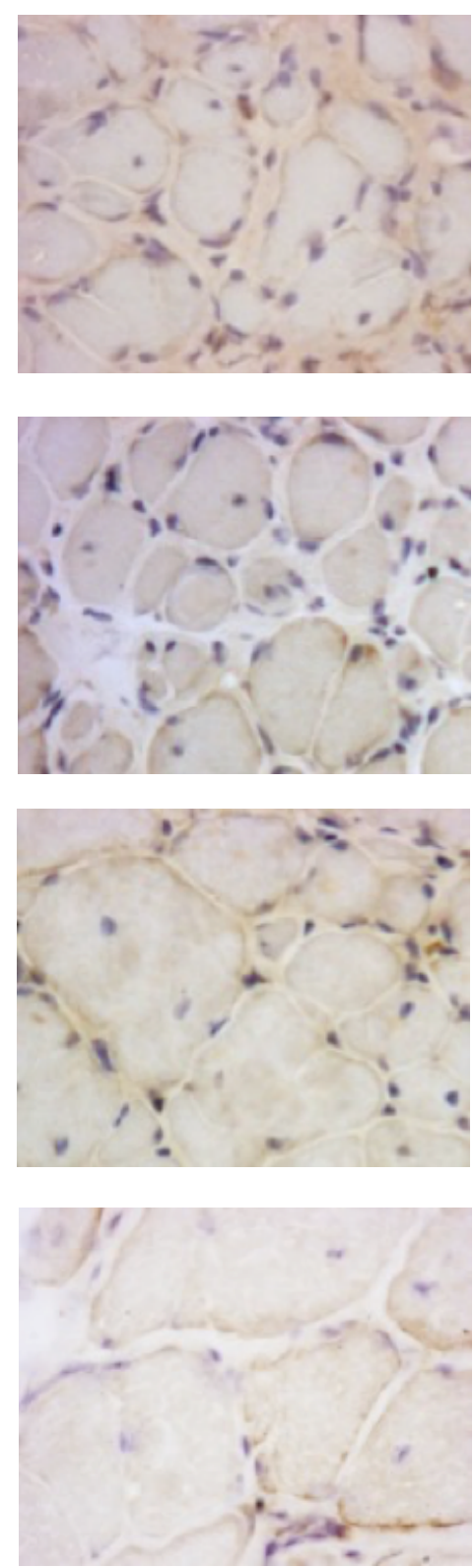

Abbildung 12: Immunhistochemische Detektion von T-Zellen in Muskelquerschnitten. Querschnitte von (a) Diaphragma, (b) M. gastrocnemius, (c) M. tibialis anterior und (d) M. quadriceps femoris nach einer 18monatigen Behandlung mit $\mathrm{NaCl}$ und IgG bzw. zwölfmonatigen Behandlung mit MS und täglicher Laufradnutzung. Ausschnitte von Aufnahmen in 40-facher Vergrößerung mit der Mikroskopkamera. 
Die Zahl der Makrophagen war im Diaphragma von mdx-Mäusen mit einer NaCl-Behandlung $(\mathrm{p}=0,0225)$ und IgG-Behandlung $(\mathrm{p}=0,0021)$ verglichen mit der MS-Gruppe nachweisbar verringert. Im M. gastrocnemius der mit IgG behandelten Tiere zeigte sich eine signifikant verringerte Makrophagenzahl gegenüber denen, die $\mathrm{NaCl}(\mathrm{p}=0,0314)$ erhalten haben. Die Makrophagendichte war im M. tibialis anterior in der IgG-Gruppe gegenüber der NaCl-Gruppe $(p=0,0047)$ und MS-Gruppe $(p=0,0003)$ signifikant erniedrigt. Eine IgGTherapie konnte im M. quadriceps femoris keine statistisch signifikante Reduktion der Makrophagen erreichen (Abb. 13).

Zusammenfassend führte $\mathrm{IgG}$ zu einer statistisch signifikanten Verringerung der Infiltration von T-Zellen und Makrophagen in der Skelettmuskulatur.

Tabelle 7: Anzahl der je Behandlungsgruppe ausgewerteten Muskeln nach immunhistochemischer Färbung von Makrophagen.

\begin{tabular}{|c|c|c|c|c|}
\hline $\mathbf{n}$ & Diaphragma & M. gastrocnemius & M. tibialis anterior & M. quadriceps femoris \\
\hline $\mathrm{NaCl}$ & 8 & 7 & 7 & 7 \\
\hline $\mathrm{MS}$ & 8 & 8 & 7 & 7 \\
\hline $\mathrm{IgG}$ & 8 & 9 & 8 & 9 \\
\hline
\end{tabular}

Berechnung der Ausreißer mit dem Grubbs-Test. Zur Detektion der Makrophagen wurden die Querschnitte mit F4/80 und DAB-Substrat inkubiert. Je Muskel wurden in 40-facher Vergrößerung zehn Aufnahmen gemacht und manuell die Anzahl der Makrophagen gezählt. 


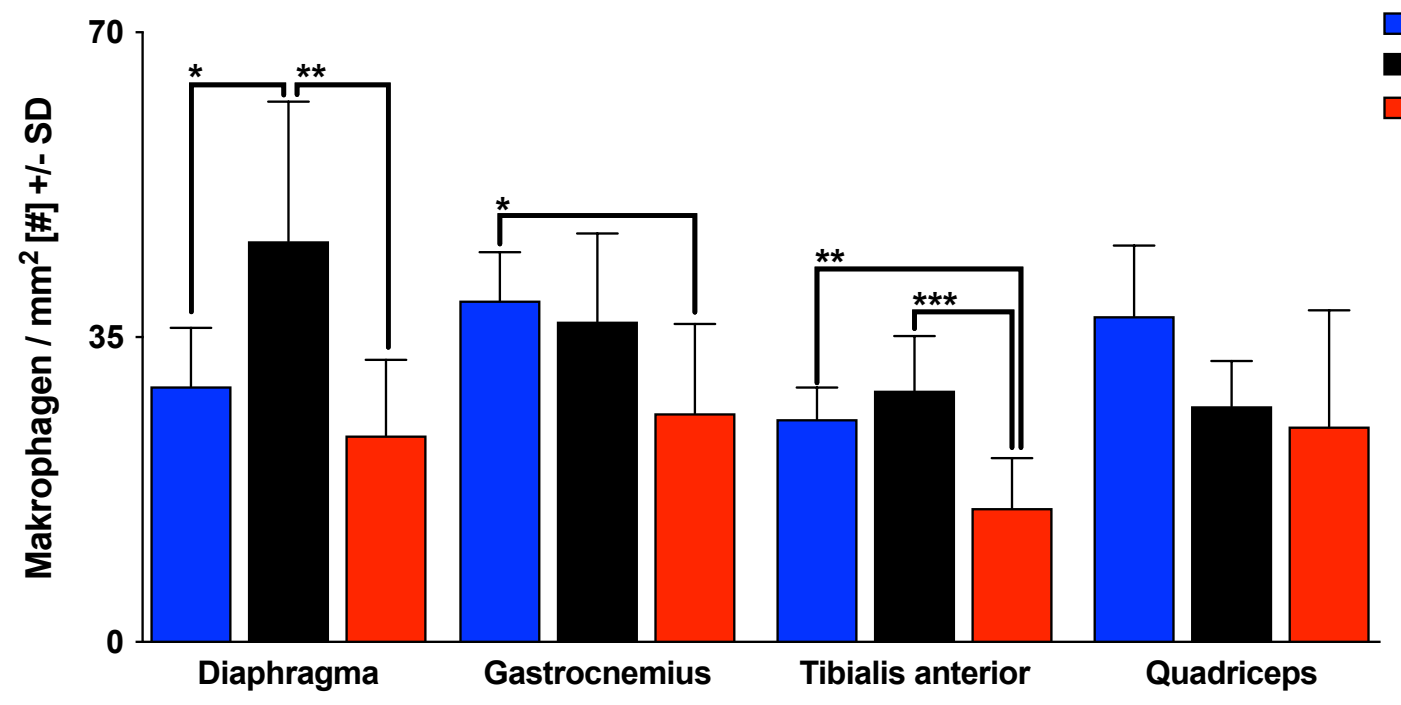

Abbildung 13: Immunhistochemische Detektion von Makrophagen in Diaphragma, M. gastrocnemius, M. tibialis anterior und M. quadriceps femoris. Die Makrophagenanzahl war im Diaphragma $\left(\mathrm{n}_{\mathrm{NaCl}}=8, \mathrm{n}_{\mathrm{MS}}\right.$ $\left.=8, \mathrm{n}_{\mathrm{IgG}}=8\right)$ der NaCl-Gruppe $(\mathrm{p}=0,0225)$ und IgG-Gruppe $(\mathrm{p}=0,0021)$ im Vergleich zur MS-Gruppe nachweisbar verringert. Im M. gastrocnemius $\left(\mathrm{n}_{\mathrm{NaCl}}=7, \mathrm{n}_{\mathrm{MS}}=8, \mathrm{n}_{\mathrm{IgG}}=9\right)$ zeigte sich eine signifikant verringerte Makrophagenanzahl in den mit IgG behandelten Tieren gegenüber der NaCl-Gruppe ( $p=0,0314)$. Die Makrophagendichte war im M. tibialis anterior $\left(\mathrm{n}_{\mathrm{NaCl}}=7, \mathrm{n}_{\mathrm{MS}}=7, \mathrm{n}_{\mathrm{IgG}}=8\right)$ der mit IgG behandelten mdx-Mäuse gegenüber den mit $\mathrm{NaCl}(\mathrm{p}=0,0047)$ und $\mathrm{MS}(\mathrm{p}=0,0003)$ behandelten mdx-Mäusen signifikant reduziert. Die Ergebnisse sind als Mittelwert mit Standardabweichung dargestellt. Zur Berechnung von Ausreißern wurde ein Grubbs-Test durchgeführt. Statistische Berechnung mit one-way Anova. ${ }^{*} \mathrm{p}<0,05, * * \mathrm{p}<0,01$, $* * * \mathrm{p}<0,001$. 
(a)

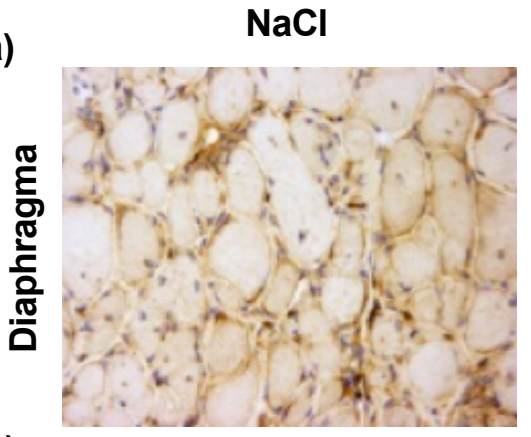

(b)

(c)
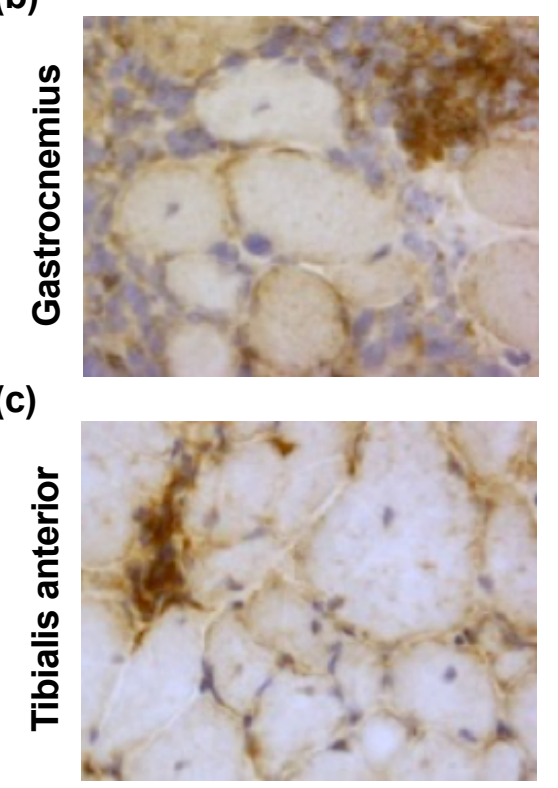

(d)

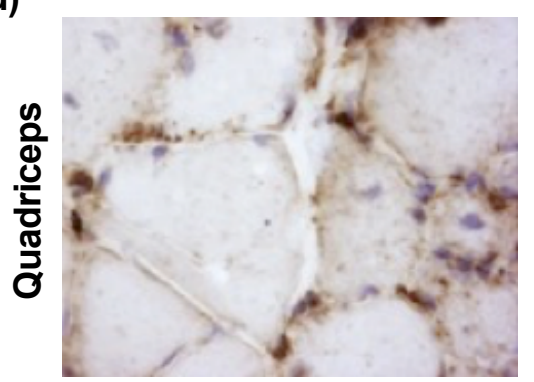

MS
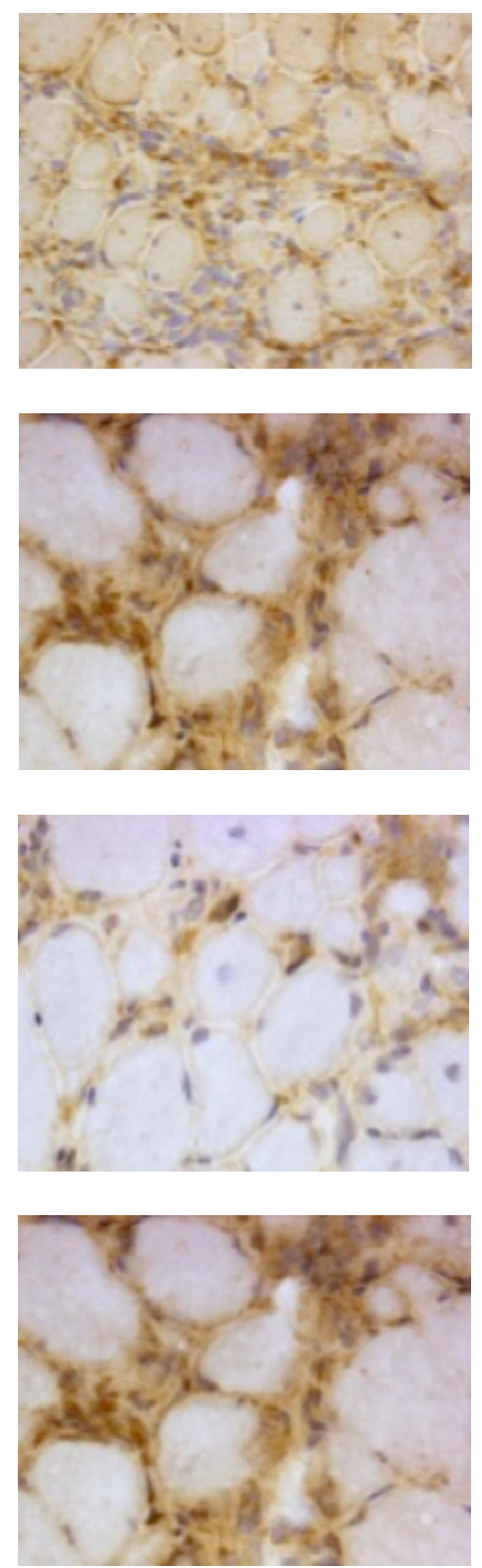

$\lg \mathbf{G}$
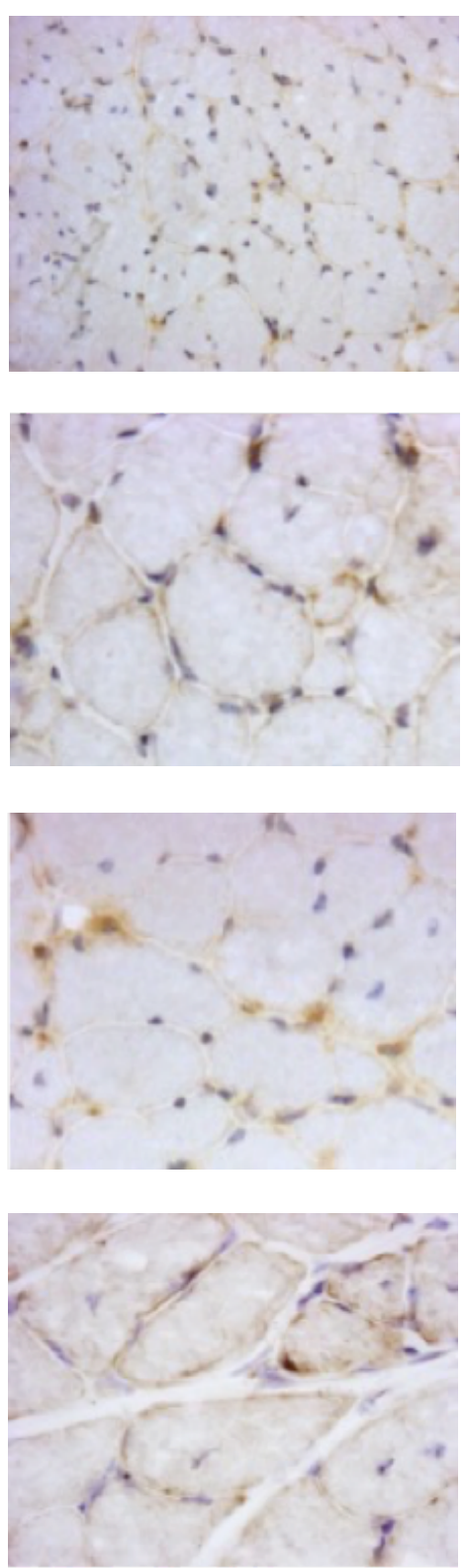

Abbildung 14: Immunhistochemische Detektion von Makrophagen in Muskelquerschnitten. (a) Diaphragma, (b) M. gastrocnemius, (c) M. tibialis anterior und (d) M. quadriceps femoris nach einer 12- bzw. 18monatigen Behandlung mit NaCl, MS und IgG und täglicher Laufradnutzung. Ausschnitte von Aufnahmen in 40-facher Vergrößerung mit der Mikroskopkamera. 


\subsubsection{Einfluss von IgG auf die Infiltration mit T-Zellen und Makrophagen in der Herzmuskulatur}

Auch in der Herzmuskulatur der mdx-Mäuse kam es zu einer Infiltration mit T-Zellen und Makrophagen im Zuge der inflammatorischen Antwort. Zudem wurden nach Schädigung die untergegangenen Muskelfasern teils fibrotisch ersetzt. In Tabelle 8 ist die Anzahl der je Behandlungsgruppe ausgewerteten Muskeln, nach vorheriger Bereinigung von Ausreißern, dargestellt. Es zeigte sich eine statistisch signifikante Reduktion von T-Zellen in den Herzmuskeln von mdx-Mäusen mit einer IgG-Behandlung gegenüber den beiden Kontrollgruppen $\mathrm{NaCl}(\mathrm{p}=0,0002)$ und MS ( $\mathrm{p}=0,0003)$ (Abb. $15 \mathrm{a})$. Gleiches gilt für das Makrophagensignal, welches in den mit IgG therapierten Mäuseherzen signifikant gegenüber der NaCl- $(p=0,0015)$ und MS-Gruppe $(p=0,0016)$ erniedrigt war (Abb. 15 b). Eine IgG-Therapie führte zudem zu einer Reduktion des auf den muskulären Schaden folgenden fibrotischen Ersatzes im Herzen. Der prozentuale Anteil der Fibrose an der gesamten Herzmasse war in mit IgG therapierten mdx-Mäusen statistisch signifikant gegenüber den mit MS behandelten Tieren reduziert $(\mathrm{p}=0,005)(\mathrm{Abb} .15 \mathrm{c})$.

Eine Langzeittherapie mit IgG führt demnach auch im Herzmuskel zu einer Verringerung der inflammatorischen Infiltration und einer Reduktion der Fibrose.

Tabelle 8: Anzahl der je Behandlungsgruppe ausgewerteten Herzen.

\begin{tabular}{|c|c|c|c|}
\hline $\mathbf{n}$ & T-Zellen & Makrophagen & Fibroseanteil \\
\hline $\mathrm{NaCl}$ & 6 & 7 & 7 \\
\hline $\mathrm{MS}$ & 7 & 7 & 7 \\
\hline $\mathrm{IgG}$ & 8 & 8 & 7 \\
\hline
\end{tabular}

Zuvor Berechnung der Ausreißer mit dem Grubbs-Test. 
(a)

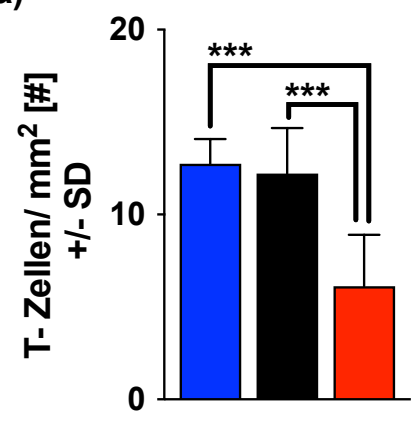

(d)

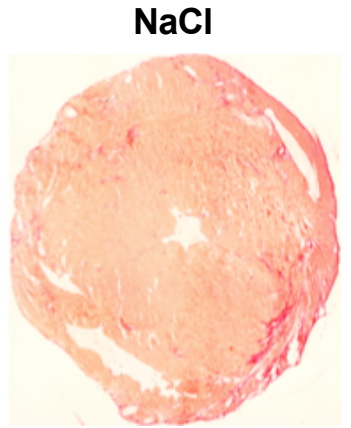

(b)

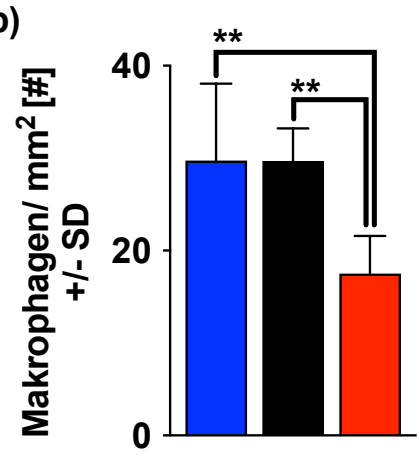

(e)

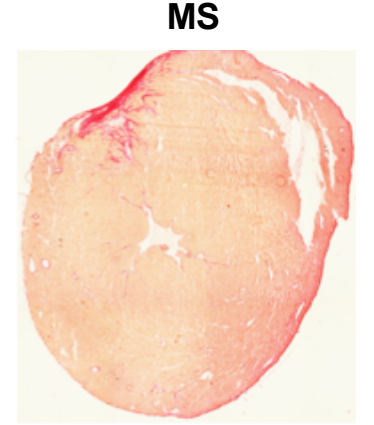

(c)

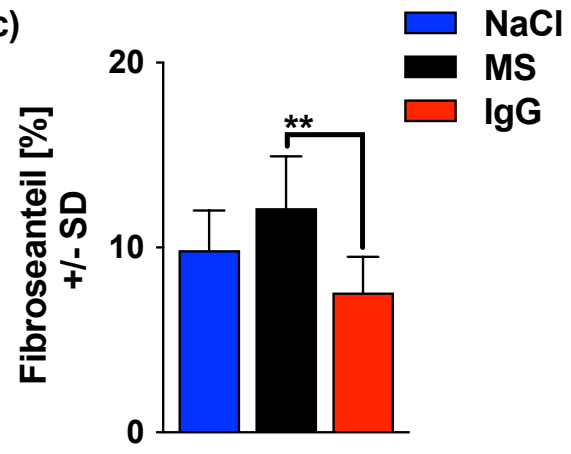

(f)

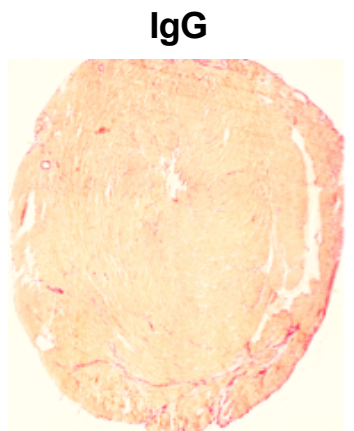

Abbildung 15: Anzahl der T-Zellen und Makrophagen im Herzen pro $\mathbf{~ m m}^{2}$ sowie prozentualer Anteil der Fibrose im gesamten Herzen. (a) Zahl der T-Zellen im Herzen. Nach einer IgG-Behandlung war die Zahl der T-Zellen ( $\left.\mathrm{n}_{\mathrm{NaCl}}=6, \mathrm{n}_{\mathrm{MS}}=7, \mathrm{n}_{\mathrm{IgG}}=8\right)$ in den Herzmuskeln von mdx-Mäusen statistisch signifikant gegenüber den beiden Kontrollgruppen $\mathrm{NaCl}(\mathrm{p}=0,0002)$ und $\mathrm{MS}(\mathrm{p}=0,0003)$ reduziert. (b) Makrophagensignal in Herzen. Das Makrophagensignal ( $\left.\mathrm{n}_{\mathrm{NaCl}}=7, \mathrm{n}_{\mathrm{MS}}=7, \mathrm{n}_{\mathrm{IgG}}=8\right)$ in den mit IgG therapierten Mäuseherzen war ebenfalls signifikant gegenüber der NaCl-Gruppe $(p=0,0015)$ und MS-Gruppe $(p=0,0016)$ erniedrigt (Abb. 15 b). (c) Fibroseanteil in mdx-Herzen. Eine IgG-Therapie führte zudem zu einer Reduktion des auf den muskulären Schaden folgenden fibrotischen Ersatzes im Herzen. Der prozentuale Anteil der Fibrose $\left(\mathrm{n}_{\mathrm{NaCl}}=7, \mathrm{n}_{\mathrm{MS}}\right.$ $=7, \mathrm{n}_{\mathrm{IgG}}=7$ ) an der gesamten Herzmasse war in mit IgG therapierten mdx-Mäusen statistisch signifikant gegenüber den mit MS behandelten Tieren reduziert $(p=0,005)$. Die Ergebnisse sind als Mittelwert mit Standardabweichung dargestellt. Statistische Berechnung mit one-way Anova. $* * \mathrm{p}<0,01, * * * \mathrm{p}<0,001$. Elastikavan-Gieson-Färbung der Herzen nach (d) NaCl- (e) MS- und (f) IgG-Behandlung zur Quantifizierung der Fibrose. 


\section{Diskussion}

Nach einer effektiven dreimonatigen Behandlung mit IgG im mdx-Mausmodell hat die vorliegende Arbeit das Ziel, Verträglichkeit und Wirkung einer langfristigen IgG-Therapie über 18 Monate zu untersuchen. Zu diesem Zweck wurde der Einfluss der Therapie auf gut etablierte klinische und paraklinische Verlaufsparameter untersucht. Diese Studie zeigt, dass IgG auch über einen 18-monatigen Untersuchungszeitraum zu einer statistisch signifikant höheren Laufradaktivität und Kraft in den Vorderläufen führt. Histologisch konnte eine Verringerung der Makrophagen und T-Zellanzahl und der myopathischen Veränderungen durch eine monatliche Therapie mit IgG in einer Dosis von $2 \mathrm{~g} / \mathrm{kg} \mathrm{KG}$ erreicht werden. Mit dieser Studie wurde eine therapeutische Wirkung und Verträglichkeit von IgG bei mdx-Mäusen in den ersten drei Monaten bestätigt und konnte auch in der Langzeitbeobachtung über insgesamt 18 Monate gezeigt werden.

In der aktuellen internationalen Behandlungsleitlinie zur DMD aus dem Jahr 2010 wird als alleinige symptomatische Behandlung eine Therapie mit GS empfohlen (Bushby et al. 2010), da Studien gezeigt haben, dass sich der Erkrankungsprogress dadurch verzögert (Biggar et al. 2006; Manzur et al. 2008). Fenichel et al. (1991) haben die Therapie mit GS über drei Jahre in der bisher längsten beschriebenen randomisierten kontrollierten Studie untersucht und einen geringeren Abfall der Muskelkraft gegenüber nicht therapierten Patienten zeigen können. Eine GS-Therapie führt zu einer Verbesserung der pulmonalen und kardialen Funktion (Mendell et al. 1989; Schram et al. 2013), da es zu einer Reduktion des sarkolemmalen Schadens, der Muskeldegeneration sowie einer Erhöhung der intrazellulären Kalziumkonzentration und Suppression der inflammatorischen Antwort in der Muskulatur von DMD-Patienten (Wehling-Henricks et al. 2004; Fisher et al. 2005) kommt. Die Lebenserwartung der heutigen DMD-Patienten konnte durch GS und andere supportive Therapien, wie regelmäßige Krankengymnastik sowie nicht-invasive Beatmungsmethoden, verlängert werden (Passamano et al. 2012), sodass die Betroffenen heute ein Lebensalter von 20 bis Anfang 40 erreichen (Eagle et al. 2002; Kieny et al. 2013; Strehle und Straub 2015). Bei einer GS-Therapie im mdx-Mausmodell hingegen zeigen sich sehr unterschiedliche Ergebnisse. In manchen Studien kam es zu einer erhöhten Muskelkraft (Hudecki et al. 1993; Granchelli et al. 2000), wiederum in anderen konnte dies nicht bestätigt werden (De Luca et al. 2003). 
DMD-Patienten haben unter anderem aufgrund der oben beschriebenen positiven Effekte der GS-Therapie heute eine erhöhte Lebenserwartung. Da jedoch, um eine ausreichende Wirksamkeit zu erreichen, eine Langzeittherapie in einer Dosierung oberhalb der Cushingschwelle notwendig ist, entwickeln die DMD-Patienten zahlreiche NW, sodass die Therapiedauer begrenzt ist. Die häufigsten bei DMD-Patienten beobachteten unerwünschten Folgeerscheinungen sind Gewichtszunahme, Osteoporose und das Cushing-Syndrom (Mendell et al. 1989; Griggs et al. 1993; Angelini und Peterle 2012). Mit dem Ziel, die Lebenserwartung und -qualität weiter zu verlängern bzw. zu verbessern, wurden in den letzten Jahren zahlreiche präklinische und klinische Untersuchungen zu einer kurativen Gentherapie durchgeführt. So wurde im mdx-Mausmodell erfolgreich eine adenovirusassoziierte (AAV) Übertragung von Minidystrophin (Kochanek et al. 1996; Wang et al. 2000), ein AntisenseOligonukleotid-vermitteltes exon skipping (Mann et al. 2001), ein durch Aminoglykoside vermitteltes read through (Barton-Davis et al. 1999) und ein Transfer von Myloblasten (Karpati et al. 1989; Vilquin et al. 1995) durchgeführt. In einer Anfang 2016 veröffentlichen Studie gelang es durch CRISPR-Cas9-basierte Genom-Editierung eine Expression von modifiziertem Dystrophin herbeizuführen (Nelson et al. 2016). Die oben genannten Gentherapien wurden bzw. werden in klinischen Studien untersucht (Mendell et al. 2013; Bushby et al. 2014; Havens und Hastings 2016). In Europa ist das Read-through-Medikament Ataluren bisher als einziges dieser Gentherapeutika zugelassen (Finkel et al. 2013), dessen klinische Effekte jedoch begrenzt sind. Zudem ist in den USA seit September 2016 Eteplirsen und seit Dezember 2019 Golodirsen zugelassen. Eteplirsen verhindert den Einbau des Exons 51 in die mRNA, sodass der Leserahmen wiederhergestellt wird und ein verkleinertes, jedoch in großen Teilen funktionsfähiges, Dystrophin entsteht. Jedoch ist eine Mutation im Exon 51 nur bei rund $14 \%$ der Betroffenen ursächlich für den Funktionsverlust des DMD-Gens und nur diese kommen entsprechend für eine Therapie mit Eteplirsen in Frage (Lim et al. 2017). Golodirsen ist ein Antisense-Oligonukleotid, das zu einem exon skipping des Exon 53 und einer Produktion eines verkürzten Dystrophinprotein führt. Es wird geschätzt, dass etwa $8 \%$ der Patienten mit DMD eine Mutation im Exon 53 haben und somit für eine Therapie mit Golodirsen in Frage kommen (Heo 2020). Bis es zum routinemäßigen Einsatz von Gentherapeutika bei DMD-Patienten kommen wird, werden noch Jahre vergehen, sodass eine alternative, krankheitsmodulierende Therapie für die heutigen und zukünftigen DMD-Patienten ein großer Gewinn wäre. Zudem wird erwartet, dass eine Immunmodulation bzw. Immunsuppression auch in Zukunft zusätzlich zu den genkorrigierenden Therapien notwendig sein wird. 
Die Diagnose DMD ist nicht immer von Geburt an bekannt, sodass es bei Beginn der Gentherapie neben der myopathischen Schädigung bereits zu einer inflammatorischen Antwort gekommen ist. Auch nach Beginn einer Gentherapie kommt es zu einem gewissen Grad an Inflammation und nur für einige Gentherapien, wie z. B. Eteplirsen, wurde nachgewiesen, dass diese gleichzeitig eine Reduktion der Inflammation herbeiführen (Cirak et al. 2011). Vielmehr kommt es bei einigen Gentherapien, wie bei den AAV-vermittelten Therapien, sogar zu einer zusätzlich induzierten akuten oder chronischen inflammatorischen Antwort (Yuasa et al. 2002; Hareendran et al. 2013). Auch hinsichtlich einer zur GS-Therapie alternativen, immunsuppressiven Therapie wurden in den letzten Jahren zahlreiche Untersuchungen durchgeführt und verschiedene immunsuppressive Substanzen wurden bereits erfolgreich im mdx-Mausmodell eingesetzt (Grounds und Torrisi 2004; De Luca et al. 2005; Hodgetts et al. 2006; Heier et al. 2013). Allerdings erzielten die bisher in klinischen Studien an DMD-Patienten getesteten Immunsuppressiva, wie beispielsweise Ciclosporin (Kirschner et al. 2010), keine ausreichende Wirksamkeit. Es wird entsprechend weiter nach einer Alternative zu GS gesucht.

Mit der vorliegenden Studie wurde nun der langfristige Einsatz von IgG als immunmodulierende Therapie im mdx-Mausmodell untersucht. Das Medikament weist ein im Vergleich zu GS und anderen Immunsuppressiva geringeres NW-Profil auf. Bis zum jetzigen Zeitpunkt gab es noch keine murine Studie, weder mit dem mdx-Mausmodell noch einem anderen Mausmodell, in der eine Therapie mit IgG über einen so langen Zeitraum untersucht wurde. Die längste murine Studie mit humanem IgG wurde in einem Mausmodell zur AlzheimerKrankheit über einen Zeitraum von insgesamt acht Monaten durchgeführt. Die IgG haben sich in dieser Zeit als gut verträglich erwiesen (Puli et al. 2012).

Die Notwendigkeit der 18-monatigen Dauer der aktuellen Studie beruht darauf, dass die chronische dystropathologische Phase bei der mdx-Maus erst nach dem zwölften Lebensmonat beginnt (Coulton et al. 1988; Muntoni et al. 1993) und schließlich die Kumulation der dystropathologischen Veränderungen bei mehr als 15 Monate alten mdx-Mäusen zu einem progredienten fibrotischen Ersatz der Muskulatur führt (Lefaucheur et al. 1995). Dementsprechend sind unsere Studienergebnisse der Wirkung einer IgG-Therapie auf das klinische Erscheinungsbild und paraklinische Parameter von mdx-Mäusen in einer späten Krankheitsphase mit dem oben beschriebenen ausgeprägten Phänotyp auch hinsichtlich der Übertragbarkeit auf DMD-Patienten interessant. 
Um therapeutische Effekte in Studien darzustellen, ist es nötig, ein sensitives EvaluationsSystem zu verwenden. Das internationale Netzwerk Treat-NMD, dessen Ziel es ist präklinische und klinische Studien von neuromuskulären Erkrankungen zu vereinheitlichen, empfiehlt in seinen SOPs das in dieser Studie verwendete Laufradsystem zur Evaluation der Mausaktivität (Grounds et al. 2008). In der IgG-Gruppe kam es zu einer gegenüber den Kontrollen signifikant höheren freiwilligen Laufradaktivität während des gesamten Behandlungszeitraums. Die lineare Regressionsanalyse zeigte einen signifikant geringeren Abfall der IgG-Gruppe in allen durch das Laufradsystem erfassten Parametern. Ein Resultat, das mit der mdx-Studie zur IgG-Therapie in der Frühphase, in der sich ebenfalls ein statistisch signifikanter geringerer Abfall in der linearen Regression ab der zwölften Woche zeigte, übereinstimmt (Zschüntzsch et al. 2016). Physiologischerweise kommt es bei einem dauerhaften Training in der Skelettmuskulatur zu einer Vielzahl von Adaptationsmechanismen, wie Muskelfaserhypertrophie, einem Fasertypenwechsel, einer Beeinflussung des Muskelmetabolismus (Lieber und Fridén 2002), einer erhöhten Mitochondrienzahl, sowie gesteigerter Mitochondrienaktivität und oxidativer Kapazität (Holloszy 1967; Röckl et al. 2007). Die Auswirkungen auf die Muskulatur bei mdx-Mäusen ist abhängig von der Trainingsart. Das unfreiwillige und kurzfristige intensive Laufbandtraining führt zu einem höheren Schaden in der Muskulatur von mdx-Mäusen (Okano et al. 2005). Die freiwillige Laufradnutzung hingegen hatte in keiner der bisher beschriebenen Untersuchungen einen negativen Einfluss auf die Muskulatur. Nach vier- oder zwölfmonatiger Laufradnutzung zeigte sich eine höhere Krafterzeugungskapazität (Hayes und Williams 1996; Selsby et al. 2013) oder keine Differenz im Vergleich zu nicht gelaufenen Kontrollen (Dupont-Versteegden et al. 1994; Carter et al. 1995). Die bisher längste Studie erfasste das Laufverhalten von mdx-Tieren über zwölf Monate. Dabei wurde nur die Laufdistanz bestimmt (Selsby et al. 2013). Demnach ist dies die erste Studie, welche die Laufradaktivität in der späten und krankheitsrelevanten Phase von mdx-Mäusen untersucht hat. Bekanntermaßen kann es bei dem verwendeten Laufradsystem zu stark interindividueller Varianz in der Nutzung des Laufrades zwischen den Tieren kommen (Grounds et al. 2008; Smythe und White 2011). Eine genaue Ursache für die Schwankungen ist nicht bekannt. Die Mäuse können hinsichtlich ihrer Intensität und Dauer der Laufradnutzung in Gruppen eingeteilt werden. In diese Arbeit wurden sowohl schwache als auch starke Läufer eingeschlossen und nur die Ergebnisse von Mäusen, die gar nicht gelaufen sind, aus der Wertung ausgeschlossen. Bei anderen Laufradstudien mit mdx-Mäusen sind hingegen auch die schwachen Läufer aus der Wertung ausgeschlossen worden. So lässt sich auch erklären, dass z. B. bei Selsby et al. (2013) während des maximalen Peaks 
die durchschnittliche Laufdistanz eines Tieres bei ca. $14000 \mathrm{~m} / 24 \mathrm{~h}$ lag und in dieser Arbeit bei ca. $6300 \mathrm{~m} / 24$ h. Das freiwillige Training im Laufrad diente in dieser Untersuchung als Maß, um krankheitsmodifizierende Effekte einer Therapie mit IgG zu ermitteln.

In dieser Arbeit war die Laufradaktivität von Weibchen im Vergleich zu Männchen niedriger. Damit die Ergebnisse der linearen Regression und Behandlungseffekte geschlechtsunabhängig betrachtet werden können, wurde für die statistische Auswertung der Laufraddaten ein Modell mit random subject intercept gewählt, das Geschlechtsunterschiede adjustiert. Es ist bekannt, das hormonelle Geschlechtsunterschiede die Muskulatur beeinflussen und die Östrogenkonzentration dabei eine entscheidende Rolle spielt. Beispielsweise wird von einer erhöhten Sensibilität gegenüber Schädigung bei sechs Wochen alten weiblichen mdxMäusen im Vergleich zu männlichen mdx-Mäusen berichtet sowie einem höheren Fibrosegrad in der Muskulatur bei alten weiblichen mdx-Mäusen (Salimena et al. 2004). Zusätzlich konnte eine geschlechtsabhängige Wirkung von Medikamenten nachgewiesen werden (Franconi et al. 2007).

Im Weiteren empfiehlt Treat-NMD, die durch das Laufradsystem erhobenen Ergebnisse therapeutischer Effekte auf körperliche Aktivität durch weitere In-vivo- (z. B. Griffkraftmessung) und Ex-vivo-Untersuchungen (z. B. isometrische Kontraktionsmessung) zu quantifizieren. In dieser Studie wurde als In-vivo-Test wöchentlich die Griffkraft der Vorderläufe gemessen. Dabei erzielten die mit IgG behandelten Tiere ab der 30. Woche signifikant höhere Werte gegenüber den Kontrollen. Zschüntzsch et al. (2016) hatten den Einfluss der Therapie mit IgG und Weller et al. (2012) von freiem und liposomalem Prednisolon in der Frühphase der Erkrankung auf die Griffkraft untersucht. In diesen Studien hatte eine immunmodulierende Therapie keinen Einfluss auf die Griffkraft der Vorderläufe gezeigt. Die Griffkraftmessung wird von vielen Variablen beeinflusst, wie Ermüdung, Kognition oder Lernfähigkeit, welche unabhängig von der Muskelfunktion sind. Zudem beschrieben zahlreiche Studien einen negativen Effekt von Training auf die Griffkraft (De Luca et al. 2005; Spurney et al. 2009). Dennoch scheint sich eine längere Behandlungsdauer mit IgG positiv auf die Griffkraft auszuwirken.

Die progrediente Herzinsuffizienz ist einer der lebenslimitierenden Faktoren der DMD. Auch bei mdx-Mäusen kommt es zu einer kardialen Beteiligung. Dementsprechend wurde in dieser Arbeit als weiterer klinischer Parameter die Herzfunktion in regelmäßigen 
Abständen echokardiografisch untersucht. Hier zeigte die mit IgG therapierte Gruppe nach 18 Monaten bessere Werte der kardialen Funktionsparameter EF und FAS. In früheren Studien fanden sich uneinheitliche Ergebnisse zum Beginn der kardialen Manifestation und damit dem Zeitpunkt von dem an Veränderungen echokardiografischer Parameter bei mdxMäusen gegenüber Wildtyp-Mäusen zu sehen sind. So berichten Spurnley et al. (2010) von einer gegenüber Wildtyp-Mäusen verringerten EF und Verkürzungsfraktion (engl:: fractional shortening, $\mathrm{FS})$ bei mdx-Mäusen nach neun bis zehn Monaten $\left(\mathrm{EF}_{\mathrm{mdx}}=40 \%\right.$, $\mathrm{EF}_{\text {Wildtyp }}$ $=54 \%, \mathrm{FS}_{\mathrm{mdx}}=23,5 \%, \mathrm{FS}_{\mathrm{Wildtyp}}=33,6 \%$ ) und Quinlan et al. (2004) nach zwölf Monaten $\left(\mathrm{EF}_{\mathrm{mdx}}=50 \%, \mathrm{EF}_{\mathrm{Wildtyp}}=54 \%, \mathrm{FS}_{\mathrm{mdx}}=26 \%, \mathrm{FS}_{\text {Wildtyp }}=28 \%\right)$. Die Variabilität zwischen den Studienergebnissen lässt sich auf die Untersucherabhängigkeit dieser Methode, die natürlichen interindividuellen Schwankungen im Krankheitsprogress und dem damit verbundenen Beginn der DCM, zurückführen. In den bisherigen Studien wurde die FS bestimmt. $\mathrm{Zu}$ ihrer Berechnung wird der linksventrikuläre endsystolische Durchmesser vom linksventrikulären enddiastolischen Durchmesser (LVEDD) subtrahiert und dieses Ergebnis durch den LVEDD geteilt. Die FS ist jedoch nur dann verwertbar, wenn eine Ventrikelsymmetrie sichergestellt ist. Bei verschiedenen Krankheitsbildern wie auch der DCM bei der DMD, bzw. bei den mdx-Mäusen, ist eine symmetrische Ventrikelwand aber nur selten gegeben, sodass in diesen Fällen empfohlen wird, die FAS zu bestimmen. Zudem hat sich für die FS gezeigt, dass geringe Veränderung der Positionierung des Querschnitts bereits zu signifikanten Veränderungen der Messergebnisse führen (Stypmann et al. 2009), wohingegen selbst größere positionelle Veränderungen zu keinen relevanten Unterschieden der ermittelten FAS-Ergebnisse geführt haben (Domanski et al. 1992). Folglich impliziert eine Veränderung der FAS auch eine reproduzierbare und valide Veränderung in der Kontraktionsfunktion. Zudem ist die Bestimmung der FAS wegen der geringeren Untersucherabhängigkeit auch für den klinischen Alltag vorteilhaft.

In unserer Studie wurde nun erstmalig der positive Effekt einer immunmodulatorischen Therapie auf die kardiale Funktion und die histopathologischen Veränderungen des Herzens bei gleichzeitiger freiwilliger Laufradnutzung nachgewiesen. Die Auswirkungen von Immunsuppressiva auf die kardiale Funktion sind in früheren Studien untersucht worden. Ermolova et al. (2014) zeigten in einer Studie mit den TNF-Antikörpern Remicade und Enbrel negative Auswirkungen auf die kardiale Funktion von mdx-Mäusen. Es gibt Hinweise darauf, dass diese TNF-Antikörper sogar eine DCM induzieren können. So berichten einige klinische Studien und Fallberichte vom Neuauftreten bzw. dem Progress einer Herzinsuffizienz unter 
der Therapie mit diesen Medikamenten (de' Clari et al. 2002; Kwon et al. 2003; Leetmaa und Markenvard 2005; Synetos et al. 2009). Die Studienergebnisse zur Auswirkung der aktuell empfohlenen immunsuppressiven Therapie mit GS auf das Herz sind uneinheitlich. Neuere Studien jedoch beschreiben einen negativen Einfluss auf die Hämodynamik der Herzen von mdx-Mäusen (Bauer et al. 2009; Guerron et al. 2010). Dieser negative Einfluss bleibt auch bei einer zusätzlichen Therapie mit Medikamenten bestehen, die einen nachgewiesenen positiven Effekt auf diese Parameter haben, wie ACE-Hemmer oder Spironolacton (Janssen et al. 2014).

Ziel einer immunmodulierenden Therapie ist die Reduktion inflammatorischer Zellen. In den vorliegenden histopathologischen Untersuchungen konnte eine statistisch signifikante Reduktion der Makrophagen, T-Zellen und fibrotisch umgebauten Anteile im Herzmuskel von mit IgG behandelten mdx-Mäusen gezeigt werden. Andere Therapiestudien haben bereits von einem positiven Effekt einer immunsuppressiven Therapie auf den fibrotischen Umbau in der Muskulatur berichtet. Eine Reduktion von Fibrose im Diaphragma konnte durch eine Vielzahl von immunsuppressiven Therapien erzielt werden. Jedoch konnte eine gleichzeitige Reduktion des fibrotischen Umbau in der Herzmuskulatur in bisherigen Studien nur durch einige immunsuppressive Therapien, wie dem TGF- $\beta$-Antikörper Halofuginone und dem TNF- $\alpha$-Antikörper Remicade, erzielt werden (Zhou und Lu 2010; Ermolova et al. 2014). Es wird vermutet, dass der fibrotische Umbau durch die Inflammation begünstigt wird. Weiter wird angenommen, dass der fibrotische Ersatz der Muskulatur die sich entwickelnde DCM bedingt, da sich die kardiale Beteiligung klinisch erst in der Phase manifestiert, in der eine Zunahme des fibrotischen Ersatzes beschrieben wird. Die Ergebnisse dieser Studie unterstützen diese Annahme, da es durch die immunmodulierende Therapie mit IgG zu einer Reduktion der Inflammation in der Herzmuskulatur und folglich zu einer verringerten Fibrose kam, womit sich auch die höheren Werte der kardialen Funktionsparameter EF und FAS unter IgG-Behandlung erklären lassen. Dies weist darauf hin, dass durch eine IgG-Therapie der Entwicklungsprozess einer DCM bei DMD-Patienten und den weiblichen Mutationsträgern verzögert oder ggf. sogar verhindert werden könnte.

In früheren Studien wurde gezeigt, dass das Myokard von mdx-Mäusen verglichen mit Wildtyp-Mäusen bei einer akuten Drucküberlastung, wie sie bei arterieller Hypertonie oder der intravenösen Medikamentengabe entsteht, deutlich mehr geschädigt wurde (Kamogawa et 
al. 2001). Um eine Druckbelastung bei einer IVIG-Therapie so gering wie möglich zu halten ist es empfehlenswert die Gesamtdosis über fünf Tage verteilt oder IgG s. c. zu applizieren.

In den zuvor diskutierten klinischen Parametern, wie Laufradaktivität und Griffkraftmessung, fallen bei den mdx-Mäusen mit NaCl-Therapie im Vergleich zur anderen Kontrollgruppe mit MS-Therapie deutlich bessere Ergebnisse auf, sodass sich die Frage nach einem supportiven Effekt bei der Applikation von $\mathrm{NaCl}$ stellt. In der Literatur wird keine Studie beschrieben, welche die therapeutische Wirkung von $\mathrm{NaCl}$ bei mdx-Mäusen untersucht hat. Eine Erklärung für unser Ergebnis liegt möglicherweise in der Aktivierung des tonicityresponsive enhancer binding protein (NFAT5), einem Transkriptionsfaktor der Rel-Familie mit osmoregulierender Funktion. Erstmals wurde die Aktivität dieses Proteins in der Niere beschrieben. Aber später konnte eine ubiquitäre Expression dieses Enzyms in allen Zelltypen gezeigt werden (López-Rodríguez et al. 1999; Miyakawa et al. 1999; Dalski et al. 2000; Trama et al. 2000). NFAT5 schützt die Zelle vor hypertonem Stress. Ist der osmolare Druck in der Zelle isoosmolar, ist NFAT5 nur partiell aktiv. Steigt der osmolare Druck in der Zelle an, wird das Protein verstärkt transkribiert, was wiederum zur Transkription von Genen verschiedener Proteine, wie dem Natrium/Myo-Inositol-Kotransporter (SMIT), dem NaCl/Taurine-Kotransporter (TauT), der Aldosereduktase und einer Erhöhung weiterer osmotisch aktiver Moleküle führt. Diese Moleküle sind osmotisch aktiv und elektrisch neutral. Folglich sinkt der osmotische Druck an der Zellwand und die Ionenstärke in der Zelle. Bei einer Gabe von $\mathrm{NaCl}$ kommt es zu einer Verschiebung des osmotischen Gleichgewichts in den Zellen und demnach auch in den Muskelzellen. Zur Bedeutung von NFAT5 in neuromuskulären Erkrankungen gibt es nur wenige Studien. In einer Studie mit NFAT5-defizienten Mäusen konnte gezeigt werden, dass die Expression von NFAT5 zu einer Myoblastenmigration- und Differenzierung im Rahmen von muskulärer Regeneration führt (O'Connor et al. 2007). In einer Studie von De Paepe et al. (2016) wurde die im Vergleich zu anderen Myopathien höchste Konzentration der Aldosereduktase in Muskelbiopsien von Patienten mit DMD detektiert. Die Expression des TauT und des SMIT wurde in den Muskelfasern, vor allem den regenerierenden und atrophen Fasern, dieser Patienten induziert (De Paepe et al. 2016). Unsere Studienergebnisse legen einen möglichen positiven Effekt von $\mathrm{NaCl}$ nahe und sprechen für eine nähergehende Untersuchung der zugrundeliegenden Effekte.

In der Albumin- und MS-Kontrollgruppe kam es zu unerwarteter Unverträglichkeit. Zschüntzsch et al. (2016) hatten in der Studie zur IgG-Behandlung in den ersten drei 
Monaten komplikationslos humanes Albumin als Kontrollsubstanz injiziert. In unserer Studie verstarben die mit Humanalbumin therapierten Tiere nach der vierten Injektion. Die Obduktion eines mit Humanalbumin behandelten Tieres zeigte die Entwicklung eines mesenchymalen Tumors. Chamberlain et al. (2007) berichteten erstmals vom Auftreten eines Rhabdomyosarkoms, einem mesenchymalen Tumor, im mdx-Mausmodell. Es wurde beobachtet, dass Rhabdomyosarkome erst nach dem zwölften Lebensmonat und auch bei Mäusen mit einem $\alpha$-Sarkoglykan-Mangel, einem Membranprotein des Sarkolemms das ebenfalls dem dystrophinassoziierten Glykoproteinkomplexes angehört, auftreten (Chamberlain et al. 2007; Fernandez et al. 2010). In diesem Zusammenhang ist zu erwähnen, dass Dystrophin auch als Tumorsuppressor fungiert (Wang et al. 2014). Das als Ersatzkontrolle verwendete MS wurde von den Mäusen unzureichend toleriert, sodass diese Gruppe frühzeitig beendet werden musste. In einer post mortem durchgeführten Obduktion fand man eine chronische interstitielle und glomeruläre Nephritis mit begleitender Glomerulosklerose und Rindenatrophie.

Neben den therapeutischen Effekten einer IgG-Behandlung auf die klinischen Parameter zeigte sich auch ein positiver Einfluss dieser Therapie auf die paraklinischen Parameter. So zeigte sich in dieser Studie bei den mit IgG behandelten Mäusen ein Trend zu einer geringeren CK-Serumkonzentration und das obwohl die Tiere eine höhere Laufleistung aufwiesen. Durch körperliche Aktivität erhöht sich physiologisch die CK im Serum (Young 1984). Dementsprechend führt auch körperliches Training bei mdx-Mäusen zu einem weiteren Anstieg der aufgrund der Grunderkrankung bereits erhöhten CK-Konzentration (De Luca et al. 2005). Grund dafür könnte ein Rückgang des belastungsabhängigen Muskelzelluntergangs bei einer Behandlung mit IgG sein. In vorherigen Studien hatte sich gezeigt, dass eine immunsuppressive Therapie zu einer Reduktion der Serum-CK-Konzentration führt. So kam es bei mdx-Mäusen, die mit Ciclosporin therapiert und bei denen regelmäßige Griffkraftmessungen erhoben wurden (De Luca et al. 2005), sowie bei einer dreimonatigen IgG-Therapie und gleichzeitigem freiwilligen Laufradtraining (Zschüntzsch et al. 2016), zu einer reduzierten Konzentration der CK im Serum gegenüber nicht therapierten mdx-Mäusen. Die hohe Variabilität der CK-Konzentration innerhalb einer Gruppe lässt sich z. B. auf die Unterschiede im Laufradverhalten der Mäuse zurückführen. Zur CK-Konzentration in der Krankheitsphase von 18 Monaten finden sich in der Literatur keine vergleichbaren Angaben. 
Die Veränderungen in der Muskulatur von mdx-Mäusen gegenüber Wildtyp-Mäusen zeigt sich auch durch ein verändertes Expressionsprofil von Zytokinen. In dieser Studie zeigte sich kein einheitlicher Einfluss einer 18-monatigen IgG-Therapie auf die Expression von TGF- $\beta$, SPP1 und MCP1 in den Extremitätenmuskeln und dem Diaphragma. Mit dem fibrotischen Umbau des Muskels bei mdx-Tieren sind v. a. die Zytokine MCP1 und SPP1 als Modulatoren von TGF- $\beta$ assoziiert. Entsprechend dem Ausmaß der Inflammation sind auch TGF- $\beta$ und folglich der Fibrosierungsgrad erhöht (Bernasconi et al. 1995; Vetrone et al. 2009). SPP1 wird als Teil der Reparaturvorgänge in Makrophagen hochreguliert, führt zu einer Verringerung von TGF- $\beta$ und hat eine chemotaktische Rolle. MCP1 wiederum wird von mononukleären Zellen freigesetzt und hat ebenfalls eine chemotaktische Rolle, indem es die Migration und Infiltration von Monozyten und Makrophagen reguliert und folglich fördernd auf Reparaturvorgänge wirkt (Leonard und Yoshimura 1990; Deshmane et al. 2009).

Die bisherige Studienlage zur Wirkung einer Immunmodulation auf die mRNA-Expression von TGF- $\beta$, SPP1 und MCP1 ist uneinheitlich. Nach einer zweimonatigen Therapie mit freiem oder liposomalem Prednisolon zeigte sich keine Beeinflussung der mRNA-Expression von TGF- $\beta$, SPP1 und MCP1 (Weller et al. 2012). Hartel et el. (2001) hingegen konnten eine Reduktion von TGF- $\beta$ im Diaphragma durch eine Therapie mit Prednisolon zeigen. Bei einer IgG-Therapie in der Frühphase der Erkrankung war die mRNA-Expression von TGF- $\beta$, SPP1 und MCP1 im M. quadriceps femoris, sowie auch MCP1 im Diaphragma, gegenüber Kontrollen reduziert, wobei nur die mRNA-Expression von SSP1 im M. quadriecps femoris gegenüber Kontrollen statistisch signifikant erniedrigt war (Zschüntzsch et al. 2016). Es gibt keine Studie, welche die Höhe der TGF- $\beta-$, SPP1- und MCP1-mRNAExpression bei 18 Monate alten mdx-Mäusen untersucht hat. Die Expression aller o. g. Mediatoren ist im Diaphragma der 18 Monate alten Mäuse gegenüber den Extremitätenmuskeln deutlich erhöht. Zwischen den Behandlungsgruppen der aktuellen Studie gab es keine signifikanten Unterschiede. In früheren Studien wurde bereits in der Frühphase der Erkrankung eine erhöhte Expression der Mediatoren TGF- $\beta$, SSP1 und MCP1 im Diaphragma beschrieben (Weller et al. 2012; Zschüntzsch et al. 2016). Dies ist vermutlich auch auf die bereits früh auftretenden, ausgeprägten dystropathologischen Veränderungen, mit einer höheren Degeneration gegenüber der Skelettmuskulatur und einem ausgeprägterem fibrotischen Umbau zurückzuführen. Des Weiteren weist das Diaphragma auch bei den über zwölf Monate alten Mäusen die stärksten dystropathologischen Veränderungen von allen Muskeln auf. 
Von besonderem Interesse ist eine differenzierte Analyse der Zytokine für die stattfindenden Regenerationsvorgänge nach einer Muskelschädigung. Die M1/Th1-Antwort mit dem Überwiegen der Zytokine trägt maßgeblich zum Abbau des geschädigten Muskels, sowie zur Proliferation von Satellitenzellen, bei. Die M2/Th2-Antwort ist an der Differenzierung von regenerierenden Muskelfasern beteiligt. Wird nun durch Immunsuppressiva einer dieser Wege komplett gehemmt, ist eine Muskelregeneration nicht regelrecht möglich. Die Analyse der Regenerationsprozesse war nicht Gegenstand der aktuellen Studie und sollte im Verlauf noch detaillierter untersucht werden.

Neben den Zytokinen und Chemokinen sind verschiedene entzündliche Zellen an der Progression der mdx-Pathologie beteiligt. Dazu zählen die Infiltration von Makrophagen und T-Zellen. In der aktuellen Studie findet sich eine statistisch signifikant verringerte Inflammation mit Makrophagen und CD4-positiven T-Zellen unter der immunmodulierenden Therapie mit IgG. Passend dazu war es in der Frühphase der Erkrankung ebenfalls zu einer reduzierten Anzahl von Makrophagen und T-Zellen unter IgG-Therapie gekommen (Zschüntzsch et al. 2016). Zahlreiche Studien beschreiben, dass eine Inhibition oder Depletion von Makrophagen oder T-Zellen eine Reduktion myopathischer Umbauvorgänge zur Folge hat (Spencer et al. 2001). Auch in unserer Studie zeigte sich dieser Zusammenhang und eine gleichzeitige Reduktion der myopathischen Veränderungen durch die immunmodulierende Therapie gegenüber Kontrollgruppen, was sich in einem verringerten CNI in Diaphragma, M. gastrocnemius, M. tibialis anterior und M. quadriceps femoris äußerte. Jedoch zeigte unsere Studie in allen Gruppen eine hohe Variabilität der Muskelfaserdurchmesser, zudem wurde der mittlere Faserdurchmesser nicht durch die Behandlung beeinflusst. In verschiedenen Studien konnte bereits zuvor gezeigt werden, dass eine freiwillige Laufradnutzung nicht zu einer Exazerbation der dystrophen Veränderung im Muskel von mdx-Mäusen führt (Landisch et al. 2008; Baltgalvis et al. 2012). Die Reduktion des CNI bei langfristiger IgG-Therapie bestätigt die Beobachtungen von Zschüntzsch et al. (2016), welche ebenfalls einen reduzierten CNI in Diaphragma und M. quadriceps femoris nach einer dreimonatigen Therapie nachwiesen. In den bisherigen Studien zeigten sich gegensätzliche Ergebnisse zur CNI-Reduktion durch eine GS-Therapie (Anderson et al. 1996; Baltgalvis et al. 2009; Weller et al. 2012). Die hohe Variabilität der Faserdurchmesser ist kennzeichnend für mdx-Muskeln und wird auf den sich wiederholenden De- und Regenerations-Zyklus zurückgeführt, sodass immer Fasern in verschiedenen Stadien nebeneinander auftreten. 
Der positive Einfluss einer immunmodulierenden Therapie, wie mit dem in unserer Studie verwendeten IgG, spiegelt sich demnach auch in der Muskelpathologie wider, da die Zahl der Makrophagen und T-Zellen lediglich reduziert und ihre Einwanderung nicht komplett inhibiert wird. Dies ist darin begründet, dass Makrophagen und T-Zellen, wie bereits oben beschrieben, keine durchweg schädigende Wirkung haben. Denn in früheren Studien wurde eine Förderung des muskulären Wachstums sowie eine Erhöhung der Regenerations- und Reparaturprozesse durch Makrophagen beschrieben. In diesem Zusammenhang lassen sich die bisherigen negativen Studienergebnisse mit immunsuppressiven Therapien, z. B. mit Ciclosporin (Kirschner et al. 2010), bei DMD-Patienten erklären. Eine immunmodulierende Therapie mit IgG hingegen ermöglicht weiterhin den Ablauf regenerativer Prozesse in der Muskulatur von mdx-Mäusen, wie die Ergebnisse unserer paraklinischen Parameter beweisen und sich sekundär auch in den positiven Ergebnissen der klinischen Parameter widerspiegelt. 


\section{$5 \quad$ Zusammenfassung}

Die Muskeldystrophie Duchenne ist mit einer Inzidenz von 1:3500 bei neugeborenen Jungen die häufigste erbliche Myopathie. Ursächlich für die Entstehung sind Mutationen im Dystrophin-Gen, einem subsarkolemmal gelegenen Protein, dessen Verlust zu Membranschädigung, einer Störung des dystrophinassoziierten Glykoproteinkomplex, Nekrose sowie dem bindegewebigem Ersatz der Muskulatur führt. Bis zum definitiven Einsatz von genmodulierenden Therapien bleibt der Einsatz von Immunsuppressiva, wie den Glukokortikosteroiden, die etablierte Standardtherapie. In zahlreichen Studien konnte gezeigt werden, dass eine langjährige Behandlung mit Glukokortikosteroiden das Fortschreiten der Muskeldystrophie Duchenne verzögert und die Lebenserwartung der Patienten verlängert. Allerdings ist der Einsatz von Glukokortikosteroiden durch ein ungünstiges Nebenwirkungsprofil eingeschränkt, sodass nach einer alternativen immunsuppressiven Behandlung gesucht wird. Die bereits bei anderen Erkrankungen erfolgreich eingesetzten humanen Immunglobuline stellen dabei eine weitere, bisher nicht untersuchte, Behandlungsmöglichkeit dar. In einer früheren Studie mit mdx-Mäusen wurde bereits erfolgreich eine Behandlung mit humanem Immunglobulin über drei Monate durchgeführt. Es kam bei den mit Immunglobulinen behandelten mdx-Mäusen zu einer stabileren Aktivität im Laufrad und einer höheren Ausdauer in der Exvivo-Muskelkraftmessung gegenüber unbehandelten Kontrollgruppen. Weiter ist es zu einer reduzierten Inflammation und weniger myopathischen Veränderungen in der Muskulatur gekommen.

Die vorliegende Arbeit hat das Ziel den Langzeitverlauf einer Behandlung mit Immunglobulin G über 18 Monate auf diverse klinische und paraklinische Verlaufsparameter zu untersuchen. Als klinische Parameter wurden Laufradaktivität, Ex-vivo-Muskelkontraktionskraft sowie Griffkraftmessung und als paraklinische Parameter die Kreatinkinase-Konzentration im Serum, Messenger-Ribonukleinsäure-Expression von relevanten Mediatoren, Zahl der CD4-positiven T-Zellen und Makrophagen sowie histopathologische Veränderungen untersucht.

Dabei wurden erstmalig mdx-Mäuse über einen Zeitraum von 18 Monaten mit einer immunmodulierenden Substanz behandelt und somit der Krankheitsverlauf nicht nur in der akut inflammatorischen, sondern auch der chronisch inflammatorisch-dystropathologischen Krankheitsphase untersucht. Die Daten der vorliegenden Langzeitstudie unterstreichen die 
fortbestehende Relevanz der reaktiven inflammatorischen Antwort in dystrophindefizienter Muskulatur von 18 Monate alten Tieren. Infolge einer 18-monatigen Therapie mit humanem Immunglobin zeigte sich eine Reduktion der myopathischen Veränderungen, eingewanderter T-Zellen und Makrophagen in der Skelett- und Herzmuskulatur. Gleichzeitig war die Freisetzung des Muskelenzyms Kreatinkinase nach einer Immunglobulin-Behandlung über 18 Monate verringert. Die Immunglobulin-Behandlung hatte eine Reduktion der Anzahl von Muskelfasern mit einem zentralisierten Zellkern zur Folge, was als Indikator für eine Reduktion der myopathischen Veränderungen gilt. Die Reduktion der Inflammation sowie der myopathischen Veränderungen führte zu einem positiven Effekt auf verschiedene klinische Parameter. So kommt es unter der Behandlung zu einem verbesserten Laufverhalten im Laufrad und einer höheren Griffkraft. Zudem zeigte sich in den regelmäßig durchgeführten Echokardiografien eine verbesserte linksventrikuläre Pumpfunktion. Diese in den paraklinischen und klinischen Untersuchungen erzielten besseren Ergebnisse der Tiere mit einer Immunglobulin-Behandlung gegenüber den Kontrollgruppen können als Ergebnis des immunmodulierenden Effektes einer langfristigen Immunglobulin-Therapie angesehen werden. In den letzten Jahren gab es zahlreiche Studien zu einer kurativen Gentherapie. In Europa ist bisher einzig das Read-through-Medikament Ataluren zugelassen. Zudem ist in den Vereinigten Staaten von Amerika Eteplirsen und Golodirsen zugelassen. Da aber nur bei insgesamt rund $35 \%$ der Betroffenen eine Nonsense-Mutation, eine Mutation im Exon 51 oder Exon 53 vorliegt, kommt nur ein geringer Anteil der Betroffenen für eine Therapie mit Ataluren, Eteplirsen oder Golodirsen in Frage. Bis es zum routinemäßigen Einsatz von Gentherapeutika bei Duchenne-Patienten kommen wird, werden noch Jahre vergehen. Zudem wird erwartet, dass eine Immunmodulation bzw. Immunsuppression auch in Zukunft in der Kombination mit genkorrigierenden Therapien notwendig sein wird. In den meisten Fällen wird eine Muskeldystrophie Duchenne im Kleinkindalter diagnostiziert, sodass bei Beginn der etwaigen Gentherapie neben der myopathischen Schädigung bereits ein gewisser Grad an Inflammation stattgefunden hat. Die Studien haben gezeigt, dass nur einige der eingesetzten Gentherapien zu einer gleichzeitigen Reduktion der Inflammation führen. Bei einigen Gentherapien, zum Beispiel den Therapien mit Adeno-assoziierten Viren, kommt es sogar zu einer zusätzlich induzierten akuten oder chronischen inflammatorischen Antwort. Dementsprechend wird auch in Zukunft bei einer genkorrigierenden Therapie eine zusätzliche immunsuppressive Therapie nötig sein, und dabei ist ein Einsatz von Immunglobulinen in Ergänzung oder als Alternative zu Glukokortikosteroiden denkbar. Auch wenn eine Immunglobulin-Behandlung kostenintensiv wäre und die Erkrankung nicht heilen könnte, so würde 
diese Therapie doch eine gut verträgliche immunmodulatorische Therapiealternative für Patienten mit Muskeldystrophie Duchenne darstellen. Es wäre wünschenswert, wenn weitere Studien die präklinischen Ergebnisse unterstützen könnten. Humanes Immunglobulin wird seit über 30 Jahren zur Behandlung verschiedener Krankheitsbilder eingesetzt, sodass es ausgiebige Erfahrungen über das akute und langfristige Nebenwirkungsprofil gibt. Dies ist insbesondere ein großer Vorteil dieses Medikamentes gegenüber den zahlreichen neuen immunmodulierenden bzw. immunsuppressiven Medikamenten, welche in den letzten Jahren zugelassen worden sind und für die noch keine Daten zu den langfristigen Nebenwirkungen vorliegen.

Nach den positiven Ergebnissen einer Immunglobulin G-Behandlung in dieser präklinischen Studie über 18 Monate und einer früheren Studie über drei Monate (Zschüntzsch et al. 2016) sollte eine klinische Studie bei DMD-Patienten erwogen werden. 


\section{$6 \quad$ Literaturverzeichnis}

Acharyya S, Villalta SA, Bakkar N, Bupha-Intr T, Janssen PM, Carathers M, Li ZW, Beg AA, Ghosh S, Sahenk Z et al. (2007): Interplay of IKK/NF-kappaB signaling in macrophages and myofibers promotes muscle degeneration in Duchenne muscular dystrophy. $\mathrm{J}$ Clin Invest 117, 889-901

Ahsan N, Palmer BF, Wheeler D, Greenlee RG Jr, Toto RD (1994): Intravenous immunoglobulin-induced osmotic nephrosis. Arch Intern Med 154, 1985-1987

Allen DH: Mechanics Reborn. In: Allen DH (Hrsg.): How mechanics shaped the modern world. Springer International Publishing, Basel 2014, 150-184

Anderson JE, McIntosh LM, Poettcker R (1996): Deflazacort but not prednisone improves both muscle repair and fiber growth in diaphragm and limb muscle in vivo in the mdx dystrophic mouse. Muscle Nerve $\underline{19}, 1576-1585$

Angelini C, Peterle E (2012): Old and new therapeutic developments in steroid treatment in Duchenne muscular dystrophy. Acta Myol $\underline{31}, 9-15$

Appell HJ, Forsberg S, Hollmann W (1988): Satellite cell activation in human skeletal muscle after training: evidence for muscle fiber neoformation. Int J Sports Med $\underline{9}$, 297-299

Ashwath ML, Jacobs IB, Crowe CA, Ashwath RC, Super DM, Bahler RC (2014): Left ventricular dysfunction in duchenne muscular dystrophy and genotype. Am J Cardiol 114, 284 289

Au CG, Butler TL, Sherwood MC, Egan JR, North KN, Winlaw DS (2011): Increased connective tissue growth factor associated with cardiac fibrosis in the mdx mouse model of dystrophic cardiomyopathy. Int J Exp Pathol 92, 57-65

Baltgalvis KA, Call JA, Nikas JB, Lowe DA (2009): The effects of prednisolone on skeletal muscle contractility in mdx mice. Muscle Nerve $\underline{40}, 443-454$ 
Baltgalvis KA, Call JA, Cochrane GD, Laker RC, Yan Z, Lowe DA (2012): Exercise training improves plantar flexor muscle function in mdx mice. Med Sci Sports Exerc 44, 16711679

Barton-Davis ER, Cordier L, Shoturma DI, Leland SE, Sweeney HL (1999): Aminoglycoside antibiotics restore dystrophin function to skeletal muscles of mdx mice. J Clin Invest $\underline{104}, 375-381$

Bauer R, Straub V, Blain A, Bushby K, MacGowan GA (2009): Contrasting effects of steroids and angiotensin-converting-enzyme inhibitors in a mouse model of dystrophin-deficient cardiomyopathy. Eur J Heart Fail 11, 463-471

Berchtold MW, Brinkmeier H, Müntener M (2000): Calcium ion in skeletal muscle: its crucial role for muscle function, plasticity, and disease. Physiol Rev $\underline{80}, 1215-1265$

Bernasconi P, Torchiana E, Confalonieri P, Brugnoni R, Barresi R, Mora M, Cornelio F, Morandi L, Mantegazza R (1995): Expression of transforming growth factor-beta 1 in dystrophic patient muscles correlates with fibrosis. Pathogenetic role of a fibrogenic cytokine. J Clin Invest $\underline{96}, 1137-1144$

Biggar WD, Harris VA, Eliasoph L, Alman B (2006): Long-term benefits of deflazacort treatment for boys with Duchenne muscular dystrophy in their second decade. Neuromuscul Disord 16, 249-255

Bish LT, Yarchoan M, Sleeper MM, Gazzara JA, Morine KJ, Acosta P, Barton ER, Sweeney HL (2011): Chronic losartan administration reduces mortality and preserves cardiac but not skeletal muscle function in dystrophic mice. PLoS ONE $\underline{6}$, e20856

Blake DJ, Tinsley JM, Davies KE (1996): Utrophin: a structural and functional comparison to dystrophin. Brain Pathol $\underline{6}, 37-47$

Blake DJ, Weir A, Newey SE, Davies KE (2002): Function and genetics of dystrophin and dystrophin-related proteins in muscle. Physiol Rev $\underline{82}$, 291-329 
Bodensteiner JB, Engel AG (1978): Intracellular calcium accumulation in Duchenne dystrophy and other myopathies: a study of 567,000 muscle fibers in 114 biopsies. Neurology $\underline{28}$, $439-446$

Bostick B, Yue Y, Long C, Duan D (2008): Prevention of dystrophin-deficient cardiomyopathy in twenty-one-month-old carrier mice by mosaic dystrophin expression or complementary dystrophin/utrophin expression. Circ Res $\underline{102}, 121-130$

Bostick B, Yue Y, Long C, Marschalk N, Fine DM, Chen J, Duan D (2009): Cardiac expression of a mini-dystrophin that normalizes skeletal muscle force only partially restores heart function in aged Mdx mice. Mol Ther 17, 253-261

Brannagan TH 3rd, Nagle KJ, Lange DJ, Rowland LP (1996): Complications of intravenous immune globulin treatment in neurologic disease. Neurology 47, 674-677

Bresolin N, Castelli E, Comi GP, Felisari G, Bardoni A, Perani D, Grassi F, Turconi A, Mazzucchelli F, Gallotti D et al. (1994): Cognitive impairment in Duchenne muscular dystrophy. Neuromuscul Disord $\underline{4}, 359-369$

Bridges LR (1986): The association of cardiac muscle necrosis and inflammation with the degenerative and persistent myopathy of MDX mice. J Neurol Sci $\underline{72}, 147-157$

Briguet A, Courdier-Fruh I, Foster M, Meier T, Magyar JP (2004): Histological parameters for the quantitative assessment of muscular dystrophy in the mdx-mouse. Neuromuscul Disord $\underline{14}, 675-682$

Brookes PS, Yoon Y, Robotham JL, Anders MW, Sheu SS (2004): Calcium, ATP, and ROS: a mitochondrial love-hate triangle. Am J Physiol Cell Physiol 287, C817-833

Bulfield G, Siller WG, Wight PA, Moore KJ (1984): X chromosome-linked muscular dystrophy (mdx) in the mouse. Proc Natl Acad Sci U S A $\underline{81}, 1189-1192$ 
Bushby K, Finkel R, Birnkrant DJ, Case LE, Clemens PR, Cripe L, Kaul A, Kinnett K, McDonald C, Pandya S et al. (2010): Diagnosis and management of Duchenne muscular dystrophy, part 1: diagnosis, and pharmacological and psychosocial management. Lancet Neurol 9, 77-93

Bushby K, Finkel R, Wong B, Barohn R, Campbell C, Comi GP, Connolly AM, Day JW, Flanigan KM, Goemans N et al. (2014): Ataluren treatment of patients with nonsense mutation dystrophinopathy. Muscle Nerve $\underline{50}, 477-487$

Call JA, Voelker KA, Wolff AV, McMillan RP, Evans NP, Hulver MW, Talmadge RJ, Grange RW (2008): Endurance capacity in maturing mdx mice is markedly enhanced by combined voluntary wheel running and green tea extract. J Appl Physiol (1985) 105, 923932

Cantini M, Massimino ML, Bruson A, Catani C, Dalla Libera L, Carraro U (1994): Macrophages regulate proliferation and differentiation of satellite cells. Biochem Biophys Res Commun 202, 1688-1696

Capote J, Kramerova I, Martinez L, Vetrone S, Barton ER, Sweeney HL, Miceli MC, Spencer MJ (2016): Osteopontin ablation ameliorates muscular dystrophy by shifting macrophages to a pro-regenerative phenotype. J Cell Biol 213, 275-288

Carter GT, Wineinger MA, Walsh SA, Horasek SJ, Abresch RT, Fowler WM Jr. (1995): Effect of voluntary wheel-running exercise on muscles of the mdx mouse. Neuromuscul Disord $\underline{5}, 323-332$

Cecchi G, Bagni MA, Griffiths PJ, Ashley CC, Maeda Y (1990): Detection of radial crossbridge force by lattice spacing changes in intact single muscle fibers. Science 250, 14091411

Chamberlain JS, Metzger J, Reyes M, Townsend D, Faulkner JA (2007): Dystrophin-deficient mdx mice display a reduced life span and are susceptible to spontaneous rhabdomyosarcoma. FASEB J 21, 2195-2204 
Chang RF, Mubarak SJ (2012): Pathomechanics of Gowers' sign: a video analysis of a spectrum of Gowers' maneuvers. Clin Orthop Relat Res $\underline{470}$, 1987-1991

Cirak S, Arechavala-Gomeza V, Guglieri M, Feng L, Torelli S, Anthony K, Abbs S, Garralda ME, Bourke J, Wells DJ et al. (2011): Exon skipping and dystrophin restoration in patients with Duchenne muscular dystrophy after systemic phosphorodiamidate morpholino oligomer treatment: an open-label, phase 2, dose-escalation study. Lancet $\underline{378}, 595-605$

Coulton GR, Morgan JE, Partridge TA, Sloper JC (1988): The mdx mouse skeletal muscle myopathy: I. A histological, morphometric and biochemical investigation. Neuropathol Appl Neurobiol 14, 53-70

Dahiya S, Givvimani S, Bhatnagar S, Qipshidze N, Tyagi SC, Kumar A (2011): Osteopontin-stimulated expression of matrix metalloproteinase- 9 causes cardiomyopathy in the $\mathrm{mdx}$ model of Duchenne muscular dystrophy. J Immunol 187, 2723-2731

Dalakas MC (2004): Intravenous immunoglobulin in autoimmune neuromuscular diseases. JAMA $\underline{291}, 2367-2375$

Dalski A, Wagner HJ, Schwinger E, Zühlke C (2000): Quantitative PCR analysis of different splice forms of NFAT5 revealed specific gene expression in fetal and adult brain. Brain Res Mol Brain Res $\underline{83}, 125-127$

de' Clari F, Salani I, Safwan E, Giannacco A (2002): Sudden death in a patient without heart failure after a single infusion of $200 \mathrm{mg}$ infliximab: does TNF-alpha have protective effects on the failing heart, or does infliximab have direct harmful cardiovascular effects? Circulation $\underline{105}$, E183

De Luca A (2019a): Use of treadmill and wheel exercise for impact on mdx mice phenotype. SOP von Treat-NMD. SOP ID Number: DMD_M.2.1.001. https://treat-nmd.org/wp-content/uploads/2016/08/MDX-DMD_M.2.1.001.pdf; abgerufen am 22.12.2019 
De Luca A (2019b): Use of grip strength meter to assess the limb strength of mdx mice. SOP von Treat-NMD. SOP ID Number: DMD_M.2.2.001. https://treat-nmd.org/wp-content/uploads/2016/08/MDX-DMD_M.2.2.001.pdf; abgerufen am 22.12.2019

De Luca A, Pierno S, Liantonio A, Cetrone M, Camerino C, Fraysse B, Mirabella M, Servidei S, Rüegg UT, Conte Camerino D (2003): Enhanced dystrophic progression in mdx mice by exercise and beneficial effects of taurine and insulin-like growth factor-1. J Pharmacol Exp Ther 304, 453-463

De Luca A, Nico B, Liantonio A, Didonna MP, Fraysse B, Pierno S, Burdi R, Mangieri D, Rolland JF, Camerino C et al. (2005): A multidisciplinary evaluation of the effectiveness of cyclosporine a in dystrophic mdx mice. Am J Pathol 166, 477-489

De Paepe B, De Bleecker JL (2013): Cytokines and chemokines as regulators of skeletal muscle inflammation: Presenting the case of Duchenne muscular dystrophy. Mediators Inflamm 2013, 540370

De Paepe B, Martin JJ, Herbelet S, Jimenez-Mallebrera C, Iglesias E, Jou C, Weis J, De Bleecker JL (2016): Activation of osmolyte pathways in inflammatory myopathy and Duchenne muscular dystrophy points to osmoregulation as a contributing pathogenic mechanism. Lab Invest $\underline{96}, 872-884$

Deshmane SL, Kremlev S, Amini S, Sawaya BE (2009): Monocyte chemoattractant protein1 (MCP-1): an overview. J Interferon Cytokine Res 29, 313-326

DGN (2018): Therapie akuter und chronischer immunvermittelter Neuropathien und Neuritidien (Leitlinien für Diagnostik und Therapie in der Neurologie). S2e-Leitlinie der Deutschen Gesellschaft für Neurologie. https://www.dgn.org/images/030130_LL_Therapie_akuter_und_chronischer_immunvermittelter_Neuropathien_und_Neuritiden_2018.pdf; abgerufen am 16.09.2018

Domanski MJ, Cunnion RE, Roberts WC (1992): Analysis of fractional area change at various levels in the normal left ventricle. Am J Cardiol 70, 1367-1368 
Dupont-Versteegden EE, McCarter RJ (1992): Differential expression of muscular dystrophy in diaphragm versus hindlimb muscles of mdx mice. Muscle Nerve $\underline{15}, 1105-1110$

Dupont-Versteegden EE, McCarter RJ, Katz MS (1994): Voluntary exercise decreases progression of muscular dystrophy in diaphragm of mdx mice. J Appl Physiol (1985) 구, 17361741

Eagle M, Baudouin SV, Chandler C, Giddings DR, Bullock R, Bushby K (2002): Survival in Duchenne muscular dystrophy: improvements in life expectancy since 1967 and the impact of home nocturnal ventilation. Neuromuscul Disord 12, 926-929

Eftimov F, Winer JB, Vermeulen M, de Haan R, van Schaik IN (2013): Intravenous immunoglobulin for chronic inflammatory demyelinating polyradiculoneuropathy. Cochrane Database Syst Rev $\underline{12}$, CD001797

Eijkhout HW, van den Broek PJ, van der Meer JW (2003): Substitution therapy in immunodeficient patients with anti-IgA antibodies or severe adverse reactions to previous immunoglobulin therapy. Neth J Med $\underline{61}, 213-217$

EMA (2018): Guideline on core SmPC for human normal immunoglobulin for intravenous administration (IVIg). European Medicines agency Committee for Medicinal Products for Human Use (CHMP). 28.06.2018. https:/www.ema.europa.eu/en/documents/scientific-guideline/guideline-core-smpc-human-normal-immunoglobulin-intravenous-administrationivig-rev-5_en.pdf; abgerufen am 06.01.2019

Emery AE (1980): Duchenne muscular dystrophy. Genetic aspects, carrier detection and antenatal diagnosis. Br Med Bull $\underline{36}, 117-122$

Emery AE (1991): Population frequencies of inherited neuromuscular diseases--a world survey. Neuromuscul Disord 1, 19-29 
Ermolova NV, Martinez L, Vetrone SA, Jordan MC, Roos KP, Sweeney HL, Spencer MJ (2014): Long-term administration of the TNF blocking drug Remicade (cV1q) to mdx mice reduces skeletal and cardiac muscle fibrosis, but negatively impacts cardiac function. Neuromuscul Disord 24, 583-595

Ervasti JM (2007): Dystrophin, its interactions with other proteins, and implications for muscular dystrophy. Biochim Biophys Acta 1772, 108-117

Ervasti JM, Campbell KP (1993): A role for the dystrophin-glycoprotein complex as a transmembrane linker between laminin and actin. J Cell Biol 122, 809-823

Fairclough RJ, Wood MJ, Davies KE (2013): Therapy for Duchenne muscular dystrophy: renewed optimism from genetic approaches. Nat Rev Genet 14, 373-378

Fayssoil A, Renault G, Guerchet N, Marchiol-Fournigault C, Fougerousse F, Richard I (2013): Cardiac characterization of $\mathrm{mdx}$ mice using high-resolution doppler echocardiography. J Ultrasound Med 32, 757-761

Feasby T, Banwell B, Benstead T, Bril V, Brouwers M, Freedman M, Hahn A, Hume H, Freedman J, Pi D et al. (2007): Guidelines on the use of intravenous immune globulin for neurologic conditions. Transfus Med Rev 21, 57-107

Fenichel GM, Florence JM, Pestronk A, Mendell JR, Moxley RT 3rd, Griggs RC, Brooke MH, Miller JP, Robison J, King W et al. (1991): Long-term benefit from prednisone therapy in Duchenne muscular dystrophy. Neurology $\underline{41}, 1874-1877$

Fernandez K, Serinagaoglu Y, Hammond S, Martin LT, Martin PT (2010): Mice lacking dystrophin or alpha sarcoglycan spontaneously develop embryonal rhabdomyosarcoma with cancer-associated p53 mutations and alternatively spliced or mutant Mdm2 transcripts. Am J Pathol 176, 416-434. 
Finkel RS, Flanigan KM, Wong B, Bönnemann C, Sampson J, Sweeney HL, Reha A, Northcutt VJ, Elfring G, Barth J et al. (2013): Phase 2a study of ataluren-mediated dystrophin production in patients with nonsense mutation Duchenne muscular dystrophy. PLoS One $\underline{8}$, e81302.

Fisher I, Abraham D, Bouri K, Hoffmann EP, Hoffman EP, Muntoni F, Morgan J (2005): Prednisolone-induced changes in dystrophic skeletal muscle. FASEB J $\underline{19}, 834-836$

Franconi F, Brunelleschi S, Steardo L, Cuomo V (2007): Gender differences in drug responses. Pharmacol Res $\underline{55}, 81-95$

Frank MM, Basta M, Fries LF (1992): The effects of intravenous immune globulin on complement-dependent immune damage of cells and tissues. Clin Immunol Immunopathol $\underline{62}$, $82-86$

Giglio V, Pasceri V, Messano L, Mangiola F, Pasquini L, Dello Russo A, Damiani A, Mirabella M, Galluzzi G, Tonali P et al. (2003): Ultrasound tissue characterization detects preclinical myocardial structural changes in children affected by Duchenne muscular dystrophy. J Am Coll Cardiol 42, 309-316

Gowers (1879): Clinical Lecture ON PSEUDO-HYPERTROPHIC MUSCULAR PARALYSIS. The Lancet $\underline{114}, 73-75$

Granchelli JA, Pollina C, Hudecki MS (2000): Pre-clinical screening of drugs using the mdx mouse. Neuromuscul Disord 10, 235-239

Grange RW (2015): Use of treadmill and wheel exercise to assess dystrophic state. SOP von Treat-NMD. SOP ID Number: DMD_M.2.1.003. https://treat-nmd.org/wp-content/uploads/2016/08/MDX-DMD_M.2.1.003-34.pdf; abgerufen am 22.12.2019

Griggs RC, Moxley RT 3rd, Mendell JR, Fenichel GM, Brooke MH, Pestronk A, Miller JP, Cwik VA, Pandya S, Robison J et al. (1993): Duchenne dystrophy: randomized, controlled trial of prednisone (18 months) and azathioprine (12 months). Neurology $\underline{43}, 520-527$ 
Grounds MD, Torrisi J (2004): Anti-TNFalpha (Remicade) therapy protects dystrophic skeletal muscle from necrosis. FASEB J $\underline{18}, 676-682$

Grounds MD, Radley HG, Lynch GS, Nagaraju K, De Luca A (2008): Towards developing standard operating procedures for pre-clinical testing in the $\mathrm{mdx}$ mouse model of Duchenne muscular dystrophy. Neurobiol Dis $\underline{31}, 1-19$

Grounds MD (2014): Quantification of histopathology in Haemotoxylin and Eosin stained muscle sections. SOP von Treat-NMD. SOP ID Number: DMD_M.1.2.007. https://treatnmd.org/wp-content/uploads/2016/08/MDX-DMD_M.1.2.007-28.pdf; abgerufen am 22.12 .2019

Guerron AD, Rawat R, Sali A, Spurney CF, Pistilli E, Cha HJ, Pandey GS, Gernapudi R, Francia D, Farajian V et al. (2010): Functional and molecular effects of arginine butyrate and prednisone on muscle and heart in the mdx mouse model of Duchenne Muscular Dystrophy. PLoS ONE $\underline{5}$, e11220

Gumerson JD, Michele DE (2011): The dystrophin-glycoprotein complex in the prevention of muscle damage. J Biomed Biotechnol 2011, 210797

Harbo T, Andersen H, Hess A, Hansen K, Sindrup SH, Jakobsen J (2009): Subcutaneous versus intravenous immunoglobulin in multifocal motor neuropathy: a randomized, singleblinded cross-over trial. Eur J Neurol 16, 631-638

Harbo T, Andersen H, Jakobsen J (2010): Long-term therapy with high doses of subcutaneous immunoglobulin in multifocal motor neuropathy. Neurology $\underline{75}, 1377-1380$

Hareendran S, Balakrishnan B, Sen D, Kumar S, Srivastava A, Jayandharan GR (2013): Adeno-associated virus (AAV) vectors in gene therapy: immune challenges and strategies to circumvent them. Rev Med Virol 23, 399-413 
Harisseh R, Chatelier A, Magaud C, Déliot N, Constantin B (2013): Involvement of TRPV2 and SOCE in calcium influx disorder in DMD primary human myotubes with a specific contribution of $\alpha 1$-syntrophin and PLC/PKC in SOCE regulation. Am J Physiol Cell Physiol 304, C881-894

Harrison BC, Allen DL, Leinwand LA (2011): IIb or not IIb? Regulation of myosin heavy chain gene expression in mice and men. Skelet Muscle 1, 5

Hart CY, Burnett JC Jr, Redfield MM (2001): Effects of avertin versus xylazine-ketamine anesthesia on cardiac function in normal mice. Am J Physiol Heart Circ Physiol 281, H19381945

Hartel JV, Granchelli JA, Hudecki MS, Pollina CM, Gosselin LE (2001): Impact of prednisone on TGF-betal and collagen in diaphragm muscle from mdx mice. Muscle Nerve $\underline{24}$, $428-432$

Havens MA, Hastings ML (2016): Splice-switching antisense oligonucleotides as therapeutic drugs. Nucleic Acids Res $\underline{44}, 6549-6563$

Hayes A, Williams DA (1996): Beneficial effects of voluntary wheel running on the properties of dystrophic mouse muscle. J Appl Physiol (1985) $\underline{80}, 670-679$

Heier CR, Damsker JM, Yu Q, Dillingham BC, Huynh T, Van der Meulen JH, Sali A, Miller BK, Phadke A, Scheffer L et al. (2013): VBP15, a novel anti-inflammatory and membranestabilizer, improves muscular dystrophy without side effects. EMBO Mol Med $\underline{5}, 1569$ 1585

Heo YA (2020): Golodirsen: First approval. Drugs 무, 329-333

Heyck H, Laudahn G: Die progressiven Muskeldystrophien. In: Heyck H, Laudahn G (Hrsg.): Die progressiv-dystrophischen Myopathien. Springer, Berlin Heidelberg 1969, 1118 
Hirst RC, McCullagh KJA, Davies KE (2005): Utrophin upregulation in Duchenne muscular dystrophy. Acta Myol 24, 209-216

Hodgetts S, Radley H, Davies M, Grounds MD (2006): Reduced necrosis of dystrophic muscle by depletion of host neutrophils, or blocking TNFalpha function with Etanercept in $\mathrm{mdx}$ mice. Neuromuscul Disord $\underline{16}, 591-602$

Hoffman EP, Dressman D (2001): Molecular pathophysiology and targeted therapeutics for muscular dystrophy. Trends Pharmacol Sci $\underline{22}, 465-470$

Hoffman EP, Brown RH, Kunkel LM (1987): Dystrophin: The Protein Product of the Duchenne Muscular Dystrophy Locus. Cell 51, 919-928

Hoffman EP, Reeves E, Damsker J, Nagaraju K, McCall JM, Connor EM, Bushby K (2012): Novel approaches to corticosteroid treatment in Duchenne muscular dystrophy. Phys Med Rehabil Clin N Am 23, 821-828

Holloszy JO (1967): Biochemical adaptations in muscle. Effects of exercise on mitochondrial oxygen uptake and respiratory enzyme activity in skeletal muscle. J Biol Chem $\underline{242}$, $2278-2282$

Hoogerwaard EM, van der Wouw PA, Wilde AA, Bakker E, Ippel PF, Oosterwijk JC, Majoor-Krakauer DF, van Essen AJ, Leschot NJ, de Visser M (1999): Cardiac involvement in carriers of Duchenne and Becker muscular dystrophy. Neuromuscul Disord $\underline{9}, 347-351$

Hudecki MS, Pollina CM, Granchelli JA, Daly MK, Byrnes T, Wang JC, Hsiao JC (1993): Strength and endurance in the therapeutic evaluation of prednisolone-treated MDX mice. Res Commun Chem Pathol Pharmacol 79, 45-60

Hughes RAC, Donofrio P, Bril V, Dalakas MC, Deng C, Hanna K, Hartung HP, Latov N, Merkies ISJ, van Doorn PA et al. (2008): Intravenous immune globulin (10\% caprylatechromatography purified) for the treatment of chronic inflammatory demyelinating polyradiculoneuropathy (ICE study): a randomised placebo-controlled trial. Lancet Neurol $\underline{7}$, $136-144$ 
Hurez V, Kaveri SV, Mouhoub A, Dietrich G, Mani JC, Klatzmann D, Kazatchkine MD (1994): Anti-CD4 activity of normal human immunoglobulin G for therapeutic use. (Intravenous immunoglobulin, IVIg). Ther Immunol $\underline{1}$, 269-277

Imbach P, Barandun S, d'Apuzzo V, Baumgartner C, Hirt A, Morell A, Rossi E, Schöni M, Vest M, Wagner HP (1981): High-dose intravenous gammaglobulin for idiopathic thrombocytopenic purpura in childhood. Lancet $\underline{1}, 1228-1231$

Iwata Y, Katanosaka Y, Arai Y, Shigekawa M, Wakabayashi S (2009): Dominant-negative inhibition of Ca2+ influx via TRPV2 ameliorates muscular dystrophy in animal models. Hum Mol Genet $\underline{18}, 824-834$

Janssen PM, Murray JD, Schill KE, Rastogi N, Schultz EJ, Tran T, Raman SV, Rafael-Fortney JA (2014): Prednisolone attenuates improvement of cardiac and skeletal contractile function and histopathology by lisinopril and spironolactone in the mdx mouse model of Duchenne muscular dystrophy. PLoS ONE $\underline{9}$, e88360

Jo WH, Eun LY, Jung JW, Choi JY, Gang SW (2016): Early Marker of Myocardial Deformation in Children with Duchenne Muscular Dystrophy Assessed Using Echocardiographic Myocardial Strain Analysis. Yonsei Med J 57, 900-904

Kamogawa Y, Biro S, Maeda M, Setoguchi M, Hirakawa T, Yoshida H, Tei C (2001): Dystrophin-deficient myocardium is vulnerable to pressure overload in vivo. Cardiovasc Res $\underline{50}$, $509-515$

Kaneko Y, Nimmerjahn F, Ravetch JV (2006): Anti-inflammatory activity of immunoglobulin $\mathrm{G}$ resulting from Fc sialylation. Science $\underline{313}$, 670-673

Karpati G, Pouliot Y, Zubrzycka-Gaarn E, Carpenter S, Ray PN, Worton RG, Holland P (1989): Dystrophin is expressed in mdx skeletal muscle fibers after normal myoblast implantation. Am J Pathol 135, 27-32 
Kaufman GN, Massoud AH, Dembele M, Yona M, Piccirillo CA, Mazer BD (2015): Induction of Regulatory T Cells by Intravenous Immunoglobulin: A Bridge between Adaptive and Innate Immunity. Front Immunol $\underline{6}, 469$

Kieny P, Chollet S, Delalande P, Le Fort M, Magot A, Pereon Y, Perrouin Verbe B (2013): Evolution of life expectancy of patients with Duchenne muscular dystrophy at AFM Yolaine de Kepper centre between 1981 and 2011. Ann Phys Rehabil Med 56, 443-454

Kinali M, Messina S, Mercuri E, Lehovsky J, Edge G, Manzur AY, Muntoni F (2006): Management of scoliosis in Duchenne muscular dystrophy: a large 10-year retrospective study. Dev Med Child Neurol 48, 513-518

Kirschner J, Schess1 J, Schara U, Reitter B, Stettner GM, Hobbiebrunken E, Wilichowski E, Bernert G, Weiss S, Stehling F et al. (2010): Treatment of Duchenne muscular dystrophy with ciclosporin A: a randomised, double-blind, placebo-controlled multicentre trial. Lancet Neurol $\underline{9}, 1053-1059$

Klehmet J, Goehler J, Ulm L, Kohler S, Meisel C, Meisel A, Harms H (2015): Effective treatment with intravenous immunoglobulins reduces autoreactive T-cell response in patients with CIDP. J Neurol Neurosurg Psychiatry $\underline{86}$, 686-691

Kochanek S, Clemens PR, Mitani K, Chen HH, Chan S, Caskey CT (1996): A new adenoviral vector: Replacement of all viral coding sequences with $28 \mathrm{~kb}$ of DNA independently expressing both full-length dystrophin and beta-galactosidase. Proc Natl Acad Sci U S A $\underline{93}$, $5731-5736$

Koenig M, Hoffman EP, Bertelson CJ, Monaco AP, Feener C, Kunkel LM (1987): Complete cloning of the Duchenne muscular dystrophy (DMD) cDNA and preliminary genomic organization of the DMD gene in normal and affected individuals. Cell $\underline{50}, 509-517$

Koenig M, Monaco AP, Kunkel LM (1988): The complete sequence of dystrophin predicts a rod-shaped cytoskeletal protein. Cell $\underline{53}, 219-228$ 
Kondo N, Kasahara K, Kameyama T, Suzuki Y, Shimozawa N, Tomatsu S, Nakashima Y, Hori T, Yamagishi A, Ogawa T et al. (1994): Intravenous immunoglobulins suppress immunoglobulin productions by suppressing $\mathrm{Ca}(2+)$-dependent signal transduction through $\mathrm{Fc}$ gamma receptors in B lymphocytes. Scand J Immunol 40, 37-42

Kutschenko A, Reinert MC, Klinker F, Paulus W, Hesse S, Liebetanz D (2011): Botulinum toxin-induced focal paresis in mice is unaffected by muscle activity. Muscle Nerve $\underline{44}, 930$ 936

Kwon HJ, Coté TR, Cuffe MS, Kramer JM, Braun MM (2003): Case reports of heart failure after therapy with a tumor necrosis factor antagonist. Ann Intern Med 138, 807-811

Landisch RM, Kosir AM, Nelson SA, Baltgalvis KA, Lowe DA (2008): Adaptive and nonadaptive responses to voluntary wheel running by mdx mice. Muscle Nerve $\underline{38}, 1290-1303$

Leetmaa TH, Markenvard JD (2005): [Dilated cardiomyopathy as a side effect of treatment with infliximab]. Ugeskr Laeg 167, 3699-3701

Lefaucheur JP, Pastoret C, Sebille A (1995): Phenotype of dystrophinopathy in old mdx mice. Anat Rec 242, 70-76

Leonard EJ, Yoshimura T (1990): Human monocyte chemoattractant protein-1 (MCP-1). Immunol Today $\underline{11}, 97-101$

Li W, Liu W, Zhong J, Yu X (2009): Early manifestation of alteration in cardiac function in dystrophin deficient mdx mouse using 3D CMR tagging. J Cardiovasc Magn Reson 11, 40

Lieber RL, Fridén J (2002): Spasticity causes a fundamental rearrangement of muscle-joint interaction. Muscle Nerve 25, 265-270

Liebetanz D, Merkler D (2006): Effects of commissural de- and remyelination on motor skill behaviour in the cuprizone mouse model of multiple sclerosis. Exp Neurol 202, 217-224 
Liebetanz D, Baier PC, Paulus W, Meuer K, Bähr M, Weishaupt JH (2007): A highly sensitive automated complex running wheel test to detect latent motor deficits in the mouse MPTP model of Parkinson's disease. Exp Neurol 205, 207-213

Lim KRQ, Maruyama R, Yokota T (2017): Eteplirsen in the treatment of Duchenne muscular dystrophy. Drug Des Devel Ther $\underline{11}, 533-545$

López-Rodríguez C, Aramburu J, Rakeman AS, Copeland NG, Gilbert DJ, Thomas S, Disteche C, Jenkins NA, Rao A (1999): NF-AT5: the NF-AT family of transcription factors expands in a new direction. Cold Spring Harb Symp Quant Biol $\underline{64}, 517-526$

Lu B, Rutledge BJ, Gu L, Fiorillo J, Lukacs NW, Kunkel SL, North R, Gerard C, Rollins BJ (1998): Abnormalities in monocyte recruitment and cytokine expression in monocyte chemoattractant protein 1-deficient mice. J Exp Med 187, 601-608

Lu H, Huang D, Saederup N, Charo IF, Ransohoff RM, Zhou L (2011): Macrophages recruited via CCR2 produce insulin-like growth factor-1 to repair acute skeletal muscle injury. FASEB J $\underline{25}, 358-369$

Lynch GS, Rafael JA, Hinkle RT, Cole NM, Chamberlain JS, Faulkner JA (1997): Contractile properties of diaphragm muscle segments from old $\mathrm{mdx}$ and old transgenic mdx mice. Am J Physiol 272, C2063-2068

Mallouk N, Jacquemond V, Allard B (2000): Elevated subsarcolemmal Ca2+ in mdx mouse skeletal muscle fibers detected with Ca2+-activated K+ channels. Proc Natl Acad Sci U S A 97, 4950-4955

Mann CJ, Honeyman K, Cheng AJ, Ly T, Lloyd F, Fletcher S, Morgan JE, Partridge TA, Wilton SD (2001): Antisense-induced exon skipping and synthesis of dystrophin in the mdx mouse. Proc Natl Acad Sci U S A $\underline{98}, 42-47$

Manzur AY, Kuntzer T, Pike M, Swan A (2008): Glucocorticoid corticosteroids for Duchenne muscular dystrophy. Cochrane Database Syst Rev, CD003725 
Marhaug G, Shah V, Shroff R, Varsani H, Wedderburn LR, Pilkington CA, Brogan PA (2008): Age-dependent inhibition of ectopic calcification: a possible role for fetuin-A and osteopontin in patients with juvenile dermatomyositis with calcinosis. Rheumatology (Oxford) $47,1031-1037$

Maron BJ, Towbin JA, Thiene G, Antzelevitch C, Corrado D, Arnett D, Moss AJ, Seidman CE, Young JB, American Heart Association et al. (2006): Contemporary definitions and classification of the cardiomyopathies: an American Heart Association Scientific Statement from the Council on Clinical Cardiology, Heart Failure and Transplantation Committee; Quality of Care and Outcomes Research and Functional Genomics and Translational Biology Interdisciplinary Working Groups; and Council on Epidemiology and Prevention. Circulation $\underline{113}, 1807-1816$

Matsumura CY, Taniguti AP, Pertille A, Santo Neto H, Marques MJ (2011): Stretch-activated calcium channel protein TRPC1 is correlated with the different degrees of the dystrophic phenotype in mdx mice. Am J Physiol Cell Physiol $\underline{301}$, C1344-1350

Mavrogeni S, Markousis-Mavrogenis G, Papavasiliou A, Kolovou G (2015): Cardiac involvement in Duchenne and Becker muscular dystrophy. World J Cardiol 푸 410-414

McDouall RM, Dunn MJ, Dubowitz V (1989): Expression of class I and class II MHC antigens in neuromuscular diseases. J Neurol Sci $\underline{89}$, 213-226

McDouall RM, Dunn MJ, Dubowitz V (1990): Nature of the mononuclear infiltrate and the mechanism of muscle damage in juvenile dermatomyositis and Duchenne muscular dystrophy. J Neurol Sci 99, 199-217

McGeachie JK, Grounds MD, Partridge TA, Morgan JE (1993): Age-related changes in replication of myogenic cells in mdx mice: quantitative autoradiographic studies. J Neurol Sci $\underline{119}, 169-179$

McGreevy JW, Hakim CH, McIntosh MA, Duan D (2015): Animal models of Duchenne muscular dystrophy: from basic mechanisms to gene therapy. Dis Model Mech $\underline{8}, 195-213$ 
McNally EM, Kaltman JR, Benson DW, Canter CE, Cripe LH, Duan D, Finder JD, Groh WJ, Hoffman EP, Judge DP et al. (2015): Contemporary cardiac issues in Duchenne muscular dystrophy. Working Group of the National Heart, Lung, and Blood Institute in collaboration with Parent Project Muscular Dystrophy. Circulation 131, 1590-1598

Mendell JR, Moxley RT, Griggs RC, Brooke MH, Fenichel GM, Miller JP, King W, Signore L, Pandya S, Florence J et al. (1989): Randomized, double-blind six-month trial of prednisone in Duchenne's muscular dystrophy. N Engl J Med 2ㅜ, 1592-1597

Mendell JR, Rodino-Klapac LR, Sahenk Z, Roush K, Bird L, Lowes LP, Alfano L, Gomez AM, Lewis S, Kota J et al. (2013): Eteplirsen for the treatment of Duchenne muscular dystrophy. Ann Neurol 74, 637-647

Misbah S, Sturzenegger MH, Borte M, Shapiro RS, Wasserman RL, Berger M, Ochs HD (2009): Subcutaneous immunoglobulin: opportunities and outlook. Clin Exp Immunol 158, $51-59$

Miyakawa H, Woo SK, Dahl SC, Handler JS, Kwon HM (1999): Tonicity-responsive enhancer binding protein, a Rel-like protein that stimulates transcription in response to hypertonicity. Proc Natl Acad Sci U S A 96, 2538-2542

Monaco AP, Bertelson CJ, Liechti-Gallati S, Moser H, Kunkel LM (1988): An explanation for the phenotypic differences between patients bearing partial deletions of the DMD locus. Genomics 2, 90-95

Monaco AP, Walker AP, Millwood I, Larin Z, Lehrach H (1992): A yeast artificial chromosome contig containing the complete Duchenne muscular dystrophy gene. Genomics $\underline{12}$, $465-473$

Moriuchi T, Kagawa N, Mukoyama M, Hizawa K (1993): Autopsy analyses of the muscular dystrophies. Tokushima J Exp Med 40, 83-93

Muntoni F, Mateddu A, Marchei F, Clerk A, Serra G (1993): Muscular weakness in the mdx mouse. J Neurol Sci 120, 71-77 
Müller T, Zierz S: Normale Anatomie der Skelettmuskulatur. In: Zierz S (Hrsg.): Muskelerkrankungen. Georg Thieme Verlag, Stuttgart 2014, 19-39

Murphy K, Travers P, Walport M, Janeway C (Hrsg.): Janeway's Immunobiology. 8. Auflage; Garland Science, New York 2012

Nadarajah VD, van Putten M, Chaouch A, Garrood P, Straub V, Lochmüller H, Ginjaar HB, Aartsma-Rus AM, van Ommen GJB, den Dunnen JT et al. (2011): Serum matrix metalloproteinase-9 (MMP-9) as a biomarker for monitoring disease progression in Duchenne muscular dystrophy (DMD). Neuromuscul Disord 21, 569-578

Nagaraju K, Gordish H (2017): Serum Creatine Kinase analysis in mouse models of muscular dystrophy. SOP von Treat-NMD. SOP ID Number:MD_M.2.2.001. https://treatnmd.org/wp-content/uploads/2016/08/MDX-MD_M.2.2.001.pdf; abgerufen am 22.12.2019

Nelson CA, Hunter RB, Quigley LA, Girgenrath S, Weber WD, McCullough JA, Dinardo CJ, Keefe KA, Ceci L, Clayton NP et al. (2011): Inhibiting TGF- $\beta$ activity improves respiratory function in mdx mice. Am J Pathol 178, 2611-2621

Nelson CE, Hakim CH, Ousterout DG, Thakore PI, Moreb EA, Castellanos Rivera RM, Madhavan S, Pan X, Ran FA, Yan WX et al. (2016): In vivo genome editing improves muscle function in a mouse model of Duchenne muscular dystrophy. Science 351, 403-407

Nigro G, Comi LI, Politano L, Bain RJ (1990): The incidence and evolution of cardiomyopathy in Duchenne muscular dystrophy. Int J Cardiol 26, 271-277

Oates-Whitehead RM, Baumer JH, Haines L, Love S, Maconochie IK, Gupta A, Roman K, Dua JS, Flynn I (2003): Intravenous immunoglobulin for the treatment of Kawasaki disease in children. Cochrane Data base Syst Rev $\underline{4}$, CD004000

O’Connor RS, Mills ST, Jones KA, Ho SN, Pavlath GK (2007): A combinatorial role for NFAT5 in both myoblast migration and differentiation during skeletal muscle myogenesis. J Cell Sci 120, 149-159 
Okano T, Yoshida K, Nakamura A, Sasazawa F, Oide T, Takeda S, Ikeda S (2005): Chronic exercise accelerates the degeneration-regeneration cycle and downregulates insulin-like growth factor-1 in muscle of mdx mice. Muscle Nerve 32, 191-199

Oldberg A, Franzén A, Heinegård D (1986): Cloning and sequence analysis of rat bone sialoprotein (osteopontin) cDNA reveals an Arg-Gly-Asp cell-binding sequence. Proc Natl Acad Sci U S A $\underline{83}, 8819-8823$

Ozawa E: The Functional Biology of Dystrophin: Structural Components and the Pathogenesis of Duchenne Muscular Dystrophy. In: Chamberlain JS, Rando TA (Hrsg.): Duchenne Muscular Dystrophy: Advances in Therapeutics. Taylor u. Francis, New York 2006, 21-54

Partridge TA (2013): The mdx mouse model as a surrogate for Duchenne muscular dystrophy. FEBS J $\underline{280}, 4177-4186$

Passamano L, Taglia A, Palladino A, Viggiano E, D’Ambrosio P, Scutifero M, Rosaria Cecio M, Torre V, DE Luca F, Picillo E et al. (2012): Improvement of survival in Duchenne Muscular Dystrophy: retrospective analysis of 835 patients. Acta Myol $\underline{31}, 121-125$

Pastoret C, Sebille A (1995): mdx mice show progressive weakness and muscle deterioration with age. J Neurol Sci $129,97-105$

Pegoraro E, Hoffman EP, Piva L, Gavassini BF, Cagnin S, Ermani M, Bello L, Soraru G, Pacchioni B, Bonifati MD et al. (2011): SPP1 genotype is a determinant of disease severity in Duchenne muscular dystrophy. Neurology $\underline{76}, 219-226$

Peña JR, Wolska BM (2005): Differential effects of isoflurane and ketamine/inactin anesthesia on cAMP and cardiac function in $\mathrm{FVB} / \mathrm{N}$ mice during basal state and beta-adrenergic stimulation. Basic Res Cardiol 100, 147-153

Petrof BJ, Shrager JB, Stedman HH, Kelly AM, Sweeney HL (1993): Dystrophin protects the sarcolemma from stresses developed during muscle contraction. Proc Natl Acad Sci U S A $\underline{90}, 3710-3714$ 
Pette D (1999): Das adaptive Potenzial des Skelettmuskels. Dtsch Z Sportmed 50, 262-271

Pette D, Staron RS (1997): Mammalian skeletal muscle fiber type transitions. Int Rev Cytol $\underline{170}, 143-223$

Piepers S, Jansen MD, Cats EA, van Sorge NM, van den Berg LH, van der Pol WL (2010): IVIg inhibits classical pathway activity and anti-GM1 IgM-mediated complement deposition in MMN. J Neuroimmunol 229, 256-262

Politano L, Nigro V, Nigro G, Petretta VR, Passamano L, Papparella S, Di Somma S, Comi LI (1996): Development of cardiomyopathy in female carriers of Duchenne and Becker muscular dystrophies. JAMA 275, 1335-1338

Porter JD, Khanna S, Kaminski HJ, Rao JS, Merriam AP, Richmonds CR, Leahy P, Li J, Guo W, Andrade FH (2002): A chronic inflammatory response dominates the skeletal muscle molecular signature in dystrophin-deficient mdx mice. Hum Mol Genet 11, 263-272

Porter JD, Guo W, Merriam AP, Khanna S, Cheng G, Zhou X, Andrade FH, Richmonds C, Kaminski HJ (2003): Persistent over-expression of specific CC class chemokines correlates with macrophage and T-cell recruitment in mdx skeletal muscle. Neuromuscul Disord 13, $223-235$

Puli L, Pomeshchik Y, Olas K, Malm T, Koistinaho J, Tanila H (2012): Effects of human intravenous immunoglobulin on amyloid pathology and neuroinflammation in a mouse model of Alzheimer's disease. J Neuroinflammation $\underline{9}, 105$

Quast I, Keller CW, Maurer MA, Giddens JP, Tackenberg B, Wang LX, Münz C, Nimmerjahn F, Dalakas MC, Lünemann JD (2015): Sialylation of IgG Fc domain impairs complement-dependent cytotoxicity. J Clin Invest 125, 4160-4170

Quinlan JG, Hahn HS, Wong BL, Lorenz JN, Wenisch AS, Levin LS (2004): Evolution of the mdx mouse cardiomyopathy: physiological and morphological findings. Neuromuscul Disord 14, 491-496 
Raman SV, Hor KN, Mazur W, Halnon NJ, Kissel JT, He X, Tran T, Smart S, McCarthy B, Taylor MD et al. (2015): Eplerenone for early cardiomyopathy in Duchenne muscular dystrophy: a randomised, double-blind, placebo-controlled trial. Lancet Neurol 14, 153-161

Röckl KS, Hirshman MF, Brandauer J, Fujii N, Witters LA, Goodyear LJ (2007): Skeletal muscle adaptation to exercise training: AMP-activated protein kinase mediates muscle fiber type shift. Diabetes $\underline{56}, 2062-2069$

Roitt IM: Antigen-erkennende Moleküle. In: Roitt IM (Hrsg.): Leitfaden der Immunologie. Steinkopff, Darmstadt 1988, 30-56

Rossi F, Sultan Y, Kazatchkine MD (1988): Anti-idiotypes against autoantibodies and alloantibodies to VIII:C (anti-haemophilic factor) are present in therapeutic polyspecific normal immunoglobulins. Clin Exp Immunol 4ㅜ 311-316

Roth DM, Swaney JS, Dalton ND, Gilpin EA, Ross J Jr. (2002): Impact of anesthesia on cardiac function during echocardiography in mice. Am J Physiol Heart Circ Physiol 282, H2134-2140

Rybakova IN, Patel JR, Ervasti JM (2000): The dystrophin complex forms a mechanically strong link between the sarcolemma and costameric actin. J Cell Biol 150, 1209-1214

Salimena MC, Lagrota-Candido J, Quírico-Santos T (2004): Gender dimorphism influences extracellular matrix expression and regeneration of muscular tissue in $\mathrm{mdx}$ dystrophic mice. Histochem Cell Biol 122, 435-444

Samuelsson A, Towers TL, Ravetch JV (2001): Anti-inflammatory activity of IVIG mediated through the inhibitory Fc receptor. Science 291, 484-486

Schara U: X-chromosomale rezessive Muskeldystrophien vom Typ Duchenne und Typ Becker und Konduktorinnenstatus. In: Schara U, Schneider-Gold C, Schrank B (Hrsg.): Klinik und Transition neuromuskulärer Erkrankungen. Springer, Berlin Heidelberg 2015, 119-128 
Schmalbruch H (1976): The morphology of regeneration of skeletal muscles in the rat. Tissue Cell $\underline{8}, 673-692$

Schram G, Fournier A, Leduc H, Dahdah N, Therien J, Vanasse M, Khairy P (2013): Allcause mortality and cardiovascular outcomes with prophylactic steroid therapy in Duchenne muscular dystrophy. J Am Coll Cardiol $\underline{61}, 948-954$

Schröder JM: Pathologie der Skelettmuskulatur. In: Remmele W, Pfeiffer J, Schröder JM (Hrsg.): Pathologie: 6 Neuropathologie Muskulatur Sinnesorgane. Springer, Berlin, Heidelberg 1995, 405-470

Schultz E, Gibson MC, Champion T (1978): Satellite cells are mitotically quiescent in mature mouse muscle: an EM and radioautographic study. J Exp Zool 206, 451-456

Selsby JT, Acosta P, Sleeper MM, Barton ER, Sweeney HL (2013): Long-term wheel running compromises diaphragm function but improves cardiac and plantarflexor function in the mdx mouse. J Appl Physiol (1985) 115, 660-666

Shanmuga Sundaram J, Mohana Rao V, Meena AK, Anandaraj MP (2006): Altered expression, intracellular distribution and activity of lymphocyte calpain II in Duchenne muscular dystrophy. Clin Chim Acta $\underline{373}, 82-87$

Sharief MK, Ingram DA, Swash M, Thompson EJ (1999): I.v. immunoglobulin reduces circulating proinflammatory cytokines in Guillain-Barré syndrome. Neurology $\underline{52}, 1833-1838$

Simonds AK (2002): Respiratory complications of the muscular dystrophies. Semin Respir Crit Care Med 23, 231-238

Singhi SC, Jayshree M, Singhi P, Banerjee S, Prabhakar S (1999): Intravenous immunoglobulin in very severe childhood Guillain-Barré syndrome. Ann Trop Paediatr $\underline{19}, 167-174$

Smerdu V, Karsch-Mizrachi I, Campione M, Leinwand L, Schiaffino S (1994): Type IIx myosin heavy chain transcripts are expressed in type IIb fibers of human skeletal muscle. Am J Physiol 267, C1723-1728 
Smythe GM, White JD (2011): Voluntary wheel running in dystrophin-deficient (mdx) mice: Relationships between exercise parameters and exacerbation of the dystrophic phenotype. PLoS Curr $\underline{3}$, RRN1295

Snow MH (1977): Myogenic cell formation in regenerating rat skeletal muscle injured by mincing. II. An autoradiographic study. Anat Rec $\underline{188}, 201-217$

Spencer MJ, Tidball JG (2001): Do immune cells promote the pathology of dystrophin-deficient myopathies? Neuromuscul Disord 11, 556-564

Spencer MJ, Mellgren RL (2002): Overexpression of a calpastatin transgene in mdx muscle reduces dystrophic pathology. Hum Mol Genet 11, 2645-2655

Spencer MJ, Montecino-Rodriguez E, Dorshkind K, Tidball JG (2001): Helper (CD4(+)) and cytotoxic $(\mathrm{CD} 8(+)) \mathrm{T}$ cells promote the pathology of dystrophin-deficient muscle. Clin Immunol $\underline{98}, 235-243$

Spurney CF (2015): Non-invasive echocardiographic assessment of cardiac function in the mdx mouse model. SOP ID Number: DMD_M.2.2.001.https://treat-nmd.org/wp-content/uploads/2016/08/MDX-DMD_M.2.2.003-44.pdf; abgerufen am 22.12.2019

Spurney CF, Knoblach S, Pistilli EE, Nagaraju K, Martin GR, Hoffman EP (2008): Dystrophin-deficient cardiomyopathy in mouse: expression of Nox 4 and Lox are associated with fibrosis and altered functional parameters in the heart. Neuromuscul Disord $\underline{18}, 371-381$

Spurney CF, Gordish-Dressman H, Guerron AD, Sali A, Pandey GS, Rawat R, Van Der Meulen JH, Cha HJ, Pistilli EE, Partridge TA et al. (2009): Preclinical drug trials in the mdx mouse: assessment of reliable and sensitive outcome measures. Muscle Nerve 39, 591-602

Spurney CF, Cha HJ, Sali A, Pandey GS, Pistilli E, Guerron AD, Gordish-Dressman H, Hoffman EP, Nagaraju K (2010): Evaluation of skeletal and cardiac muscle function after chronic administration of thymosin beta- 4 in the dystrophin deficient mouse. PLoS ONE $\underline{5}$, e8976 
Stangel M, Kiefer R, Pette M, Smolka MN, Marx P, Gold R (2003): Side effects of intravenous immunoglobulins in neurological autoimmune disorders--a prospective study. J Neurol $\underline{250}, 818-821$

Stedman HH, Sweeney HL, Shrager JB, Maguire HC, Panettieri RA, Petrof B, Narusawa M, Leferovich JM, Sladky JT, Kelly AM (1991): The mdx mouse diaphragm reproduces the degenerative changes of Duchenne muscular dystrophy. Nature $\underline{352}, 536-539$

Stohl W, Elliot JE (1996): In vitro inhibition by intravenous immunoglobulin of human T cell-dependent B cell differentiation induced by staphylococcal superantigens. Clin Immunol Immunopathol $\underline{79}, 122-133$

Strehle EM, Straub V (2015): Recent advances in the management of Duchenne muscular dystrophy. Arch Dis Child $\underline{100}, 1173-1177$

Stuckey DJ, Carr CA, Camelliti P, Tyler DJ, Davies KE, Clarke K (2012): In vivo MRI characterization of progressive cardiac dysfunction in the $\mathrm{mdx}$ mouse model of muscular dystrophy. PLoS ONE $\underline{7}$, e28569

Stypmann J, Engelen MA, Troatz C, Rothenburger M, Eckardt L, Tiemann K (2009): Echocardiographic assessment of global left ventricular function in mice. Lab Anim $\underline{43}, 127-137$

Synetos A, Toutouzas K, Aznaouridis K, Lerakis S, Stefanadis C (2009): Dilated cardiomyopathy induced by anti-tumor necrosis factor. Int J Cardiol 132, e26-27

Tan E, Hajinazarian M, Bay W, Neff J, Mendell JR (1993): Acute renal failure resulting from intravenous immunoglobulin therapy. Arch Neurol 50, 137-139

Tidball JG (2005): Inflammatory processes in muscle injury and repair. Am J Physiol Regul Integr Comp Physiol 288, R345-353

Tidball JG, Spencer MJ (2000): Calpains and muscular dystrophies. Int J Biochem Cell Biol $\underline{32}, 1-5$ 
Tidball JG, Wehling-Henricks M (2007): Macrophages promote muscle membrane repair and muscle fibre growth and regeneration during modified muscle loading in mice in vivo. J Physiol 578, 327-336

Trama J, Lu Q, Hawley RG, Ho SN (2000): The NFAT-related protein NFATL1 (TonEBP/NFAT5) is induced upon $\mathrm{T}$ cell activation in a calcineurin-dependent manner. $\mathrm{J}$ Immunol 165, 4884-4894

Turner PR, Westwood T, Regen CM, Steinhardt RA (1988): Increased protein degradation results from elevated free calcium levels found in muscle from mdx mice. Nature $\underline{335}$, $735-738$

Vassilev TL, Kazatchkine MD, Duong Van Huyen JP, Mekrache M, Bonnin E, Mani JC, Lecroubier C, Korinth D, Baruch D, Schriever F et al. (1999): Inhibition of cell adhesion by antibodies to Arg-Gly-Asp (RGD) in normal immunoglobulin for therapeutic use (intravenous immunoglobulin, IVIg). Blood 93, 3624-3631

Vetrone SA, Montecino-Rodriguez E, Kudryashova E, Kramerova I, Hoffman EP, Liu SD, Miceli MC, Spencer MJ (2009): Osteopontin promotes fibrosis in dystrophic mouse muscle by modulating immune cell subsets and intramuscular TGF-beta. J Clin Invest 119, 15831594

Villalta SA, Nguyen HX, Deng B, Gotoh T, Tidball JG (2009): Shifts in macrophage phenotypes and macrophage competition for arginine metabolism affect the severity of muscle pathology in muscular dystrophy. Hum Mol Genet $\underline{18}, 482-496$

Vilquin JT, Wagner E, Kinoshita I, Roy R, Tremblay JP (1995): Successful histocompatible myoblast transplantation in dystrophin-deficient $\mathrm{mdx}$ mouse despite the production of antibodies against dystrophin. J Cell Biol 131, 975-988

Wagner S, Knipp S, Weber C, Hein S, Schinkel S, Walther A, Bekeredjian R, Müller OJ, Friedrich O (2012): The heart in Duchenne muscular dystrophy: early detection of contractile performance alteration. J Cell Mol Med 16, 3028-3036 
Wang B, Li J, Xiao X (2000): Adeno-associated virus vector carrying human minidystrophin genes effectively ameliorates muscular dystrophy in mdx mouse model. Proc Natl Acad Sci U S A $\underline{97}, 13714-13719$

Wang Y, Marino-Enriquez A, Bennett RR, Zhu M, Shen Y, Eilers G, Lee JC, Henze J, Fletcher BS, Gu Z et al. (2014): Dystrophin is a tumor suppressor in human cancers with myogenic programs. Nat Genet $\underline{46}, 601-606$

Warren GL, O'Farrell L, Summan M, Hulderman T, Mishra D, Luster MI, Kuziel WA, Simeonova PP (2004): Role of CC chemokines in skeletal muscle functional restoration after injury. Am J Physiol Cell Physiol 286, C1031-C1036

Warren GL, Hulderman T, Mishra D, Gao X, Millecchia L, O’Farrell L, Kuziel WA, Simeonova PP (2005): Chemokine receptor CCR2 involvement in skeletal muscle regeneration. FASEB J $\underline{19}, 413-415$

Wehling M, Spencer MJ, Tidball JG (2001): A nitric oxide synthase transgene ameliorates muscular dystrophy in mdx mice. J Cell Biol 155, 123-131

Wehling-Henricks M, Lee JJ, Tidball JG (2004): Prednisolone decreases cellular adhesion molecules required for inflammatory cell infiltration in dystrophin-deficient skeletal muscle. Neuromuscul Disord 14, 483-490

Weller C, Zschüntzsch J, Makosch G, Metselaar JM, Klinker F, Klinge L, Liebetanz D, Schmidt J (2012): Motor performance of young dystrophic mdx mice treated with long-circulating prednisolone liposomes. J Neurosci Res $\underline{90,}$ 1067-1077

Whitehead NP, Yeung EW, Allen DG (2006): Muscle damage in mdx (dystrophic) mice: role of calcium and reactive oxygen species. Clin Exp Pharmacol Physiol $\underline{33}$, 657-662

Wittstock M, Benecke R, Zettl UK (2003): Therapy with intravenous immunoglobulins: complications and side-effects. Eur Neurol 50, 172-175 
Xu C, Poirier B, Duong Van Huyen JP, Lucchiari N, Michel O, Chevalier J, Kaveri S (1998): Modulation of endothelial cell function by normal polyspecific human intravenous immunoglobulins: a possible mechanism of action in vascular diseases. Am J Pathol 153, $1257-$ 1266

Yeung EW, Whitehead NP, Suchyna TM, Gottlieb PA, Sachs F, Allen DG (2005): Effects of stretch-activated channel blockers on $[\mathrm{Ca} 2+] \mathrm{i}$ and muscle damage in the mdx mouse. $\mathrm{J}$ Physiol $\underline{562}, 367-380$

Yoon MS, Chan A, Gold R (2011): Standard and escalating treatment of chronic inflammatory demyelinating polyradiculoneuropathy. Ther Adv Neurol Disord $\underline{4}$, 193-200

Young A (1984): Plasma creatine kinase after the marathon--a diagnostic dilemma. Br J Sports Med 18, 269-272

Yuasa K, Sakamoto M, Miyagoe-Suzuki Y, Tanouchi A, Yamamoto H, Li J, Chamberlain JS, Xiao X, Takeda S (2002): Adeno-associated virus vector-mediated gene transfer into dystrophin-deficient skeletal muscles evokes enhanced immune response against the transgene product. Gene Ther $\underline{9}, 1576-1588$

Yuki N, Watanabe H, Nakajima T, Späth PJ (2011): IVIG blocks complement deposition mediated by anti-GM1 antibodies in multifocal motor neuropathy. J Neurol Neurosurg Psychiatry $\underline{82}, 87-91$

Zanou N, Iwata Y, Schakman O, Lebacq J, Wakabayashi S, Gailly P (2009): Essential role of TRPV2 ion channel in the sensitivity of dystrophic muscle to eccentric contractions. FEBS Lett $\underline{583}, 3600-3604$

Zatz M, Rapaport D, Vainzof M, Passos-Bueno MR, Bortolini ER, Pavanello R de C, Peres CA (1991): Serum creatine-kinase (CK) and pyruvate-kinase (PK) activities in Duchenne (DMD) as compared with Becker (BMD) muscular dystrophy. J Neurol Sci 102, 190-196

Zhou L, Lu H (2010): Targeting fibrosis in Duchenne muscular dystrophy. J Neuropathol Exp Neurol $\underline{69}, 771-776$ 
Zschüntzsch J, Zhang Y, Klinker F, Makosch G, Klinge L, Malzahn D, Brinkmeier H, Liebetanz D, Schmidt J (2016): Treatment with human immunoglobulin G improves the early disease course in a mouse model of Duchenne muscular dystrophy. J Neurochem 136 , 351-362 


\section{Danksagung}

An erster Stelle möchte ich Herrn Prof. Dr. med. M. Bähr danken, durch den die optimalen Arbeitsbedingungen für dieses Projekt geschaffen wurden und die Durchführung dieses Projektes ermöglicht wurde.

Ein ganz besonderer Dank gilt Prof. Dr. med. J. Schmidt, in dessen Arbeitsgruppe ich jahrelang mitarbeiten durfte und der jederzeit dieses Projekt unterstützt hat.

Auch gilt mein Dank meiner Betreuerin Dr. med. J. Zschüntzsch, die mir immer wieder mit Rat und Tat zur Seite stand.

Im Weiteren möchte ich Herrn Prof. Dr. med. D. Liebetanz für die Möglichkeit der Nutzung des Laufradsystems danken sowie Herrn Dr. med. F. Klinker für die technische Unterstützung in allen Laufradangelegenheiten.

Weiterhin möchte ich mich bei Dr. med. A. Wrede für seine fachkundige Hilfestellung in der Gewebeverarbeitung und Auswertung bedanken sowie bei PD Dr. rer. nat. L. Zelarayan, Dr. med. M. Tiburcy und R. Blume für die Durchführung und Auswertung der Echokardiografien.

Ich danke Fatima Agdas, Marit Hubrecht und Iris Iben für ihre technische Assistenz und immerwährende Unterstützung. 